NEWTON KIYOSHI FUKUMASU

MODELAGEM DE UMA CHAMA DE DIFUSÃO TURBULENTA PELA SIMULAÇÃO DE GRANDES ESCALAS

São Paulo 
NEWTON KIYOSHI FUKUMASU

\section{MODELAGEM DE UMA CHAMA DE DIFUSÃO TURBULENTA PELA SIMULAÇÃO DE GRANDES ESCALAS}

Dissertação apresentada à Escola Politécnica da Universidade de de São Paulo para obtenção do Título de Mestre em Engenharia

Área de Concentração:

Engenharia Mecânica de Energia e Fluidos

Orientador: Prof. Dr.

Guenther Carlos Krieger Filho

São Paulo 
Este exemplar foi revisado e alterado em relação à versão original, sob responsabilidade do autor e com a anuência de seu orientador.

São Paulo, ..... de janeiro de 2010

Assinatura do autor

Assinatura do orientador

\section{FICHA CATALOGRÁFICA}

Fukumasu, Newton Kiyoshi

Modelagem de uma chama de difusão turbulenta pela simulação de grandes escalas/ N.K. Fukumasu - ed. rev. - São Paulo, 2010. $138 \mathrm{p}$.

Dissertação (Mestrado) - Escola Politécnica da Universidade de São Paulo. Departamento de Engenharia Mecânica.

1.Turbulência atmosférica (Simulação Numérica) 2.Combustão (Modelagem matemática) I.Universidade de São Paulo. Escola Politécnica. Departamento de Engenharia Mecânica II. t. 
Dedico este trabalho aos meus pais pelo incentivo e apoio recebidos na realização de mais uma etapa da minha vida alcançada com sucesso. 


\section{Agradecimentos}

Ao meu orientador professor Dr. Guenther Carlos Krieger Filho pelo auxílio prestado bem como pelas discussões sobre os problemas enfrentados durante o desenvolvimento deste trabalho.

Aos professores amigos que me incentivaram e auxiliram nas horas de difíceis tomadas de decisões.

Aos colegas do Laboratório de Engenharia Térmica e Ambiental e da equipe de Aerodesign PoliAclive pelas grandes conversas e discussões.

Ao Departamento de Engenharia Mecânica da Escola Politécnica da Universidade de São Paulo pela disponibilidade de suas instalações para a execução deste trabalho, sem os quais não seria possível alcançar os resultados obtidos.

Ao Conselho Nacional de Desenvolvimento Científico e Tecnológico (CNPq) pelo auxílio financeiro segundo o projeto 133074/2007-2. 


\section{Resumo}

Este trabalho objetivou a ampliação dos conhecimentos sobre a dinâmica de chamas de difusão turbulenta. A abordagem escolhida foi o método numérico da simulação de grandes escalas turbulentas (LES) acoplado ao modelo de combustão do tipo folha de chama ou "Flamesheet". A modelagem dos efeitos de dissipação das pequenas escalas turbulentas, foi realizada pelo modelo de Smagorinsky (1963). Foi feita a verificação e validação do código implementado pelo método das soluções manufaturadas, descrito por Roache (2002), e pelas soluções de engenharia do tipo tampa móvel em cavidade laminar, escoamento de Poiseuille e jato laminar. Neste trabalho foi estudada a chama de difusão turbulenta do tipo D, padronizada pelo "SANDIA National Laboratories". Foi verificado que, quando estudado o jato isotérmico, este obedece ao critério de jato auto-sustentável, definido por Hussein et al. (1994). Já os resultados obtidos para o jato reativo, quando comparados aos dados experimentais obtidos por Masri et al. (1996) e Barlow e Frank (1998), apresentaram boa concordância para os campos de velocidades e razoável correspondência para os campos de fração de mistura e temperatura, indicando que maiores estudos são necessários. 


\section{Abstract}

The mean goal of this work was to better understand the dynamics of turbulent diffusion flames. The turbulent flow was resolved appling the methodology of Large Eddy Simulation, coupled with the Flamesheet model for reactive systems. The effects of the turbulent subgrid dissipation were accounted with the Smagorinsky (1963) subgrid model. The numerical code verification and validation were accomplished with the manufactured solutions method, described by Roache (2002), and with the method of engineering solutions of the type of moveable wall in laminar cavity flow, Poiseuille flow and laminar jet flow. In this work was studied the turbulent flame of the type D flow, standardized by the SANDIA National Laboratories. It was verified that, when the isotermal jet flow was studied, the criterium of a self-sustained jet, defined by Hussein et al. (1994), was achieved. The results for the reactive flow, when compared against experimental data obtained by Masri et al. (1996) e Barlow e Frank (1998), presented resonable agreement for the velocity field and satisfactory correspondence for mixture fraction and temperature fields, indicating that further studies are necessary. 


\section{Sumário}

1 Introdução 1

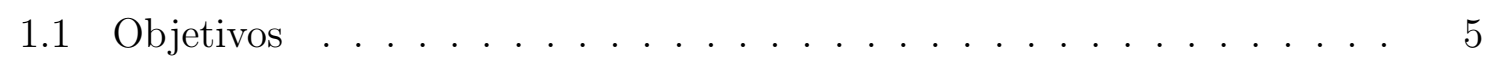

1.2 Organização . . . . . . . . . . . . . . . . . . . . 6

2 Escoamentos turbulentos reativos $\quad 8$

2.1 Sistema de equações que regem o movimento de um fluido em um domínio

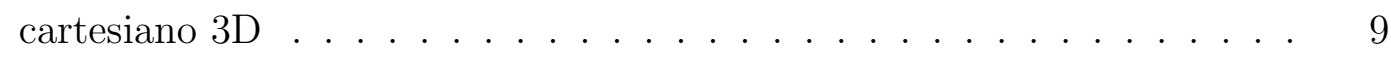

2.2 Discretização espacial . . . . . . . . . . . . . . . . . . . . . . . . . 10

2.3 Discretização temporal . . . . . . . . . . . . . . . . . . . . . . . . . . . 12

2.3.1 Método Adams - Bashforth . . . . . . . . . . . . . . 13

2.3 .2 Método Adams - Moulton . . . . . . . . . . . . . . . . 14

2.3.3 Determinação do incremento de tempo . . . . . . . . . . . . . . 14

2.4 Condições de contorno e inicial . . . . . . . . . . . . . . . 16

2.4.1 Condição de contorno do tipo de entrada . . . . . . . . . . . . 18

2.4.1.1 Condições flutuantes na entrada . . . . . . . . . . . 18

2.4.2 Condição de contorno do tipo de saída . . . . . . . . . . . . . . 19

2.4.2.1 Região de alta difusividade ou "buffer domain" . . . . 19

2.4.3 Condição de contorno do tipo parede . . . . . . . . . . . . . 19

2.4.4 Condições de contorno de simetria e periodicidade . . . . . . . . 20 
2.4.5 Condições iniciais do escoamento . . . . . . . . . . . 20

2.5 Modelagem dos efeitos da turbulência . . . . . . . . . . . . . . . 21

2.5.1 Metodologia LES . . . . . . . . . . . . . . . . 25

2.5.1.1 Modelo de Smagorinsky para a modelagem dos efeitos de dissipação submalha . . . . . . . . . . . . . . . 28

2.6 Modelagem dos efeitos de combustão . . . . . . . . . . . . . . . . . . . . 29

2.6.1 Modelo de folha de chama ou "Flamesheet" . . . . . . . . . . . 31

2.6.2 Modelo "Flamesheet" para escoamentos turbulentos . . . . . . . 36

2.6.2.1 Método " $\beta$-PDF" . . . . . . . . . . . . . . 37

3 Escoamentos baixo Mach $\quad 41$

3.1 Método Adams-Bashforth-Moulton para escoamentos turbulentos e isotérmicos 43

3.2 Método Adams-Bashforth-Moulton para escoamentos reativos . . . . . 45

3.3 Fluxo de informações no método Adams-Bashforth-Moulton ..... 47

4 Implementação do LECS 48

4.1 Histórico de desenvolvimento . . . . . . . . . . . . . . . . . . . . . . 49

4.2 Organização do programa . . . . . . . . . . . . . . . . 51

4.3 Organização das informações . . . . . . . . . . . . . . . . . . . . 53

$\begin{array}{lll}5 & \text { Verificação e validação } & 57\end{array}$

5.1 Método das soluções manufaturadas . . . . . . . . . . . . . . . . . 58

5.1 .1 Soluções analíticas empregadas . . . . . . . . . . . . . 59

5.2 Validação com escoamentos de engenharia . . . . . . . . . . . . . . 63

5.2.1 Escoamento laminar em cavidade com tampa móvel . . . . . . . 63

5.2 .2 Escoamento laminar em dutos retangulares . . . . . . . . . . . 66

5.2.3 Escoamento de jatos laminares . . . . . . . . . . . . . . . . 68 
6 Análise do escoamento de um jato circular turbulento $\quad 72$

6.1 Estudo de uma chama de difusão turbulenta . . . . . . . . . . . . . . . 73

6.2 Experimento numérico do jato isotérmico . . . . . . . . . . . . . 74

6.2.1 Resultados . . . . . . . . . . . . . . . 77

6.2.1.1 Cálculo da cascata de energia . . . . . . . . . . 77

6.3 Experimento numérico do jato reativo . . . . . . . . . . . . . 84

6.3.1 Resultados....................... 84

6.3.1.1 Cálculo da cascata de energia . . . . . . . . . . 94

6.4 Análise do decaimento da velocidade axial na linha de centro . . . . . . 96

$\begin{array}{llr}7 & \text { Conclusões } & 97\end{array}$

$\begin{array}{llr}8 & \text { Bibliografia } & 100\end{array}$

$\begin{array}{ll}\text { A Método dos volumes finitos } & 106\end{array}$

B Método dos passos fracionados $\quad 110$

C Método de Germano e Lilly $\quad 113$

$\begin{array}{ll}\text { D Solução de sistemas algébricos } & 115\end{array}$

D.1 Solução por Jacobi . . . . . . . . . . . . . . . . . . . . 115

D.2 Solução por Gauss-Siedel . . . . . . . . . . . . . . . . . . 115

$\begin{array}{ll}\text { E Formato do arquivo de entrada } & 117\end{array}$

$\begin{array}{llr}\text { F Formato do arquivo de malha } & 118\end{array}$ 


\section{Lista de Figuras}

2.1 Discretização espacial em volumes elementares . . . . . . . . . . . . . . 11

2.2 Aplicação das condições de contorno . . . . . . . . . . . . . . . 17

2.3 Exemplo de jato turbulento f . . . . . . . . . . . . . . . . . . . . 21

2.4 Composição do sinal turbulento . . . . . . . . . . . . . . . . . . 22

2.5 Transporte de energia pelas escalas do movimento . . . . . . . . . . 23

2.6 Representação da densidade de energia na cascata de Kolmogorov . . . 23

2.7 Gráfico da fração mássica dos reagentes e produtos em função da fração de mistura . . . . . . . . . . . . . . . . . . . . . 34

2.8 Gráfico da distribuição de temperatura e da densidade da mistura em função da fração de mistura . . . . . . . . . . . . . . . . . . . 34

2.9 Esboço das distribuições PDF em um jato turbulento reativo. Fonte: Versteeg e Malalasekera (2007) . . . . . . . . . . . . . . . 38

2.10 Distribuição da densidade de probabilidade pela função " $\beta$-PDF" para diversos valores de $(\alpha)$ e $(\beta) \ldots \ldots . \ldots . \ldots . \ldots 39$

4.1 Diagrama funcional do programa LECS . . . . . . . . . . . . . . . . . 53

5.1 Variação do erro de cálculo com o refino da malha . . . . . . . . . . . . 61

5.2 Ordem da variação do erro com o refino da malha . . . . . . . . . . 62

5.3 Variação do erro de cálculo com o refino da malha . . . . . . . . . . . 62

5.4 Ordem da variação do erro com o refino da malha . . . . . . . . . . 63 
5.5 Domínio computacional utilizado na validação do código numérico pelo escoamento laminar em cavidades, no sistema coordenado de eixos cartesianos. . . . . . . . . . . . . . . . .

5.6 Distribuição da componente da velocidade $\left(u_{x}\right)$ na linha central para as diversas malhas utilizadas. . . . . . . . . . . . . . . . . . .

5.7 Distribuição da magnitude da vorticidade no plano médio do domínio computacional para as malhas analisadas; a) 32x32x4 volumes, b) 64x64x4 volumes e c) 128x128x4 volumes. . . . . . . . . . . . . . .

5.8 Distribuição da componente da velocidade $\left(u_{x}\right)$ superposta aos vetores da velocidade não normalizados para a malha $64 \mathrm{x} 64 \mathrm{x} 4$ volumes. . . . .

5.9 Domínio computacional utilizado na validação do código numérico pelo escoamento laminar entre placas planas, no sistema coordenado de eixos cartesianos. (A dimensão do domínio no eixo Z foi escalada para melhor representação.) . . . . . . . . . . . . . . . . .

5.10 Comparação entre os perfis de velocidade axial na saída do domínio

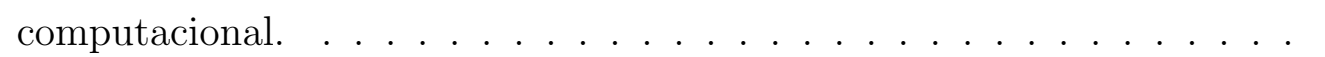

5.11 Distribuição da velocidade axial para as malhas com diferentes refinos; (a) 160x32x4 volumes e (b) 320x64x4 volumes. . . . . . . . . . . . .

5.12 Domínio computacional utilizado na validação do código numérico pelo escoamento de um jato laminar, no sistema coordenado de eixos cartesianos. . . . . . . . . . . . . . . . . .

5.13 Comparação entre os resultados numéricos e analítico para a velocidade axial na linha de centro do jato. . . . . . . . . . . . . . .

5.14 Distribuição da velocidade axial no plano médio do domínio computacional.

6.1 Chama D utilizada como padrão para validação de modelos de combustão. Apresentação da chama principal e das chamas pilotos, localizadas na região de "co-flow". Fonte: site do Laboratório SANDIA . . . 
6.2 Definição da componente axial da velocidade, e sua perturbação, na entrada do domínio computacional. Fonte: dados do site do Laboratório SANDIA . . . . . . . . . . . . . . . . . 75

6.3 Domínio utilizado para a solução do escoamento do jato turbulento. . . 76

6.4 Malha utilizada na discretização do domínio computacional. a) vista superior, b) vista frontal. . . . . . . . . . . . . . . . . . 76

6.5 Distribuição da velocidade axial filtrada no plano médio do domínio computacional: a) campo da velocidade filtrada, b) campo da velocidade média temporal. . . . . . . . . . . . . . . . . . . . .

6.6 Detalhes do campo de velocidades axial: a) próximo ao bocal do jato, b) numa região de esocamento plenamente desenvolvido. Vetores com mesma distribuição de tamanho. . . . . . . . . . . . . . . . . . . 79

6.7 Distribuição da viscosidade efetiva (molecular + turbulenta) no plano médio do domínio computacional. . . . . . . . . . . . . . . . . . 80

6.8 Detalhe da distribuição da viscosidade efetiva no plano médio do domínio computacional na região próxima ao bocal de saída do jato principal.

6.9 Perfil da velocidade axial média na linha de centro do domínio estudado. 81

6.10 Perfis da velocidade axial média ao longo da direção $\mathrm{X}$, nos planos $(x / D)$ iguais a 5, 10, 20, 30 e 50 .

6.11 Figura ilustrativa com os pontos $P_{1}, P_{2}$ e $P_{3}$ selecionados para a obtenção das estatísticas no cálculo do espectro de energia cinética turbulenta.

6.12 Espectro de energia calculado para o ponto $P_{1} \ldots \ldots \ldots$. . . . . . 83

6.13 Espectro de energia calculado para o ponto $P_{2} \ldots \ldots \ldots$. . . . . . 83

6.14 Espectro de energia calculado para o ponto $P_{3} \ldots \ldots \ldots$. . . . . . . 83

6.15 Distribuição da velocidade axial filtrada no plano médio do domínio computacional para o jato reativo: a) campo da velocidade filtrada, b) campo da velocidade média temporal. . . . . . . . . . . . . . . . 
6.16 Detalhes do campo de velocidades axial do jato reativo: a) próximo ao bocal do jato, b) numa região de esocamento plenamente desenvolvido. Vetores com mesma distribuição de tamanho.

6.17 Distribuição da temperatura da mistura no plano médio do domínio computacional.

6.18 Distribuição da densidade da mistura no plano médio do domínio computacional. .

6.19 Distribuição da viscosidade efetiva (molecular + turbulenta) no plano médio do domínio computacional para o jato reativo.

6.20 Comparação entre a velocidade axial média calculada pelo algorítmo implementado e a obtida experimentalmente por Masri et al. (1996).

6.21 Perfil da temperatura filtrada na linha de centro do domínio estudado.

6.22 Perfil da densidade filtrada na linha de centro do domínio estudado. . .

6.23 Perfis da velocidade axial média ao longo da direção $\mathrm{X}$, nos planos $(x / D)$ iguais a $5,10,20,30$ e $50 \ldots \ldots 91$

6.24 Perfis da temperatura filtrada ao longo da direção $\mathrm{X}$, nos planos $(x / D)$ iguais a $5,10,20,30$ e 50 .

6.25 Perfis da densidade filtrada ao longo da direção $\mathrm{X}$, nos planos $(x / D)$ iguais a $5,10,20,30$ e 50

6.26 Distribuição da fração de mistura no plano médio do domínio computacional: a) fração de mistura filtrada, b) fração de mistura média. . . . .

6.27 Perfis da fração de mistura média ao longo da direção X, nos planos $(x / D)$ iguais a $5,10,20,30$ e 50.

6.28 Espectro de energia calculado para o ponto $P_{1} \ldots \ldots \ldots$. . . . . . . 94

6.29 Espectro de energia calculado para o ponto $P_{2} \ldots \ldots \ldots$. . . . . . . 94

6.30 Espectro de energia calculado para o ponto $P_{3} \ldots \ldots \ldots$. . . . . . 95

6.31 Comparação do decaimento da velocidade na linha de centro dos jatos turbulentos isotérmico e reativo com o proposto por Hussein et al. (1994). 96 
A.1 Exemplo de discretização espacial de um volume em um domínio computacional por células igualmente espaçadas. . . . . . . . . . . . . . . 107

A.2 Exemplo de discretização espacial de um volume em um domínio computacional por meio de células com espaçamento refinado no centro do domínio. . . . . . . . . . . . . . . . . 107

A.3 Volume genérico utilizado para a discretização espacial do domínio computacional; nomeclatura das faces a ser utilizada nas equações discretizadas. . . . . . . . . . . . . . . . . . 108

F.1 Exemplo do arquivo da malha com os comandos *NODE e *ELEMENT. 118 


\section{Lista de símbolos}

$\rho$ : densidade do fluido

$u_{i}$ : campo de velocidades nas coordenadas cartesianas; $i=X, Y$ e $Z$

$X$ : eixo coordenado do sistema cartesiano

$Y$ : eixo coordenado do sistema cartesiano

$Z$ : eixo coordenado do sistema cartesiano

$t$ : tempo

$x_{i}$ : comprimento em coordenadas cartesianas; $i=X, Y$ e $Z$

$P$ : pressão relativa

$\mu$ : viscosidade molecular

$g_{i}$ : aceleração da gravidade nas coordenadas cartesianas; $i=X, Y$ e $Z$

$S_{u_{i}}$ : termo fonte das equações de conservação de quantidade de movimento

$h$ : entalpia

$k$ : coeficiente de condução de calor

$T$ : temperatura

$\Phi$ : termo fonte de radiação na equação de transporte da entalpia

$S_{h}$ : termo fonte da equação de transporte da entalpia

$\phi$ : variável genérica a ser transportada

$\Gamma$ : coeficiente do termo difusivo na equação de transporte genérica

$S_{\phi}$ : termo fonte da equação de transporte de uma propriedade genérica 
$e$ : energia total

$H$ : comprimento entre os centróides de células adjacentes no esquema de discretização CDS

$x$ : posição genérica no eixo cartesiano

$E(x)$ : função erro

$\beta_{k}$ : coeficientes das equações de discretização temporal

$\Delta t$ : incremento de tempo

$n$ : posição temporal

CFL: número de Courant, Friedrichs e Lewy

$\mu_{e}:$ viscosidade efetiva

$\phi_{f}$ : valor da propriedade $\phi$ na face $f$

$\eta_{k}$ : escala de comprimento de Kolmogorov

$\tau_{\eta}^{k}$ : escala de tempo de Kolmogorov

$u_{\eta}^{k}$ : escala de velocidade de Kolmogorov

$\nu$ : viscosidade cinemática

$\epsilon$ : taxa de dissipação de energia turbulenta

$K$ : número de onda

$u^{\prime}$ : resíduo submalha da velocidade

$\bar{u}^{\prime}$ : resíduo filtrado da velocidade

$U$ : campo real da velociade

$\bar{U}$ : campo filtrado da velocidade

$\bar{\phi}$ : variável genérica filtrada

$\phi^{\prime}$ : resíduo submalha da variável genérica

$\tau_{i j}$ : tensor das tensões residuais

$V_{c}$ : volume da célula

$\Delta$ : filtro das equações de conservação 
$L_{i j}$ : tensor das tensões de Leonard

$C_{i j}$ : tensor das tensões cruzadas

$R_{i j}$ : tensor das tensões submalha de Reynolds

$\tau_{i j}^{+}$: tensor das tensões viscosas modificado

$\overline{P^{+}}$: campo das pressões modificadas

$\bar{S} i j$ : tensor das deformações do fluido

$\bar{S}$ : taxa de deformação do fluido

$\mu_{t}$ : viscosidade turbulenta

$l_{s}:$ comprimento de mistura de Prandtl

$C_{s}$ : constante de Smagorinsky

$Y_{k}$ : fração mássica da espécie $\mathrm{k}$

$\Delta h_{c}$ : entalpia de combustão

$\dot{\omega}_{k}$ : taxa de consumo da espécie $\mathrm{k}$

$S_{c k}$ : número de Schmidt

$\sigma_{h}$ : número de Prandtl

Le: número de Lewis

$c_{p}$ : calor específico a pressão constante

$D_{k}$ : coeficiente de difusão binária da espécie $\mathrm{k}$

$f$ : fração de mistura

$f_{s t}$ : fração de mistura estequiométrica

$h^{*}$ : entalpia normalizada no modelo de combustão

p: pressão termodinâmica

$R_{u}$ : constante universal dos gases

$M W_{k}$ : peso molecular da espécie $\mathrm{k}$

$\bar{\rho}$ : densidade filtrada do fluido 
$P_{\phi}$ : função densidade de probabilidade da variável genérica

$F_{\phi}$ : função probabilidade da variável genérica

$\Gamma^{\phi}$ : função gama

$\bar{f}$ : fração de mistura filtrada

$\bar{f}^{\prime \prime 2}$ : variância da fração de mistura

$\alpha$ : coeficiente da função densidade de probabilidade

$\beta$ : coeficiente da função densidade de probabilidade

$M_{a}:$ número de Mach

$c$ : velociade do som no meio

$A$ : representação dos termos advectivos na equação de transporte

$D$ : representação dos termos difusivos na equação de transporte

$L_{\infty}$ : norma infinito ou do supremo

$L_{2}$ : norma euclidiana ou da distância

Re: número de Reynolds

$u_{i_{c l}}$ : velocidade na linha de centro do domínio computacional

$D$ : diâmetro do bocal de saída do jato

Bu: coeficiente de decaimento da velociade média na linha de centro do domínio computacional 
Capítulo 1

\section{Introdução}


Devido à crescente demanda energética no desenvolvimento das necessidades humanas, faz-se necessária a utilização de sistemas de conversão de energia com alto índice de eficiência, minimizando as perdas, desperdícios e emissão de poluentes para atmosfera. É nesse âmbito que a utilização de métodos numéricos se encontra, permitindo a predição e a ampliação do entendimento dos diversos processos de conversão de energia térmica, tal qual a queima de combustíveis baseados em hidrogênio, hidrocarbonetos, renováveis ou não.

Devido à experiência do grupo de Engenharia Térmica e Meio Ambiente da Escola Politécnica da Universidade de São Paulo, este acolhe o desenvolvimento deste trabalho, possibilitando a sua inserção em projetos como "Modelagem de Chamas de Difusão com a Técnica de Simulação de Grandes Estruturas Turbulentas" (FAPESP 03/12120-9), permitindo a manutenção às pesquisas realizadas e a contínua inovação tecnológica que o ambiente das simulações numéricas propicia.

A simulação da dinâmica dos fluidos para jatos turbulentos reativos livres é baseada em métodos numéricos que compreendem duas importantes áreas da física: turbulência e combustão.

Todo algoritmo numérico deve ser verificado e validado. A verificação de um código em desenvolvimento consiste na garantia de que o mesmo foi implementado sem erros. Já a validação de um código é realizada para determinar se os modelos matemáticos implementados sustentam as principais hipóteses físicas.

Para fazer a verificação da implementação dos modelos matemáticos aplicados, Roache (2002) propõe a utilização do método de soluções manufaturadas. Este método permite a verificação da existência de erros de implementação, bem como a ordem do decaimento dos erros inerentes à modelagem.

Na validação de códigos numéricos é usual utilizar escoamentos de engenharia. Alguns escoamentos possuem soluções analíticas ou dados experimentais, permitindo a comparação com a solução obtida pelo código desenvolvido. Os casos mais utilizados são o escoamento em cavidades com tampa móvel e os escoamentos em dutos longos. Estes escoamentos são, usualmente, laminares e isotérmicos.

Devido à inerente complexidade dos escoamentos turbulentos, diversos traba- 
lhos analisam os modelos físicos disponíveis para representar os efeitos da turbulência, bem como os aspectos matemáticos de implementação desses modelos.

Choi e Moin (1993) verificaram que, aplicando-se algoritmos totalmente implícitos para a solução de escoamentos com camada limite turubulenta, as escalas temporais de escoamento transitórios devem ser menores que as escalas de tempo de Kolmogorov para que as flutuações turbulentas sejam auto-sustentadas.

Pfuderer et al. (1996) analisaram diversos modelos turbulentos de ordem zero e realizaram experimentos utilizando a técnica de espectroscopia Raman em busca do melhor modelo para descrever a interação entre a dinâmica da turbulência e a combustão. Eles aplicaram os modelos de combustão "laminar flamelet" e equilíbrio químico, baseado na fração de mistura dos reagentes. Verificaram que o modelo de combustão baseado em equilíbrio químico representava adequadamente as propriedades da chama de difusão, ao contrário do modelo "laminar flamelet".

Devido à necessidade de melhor entender os efeitos da turbulência sobre os escoamentos reativos e à possibilidade de capturar as flutuações temporais dos escoamentos turbulentos, desenvolveu-se o método de simulação de grandes escalas (LES), o qual foi inicialmente proposto para a solução da camada limite planetária, como discutido por Moeng (1984). Entretanto, outras aplicações mais recentes, como a análise das perturbações acústicas discutidas por Kaufmann, Nicoud e Poinsot (2002), utilizam versões modificadas das equações filtradas aplicadas no método LES.

No método LES, busca-se a solução das grandes escalas turbulentas e a modelagem dos efeitos das pequenas escalas. Ao resolver apenas as grandes escalas turbulentas, um modelo matemático é necessário para incluir os efeitos de dissipação das pequenas escalas do movimento turbulento. Assim, Smagorinsky (1963) propôs uma correlação entre as tensões viscosas e a viscosidade para modelar os efeitos de dissipação de energia pelas pequenas escalas turbulentas. Esta correlação é conhecida por modelos submalha.

Armênio e Sarkar (2002) discutem a solução do escoamento em um duto por meio da aplicação da metodologia LES com a utilização de uma lei de parede para o desenvolvimento da camada limite. Assim, apesar da metodologia LES possibilitar 
a solução das equações de Navier-Stokes para baixo número de Reynolds, usualmente em camadas limites próximas a paredes, usualmente são utilizadas soluções empíricas como as função de parede, minimizando o custo computacional e obtendo-se resultados compatíveis com experimentos.

Com a melhora no poder computacional disponível, novos modelos submalha foram desenvolvidos. He, Wang e Lele (2002) discutem três destes modelos e chegam à conclusão de que o modelo apresentado por Germano et al. (1991), baseado no modelo original proposto por Smagorinsky, apresenta as melhores predições para sistemas transientes.

Existem diversos modelos para considerar os efeitos do processo de combustão, porém, devido à complexidade das soluções dos escoamentos turbulentos resolvidos pela metodologia LES, usualmente opta-se por modelos de combustão mais simples, geralmente baseados no transporte de um escalar chamado fração de mistura. No caso de jatos livres não pré-misturados, Cook, Riley e Kosály (1997) discutem a possibilidade da utilização da metodologia LES para a turbulência acoplado ao modelo "flamelet" de combustão, comparando os resultados com os obtidos pela simulação numérica direta (DNS). Concluem que os resultados apresentam boa correlação e a acurácia melhora proporcionalmente ao aumento do número de Damköhler. Este número relaciona o tempo de reação entre as espécies e o tempo do transporte advectivo da massa dos reagentes e produtos.

Kempf, Lindstedt e Janicka (2005) discutem o uso da metodologia LES junto ao "flamelet" e o modelo submalha dinâmico apresentado por Germano et al. (1991) para a solução do escoamento de um jato livre não pré-misturado estabilizado por um "Bluff-body". Eles compararam os resultados com valores obtidos experimentalmente e concluíram que os desvios encontrados nas predições das concentrações dos componentes eram devidos à má solução do escoamento. Assim eles mostraram a importância em bem predizer o escoamento para melhor resolver os efeitos termoquímicos.

Branley e Jones (2001) também reportaram problemas com a predição da composição dos produtos de combustão, utilizando um modelo baseado na fração de mistura e equilíbrio químico. O modelo submalha dinâmico foi utilizado e aplicou-se um modelo 
de discretização TVD para evitar valores não físicos da fração de mistura. Concluíram que o modelo de combustão utilizado é robusto o suficiente e os desvios encontrados são oriundos do acoplamento entre os efeitos da combustão e os da turbulência.

Rauwoens et al. (2009) verificam as dificuldades encontradas por Kempf, Lindstedt e Janicka (2005) e Branley e Jones (2001), em que variações no campo da densidade do fluido implicam em gradientes no campo das velocidades e da pressão, consolidando o fato de que se faz necessário um algorítmo robusto para a solução das equações de Navier-Stokes, mesmo para pequenas variações na densidade.

Mustata et al. (2005) aplica o método Euleriano de campos estocásticos para o modelo sub-malha das equações de transporte das espécies químicas, apresentando melhoras nas predições do campo de temperatura e distribuição das concentrações dos produtos de combustão. Entretanto, este modelo gera um alto custo computacional devido ao aumento da complexidade da modelagem matemática.

Saindo da esfera acadêmica, a metodologia LES passa a ser aplicada na predição das propriedades do escoamento em geometrias complexas como realizado por Mare, Jones e Menzies (2004), os quais efetuaram a simulação de uma câmara de combustão completa utilizando o modelo de cobustão simplificado, neste caso o modelo "flamelet", abrindo a possibilidade de testar configurações mais complexas com o aumento da capacidade computacional.

Devido à grande flexibilidade da metodologia LES, esta metodologia será aplicada neste trabalho para a solução de escoamentos turbulentos isotérmicos e reativos. Como apresentados pelos trabalhos acima, dada a complexa implementação da metodologia LES, nos escoamentos em que houver reação química de combustão neste trabalho, o modelo "Flamesheet" será empregado no cálculo dos efeitos da combustão dos resgentes sobre os campos de densidade e temperatura da mistura.

\subsection{Objetivos}

Este trabalho objetiva a ampliação dos conhecimentos sobre a dinâmica das chamas de difusão turbulenta pela modelagem matemática, desenvolvimento de um 
código computacional e simulação numérica deste tipo de sistema.

Os principais trabalhos com simulação numérica de chamas de difusão turbulentas e reativas são os apresentados por Branley e Jones (2001), Mare, Jones e Menzies (2004) e Kempf, Lindstedt e Janicka (2005), os quais aplicaram a metodologia LES acoplada a um modelo de combustão. Eles utilizaram tanto o modelo de Smagorinsky padrão quanto o Dinâmico para a modelagem submalha. Para a modelagem da combustão, aplicaram os modelos simplificados, baseado no transporte de um escalar passívo, como o modelo de equilíbrio químico e o "flamelet".

A abordagem escolhida, no presente trabalho, foi o método da simulação de grandes escalas turbulentas (LES), a qual representa, atualmente, a metodologia de modelagem dos efeitos da turbulência mais promissora. Para o modelo de combustão, optou-se pelo modelo do tipo folha de chama ou "Flamesheet", o qual, assim como os utilizados pelos principais trabalhos publicados, se baseia no transporte de um escalar passívo chamado fração de mistura.

Os resultados obtidos das simulações numéricas serão comparados aos dados experimentais, de forma a validar os modelos utilizados e a implementação realizada.

\subsection{Organização}

Este trabalho está dividido em oito capítulos. O primeiro é composto pela introdução, a qual dá um panorama geral sobre este trabalho, bem como uma breve discussão sobre os modelos mais utilizados para a análise de chamas de difusão turbulentas não pré-misturadas.

O segundo capítulo trata da teoria dos modelos utilizados, além de detalhes de sua implementação computacioal. Já o terceiro capítulo discute detalhes do modelo de acoplamento da pressão-velocidade necessário no estudo de escoamentos com baixo número de Mach. É discutido também a implementação da variação da densidade do fluido neste acoplamento.

O quarto capítulo discute a implementação do código computacional, bem como sua organização e a sequência lógica dos cálculos realizados. 
O quinto capítulo expressa a verificação, pelo método das soluções manufaturadas, e a validação, por escoamentos de engenharia, dos algorítmos implementados

No sexto capítulo, são exploradas as condições de contorno da chama de difusão a ser estudada, bem como os resultados obtidos para os escoamentos isotérmico e reativo.

O sétimo capítulo apresenta as conclusões deste trabalho e a bibliografia utilizada neste trabalho é listada no oitavo capítulo.

Apêndices foram incluidos para complementar a discussão dos modelos utilizados. O apêndice A traz uma forma de derivação do método dos volumes finitos.

O apêndice B discute o método "Fractional Steps" de acoplamento pressãovelocidade implementado e validado no código numérico.

No apêndice C são apresentados detalhes do modelo submalha dinâmico. Este modelo foi implementado no código numérico, porém não foi utilizado na solução dos escoamentos analisados.

O apêndice D mostra os métodos de solução dos sistemas algébricos implementados.

Os apêndices E e F apresentam detalhes do arquivo de entrada de parâmetros para o solucionador númerico e o formato do arquivo da malha computacional utilizado, respectivamente. 
Capítulo 2

Modelo físico-matemático para

cálculo de escoamentos turbulentos

reativos 


\subsection{Sistema de equações que regem o movimento de um fluido em um domínio cartesiano 3D}

A maioria dos escoamentos naturais ou de engenharia podem ser descritos pelo sistema de equações, equações (2.1) a (2.4), as quais representam, respectivamente, a conservação da massa, da quantidade de movimento, da entalpia e uma equação de estado para o fluido. Essas equações são apresentadas, em sua forma conservativa, para escoamentos compressíveis em coordenadas cartesianas e fluidos Newtonianos, de acordo com Versteeg e Malalasekera (2007).

Um fluido é denomimando Newtoniano quando as tensões cisalhantes são proporcionais ao gradiente das velocidades normais a essas tensões.

$$
\frac{\partial}{\partial t}(\rho)+\frac{\partial}{\partial x_{i}}\left(\rho u_{i}\right)=0
$$

$$
\begin{aligned}
& \frac{\partial}{\partial t}\left(\rho u_{i}\right)+\frac{\partial}{\partial x_{j}}\left(\rho u_{i} u_{j}\right)=-\frac{\partial P}{\partial x_{i}}+\frac{\partial}{\partial x_{j}}\left(\mu \frac{\partial u_{i}}{\partial x_{j}}\right)+\rho g_{i}+S_{u_{i}} \\
& \frac{\partial}{\partial t}(\rho h)+\frac{\partial}{\partial x_{j}}\left(\rho u_{j} h\right)=-P \frac{\partial u_{i}}{\partial x_{i}}+\frac{\partial}{\partial x_{j}}\left(k \frac{\partial T}{\partial x_{j}}\right)+\Phi+S_{h} \\
& P=P(\rho, T)
\end{aligned}
$$

De acordo com Maliska (2004), Munson, Young e Okiishi (2003), Hoffmann e Chiang (2000), Versteeg e Malalasekera (2007) entre outros, quando um fluido Newtoniano é estudado com propriedades constantes no espaço e no tempo, tal como a viscosidade em escoamentos isotérmicos, é possível definir uma equação genérica de 
transporte de uma quantidade $(\phi)$, equação (2.5), a qual recupera as equações (2.1) a (2.4) para determinados valores da quantidade $(\phi)$.

$$
\frac{\partial}{\partial t}(\rho \phi)+\frac{\partial}{\partial x_{j}}\left(\rho u_{j} \phi\right)=\frac{\partial}{\partial x_{j}}\left(\Gamma \frac{\partial \phi}{\partial x_{j}}\right)+S_{\phi}
$$

Esta equação pode ser dividida em quatro termos fisicamente distintos: temporal, advectivo, difusivo e termo fonte. Assim, para $\phi=1, \phi=u_{i}$ e $\phi=e$, obtêm-se as equações de conservação da massa, da quantidade de movimento e da energia, respectivamente. Além destas equações, é possível realizar o transporte de outras quantidades, como espécies químicas, energia cinética turbulenta, taxa de dissipação turbulenta, entre outras, cada qual com seu respectivo termo fonte.

\subsection{Discretização espacial}

A discretização espacial consiste na aproximação das derivadas espaciais, das equações de Navier-Stokes, por funções matemáticas como as séries polinomiais, ex-

ponenciais, trigonométricas, etc. É usual definir essas funções por meio das séries de Taylor, permitindo, inclusive, determinar a ordem do erro envolvido nessa aproximação.

Segundo Pitsch e Steiner (2000), Boersma, Brethouwer e Nieuwstadt (1998), Branley e Jones (2001) entre outros, para LES é necessário que a discretização espacial apresente, no mínimo, erro de segunda ordem, sendo usual a aplicação de discretizações de ordens superiores. Essa restrição é devida à necessidade de se obter resultados precisos para escoamentos turbulentos, permitindo a melhor representação das perturbações e pequenas variações das propriedades contidas num escoamento.

Para garantir o decaimento de segunda ordem para o erro, neste trabalho foi implementado o método das diferenças centrais (CDS) para a aproximação da derivada espacial de uma função $f(x)$, representado pela equação (2.6), no volume central em $(x)$, com espaçamento $(H)$ entre os centros das células adjacentes, como mostrado pela figura 2.1 . 


$$
\frac{\partial f(x)}{\partial x}=\frac{f(x+H)-f(x-H)}{2 H}
$$

\section{Direção x}

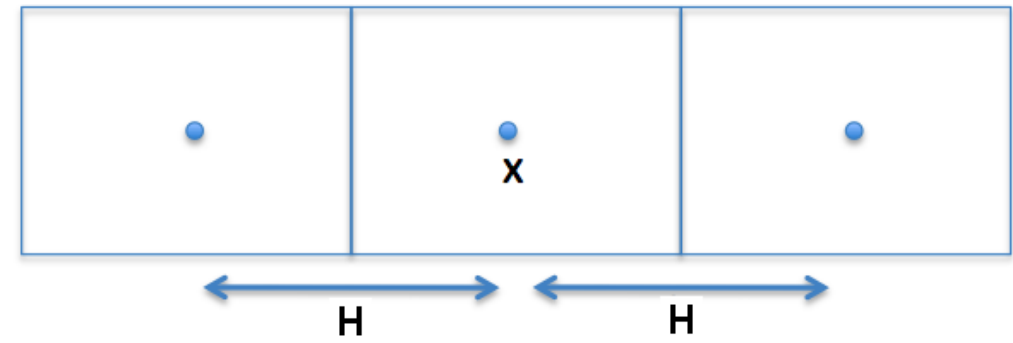

Figura 2.1: Discretização espacial unidimensional em volumes elementares: distância entre centros $(H)$ e elemento central em $(x)$

Ao se expandir a função $(f(x))$ em séries de Taylor nos pontos $(x-H)$ e $(x+H)$ até terceira ordem no espaço, obtem-se a equação (2.7), com o termo $(E(x))$ dado pela equação (2.8). O termo $(E(x))$ é diretamente proporcional à quantidade $\left(H^{2}\right)$, ou seja, este termo diminui com o quadrado da redução de $(H)$, indicando que a equação $(2.7)$ apresenta erro de segunda ordem, representado pelo termo $(E(x))$.

$$
\begin{aligned}
& \frac{\partial f(x)}{\partial x}=\frac{f(x+H)-f(x-H)}{2 H}-E(x) \\
& E(x)=\frac{H^{2}}{12}\left(\frac{\partial^{3} f(x+H)}{\partial x^{3}}+\frac{\partial^{3} f(x-H)}{\partial x^{3}}\right)
\end{aligned}
$$

No algorítmo numérico, foi implementada uma variação da discretização CDS de forma a permitir o uso de malhas com espaçamento variável entre os centros dos volumes. 


\subsection{Discretização temporal}

A discretização temporal consiste na aproximação das derivadas temporais das equações de Navier-Stokes por funções matemáticas, como feito na discretização espacial.

Diversos métodos de discretização temporal podem ser aplicados no cálculo de escoamentos turbulentos reativos. Ao longo deste trabalho, três métodos foram implementados e avaliados quanto a sua eficiência na solução das propriedades do escoamento.

Como continuidade ao trabalho de Araújo (2006), um método totalmente implícito, apresentado por Maliska (2004), foi analisado e implementado. Entretanto, este método apresenta erro com decaimento de primeira ordem, o que não é suficiente para a solução de escoamentos turbulentos pelo método LES.

Um segundo método foi implementado, baseado na discretização de CrankNicolson, apresentado por Kim e Moin (1985) e rediscutido por Ferziger (2002). Este método é discutido e detalhado, junto ao método dos passos fracionados para o acoplamento entre a pressão e velocidade, no Apêndice B deste trabalho. Apesar deste método possuir bom desempenho para o cálculo de escoamentos turbulentos, o mesmo não ocorreu para escoamentos reativos, na forma originalmente proposta, na qual os efeitos devidos à combustão são calculados apenas no final de cada iteração do algorítmo.

Por fim, um terceiro método de discretização temporal foi analisado e implementado. Pitsch e Steiner (2000), Boersma, Brethouwer e Nieuwstadt (1998), Branley e Jones (2001), entre outros, utilizaram uma combinação entre os métodos AdamsBashforth e Adams-Moulton para discretização temporal. Este método apresenta decaimento de segunda ordem para o erro, além de um bom desempenho na solução de escoamentos turbulentos reativos. Assim, este método foi adotado neste trabalho para a solução dos problemas propostos. 


\subsubsection{Método Adams - Bashforth}

Butcher (2003) apresenta o método Adams-Bashforth multi-passos. Neste trabalho, o método com dois passos foi empregado por apresentar decaimento de segunda ordem para o erro, como discutido em Hairer, Nørsett e Wanner (1993).

A equação (2.9) é a representação genérica deste método. Devido à necessidade de se utilizar um método que apresente erro com decaimento de segunda ordem, as constantes foram definidas como $\beta_{1}=\frac{1}{2}\left(2+\frac{\Delta t_{n}}{\Delta t_{n-1}}\right), \beta_{2}=-\frac{1}{2}\left(\frac{\Delta t_{n}}{\Delta t_{n-1}}\right)$ e $\beta_{3 \ldots k}=0$, como apresentado na equação (2.10). Quando o incremento de tempo é constante, recuperam-se os termos $\beta_{1}=\frac{3}{2}$ e $\beta_{2}=-\frac{1}{2}$.

$$
\begin{aligned}
& y_{n}=y_{n-1}+\Delta t\left(\beta_{1} f\left(t_{n-1}, y_{n-1}\right)+\beta_{2} f\left(t_{n-2}, y_{n-2}\right)+\ldots+\beta_{k} f\left(t_{n-k}, y_{n-k}\right)\right) \\
& y_{n}=y_{n-1}+\frac{\Delta t}{2}\left(\left(2+\frac{\Delta t_{n}}{\Delta t_{n-1}}\right) f\left(t_{n-1}, y_{n-1}\right)-\left(\frac{\Delta t_{n}}{\Delta t_{n-1}}\right) f\left(t_{n-2}, y_{n-2}\right)\right)
\end{aligned}
$$

Para o uso do método de dois passos, equação (2.10), é necessário avaliar $f\left(t_{n-1}, y_{n-1}\right)$ e $f\left(t_{n-2}, y_{n-2}\right)$. Assim, considera-se que o campo em $\left(t_{n-2}\right)$ seja o campo inicial $\left(y_{n-2}\right)$ e, para o campo $\left(t_{n-1}\right)$, é usual aplicar a equação (2.11) para se encontrar o campo $\left(y_{n-1}\right)$.

$$
y_{n-1}=y_{n-2}+\Delta t f\left(t_{n-2}, y_{n-2}\right)
$$

A equação (2.11) representa o método de integração de Euler, derivado da equação (2.9) com constantes $\beta_{1}=1$ e $\beta_{2 \ldots k}=0$ para incremento de tempo constante.

Entretanto, verificou-se que, partindo-se da solução $y_{n-1}=y_{n-2}=0$, os resultados não apresentavam forte dependência da solução inicial quando em regime estatísticamente permanente, isto é, instante de tempo em que as médias temporais das quantidades estudadas tornaram-se constantes. Logo, a inicialização do escoamento por este método foi utilizada. 


\subsubsection{Método Adams - Moulton}

O método Adams-Moulton, discutido por Butcher (2003), se assemelha ao método Adams-Bashforth com a adição de um termo implícito na equação genérica (2.9), como mostrado na equação (2.12).

$$
y_{n}=y_{n-1}+\Delta t\left(\beta_{0} f\left(t_{n}, y_{n}\right)+\beta_{1} f\left(t_{n-1}, y_{n-1}\right)+\ldots+\beta_{k} f\left(t_{n-k}, y_{n-k}\right)\right)
$$

Segundo Butcher (2003), a seleção das constantes é feita de modo a se obter a ordem desejada para o decaimento do erro, logo, neste este trabalho, para se manter um erro de segunda ordem, selecionam-se as constantes $\beta_{0}=0, \beta_{1}=\frac{1}{2}\left(\frac{\Delta t_{n}}{\Delta t_{n-1}}\right)$,

$\beta_{2}=\frac{1}{2}\left(\frac{\Delta t_{n}}{\Delta t_{n-1}}\right)$ e $\beta_{3 \ldots k}=0$, o que implica na equação (2.13) para o caso com incremento de tempo variável. Para o caso com incremento de tempo constante, recuperam-se os termos $\beta_{1}=\frac{1}{2}, \beta_{2}=\frac{1}{2}$.

$$
y_{n}=y_{n-1}+\frac{\Delta t}{2}\left(\left(\frac{\Delta t_{n}}{\Delta t_{n-1}}\right) f\left(t_{n-1}, y_{n-1}\right)+\left(\frac{\Delta t_{n}}{\Delta t_{n-1}}\right) f\left(t_{n-2}, y_{n-2}\right)\right)
$$

Dada a semelhança deste método com o método Adams-Bashforth, o problema para a determinação do campo inicial, quando necessário, é resolvido com o mesmo procedimento.

\subsubsection{Determinação do incremento de tempo}

Neste trabalho, o incremento de tempo pode ser definido como constante ou variável ao longo da solução dos escoamentos. É usual utilizar incrementos constantes quando as análises objetivam a retirada de dados estatísticos para estudo de modelos de turbulência, cálculo de freqüências de liberação de vórtices, etc. Entretanto, devido à necessidade de minimização do tempo de processamento, é usual a utilização de um incremento de tempo variável. 
Existem diversas metodologias para o cálculo do incremento de tempo durante uma simulação numérica. Um método baseado no trabalho de Courant, Friedrichs e Lewy (1967) e modificado por Boersma, Brethouwer e Nieuwstadt (1998), é apresentado, na forma unidimensional, pela equação (2.14). Nesta equação, $(C F L)$ é uma constante definida entre 0,0 e 1,0.

$$
\Delta t_{n}=C F L \frac{\Delta x_{n}}{\left|u_{x_{n-1}}\right|}
$$

Essa metodologia representa uma condição de restrição para o incremento de tempo, ou seja, dada uma onda de informação que se propaga entre os volumes do domínio computacional, o incremento de tempo de cada volume deve ser inferior ao tempo levado por essa onda para se propagar para os volumes adjacentes. Assim, o menor tempo necessário, para todas as variáveis em todos os volumes, é aplicado de forma global, garantindo que a informação não ultrapasse nenhum volume.

Apesar de ser amplamente utilizada, a metodologia proposta por Courant, Friedrichs e Lewy (1967), foi derivada para escoamentos dominantemente advectivos. Logo, este método não apresenta bom desempenho para escoamentos dominantemente difusivos. Assim, uma metodologia que considere escoamentos advectivos e difusivos simultâneos se faz necessária. Para satisfazer esse requisito, Boersma, Brethouwer e Nieuwstadt (1998) apresentam o critério para seleção do incremento de tempo, reproduzido pela equação (2.15). Nesta equação, $(i)$ são as componentes nos eixos coordenados e, para a metodologia LES, $\left(\mu_{e}\right)$ é a viscosidade efetiva do fluído estudado.

$$
\Delta t_{n}=\frac{C F L}{\frac{u_{x_{i}}^{n-1}}{\Delta x_{i}{ }^{n}}+\mu_{e}\left(\frac{1}{\Delta x_{i}{ }^{n}}\right)^{2}}
$$

Assim, nas análises realizadas neste trabalho, o critério para o cálculo do incremento de tempo foi sempre baseado na equação (2.15). 


\subsection{Condições de contorno e inicial}

As condições de contorno ou fronteira são usadas para representar as condições de cada variável no contorno do domínio estudado.

Genericamente, as condições de contorno são baseadas nas restrições numéricas conhecidas por condição de Dirichlet, de Neumann ou uma conbinação entre elas.

Neste trabalho, inicialmente foi proposta a utilização da metodologia das células fantasmas, como apresentado por Versteeg e Malalasekera (1998). Entretanto, esta metodologia, não apresentou o desempenho desejado quanto a incorporação das condições de contorno na solução dos campos de velocidade e pressão, além de tornar difícil a implementação e uso de malhas não estruturadas. Logo, foi desenvolvida uma metodologia que permite a inclusão direta da condição de contorno nos termos fontes das equações algébricas a serem resolvidas.

A metodologia aplicada neste trabalho inclui a informação oriunda da condição de contorno por meio do cálculo da propriedade em estudo na posição $i+1$. Com isso, aplica-se essa informação diretamente nas equações algébricas discretizadas, dispensando o uso de volumes adicionais, minimizando o consumo de memória, tempo de processamento e a necessidade de tratamento específico do solucionador algébrico nos contornos, além de se considerar a influência das condições de contorno diretamente na solução das equações.

A figura 2.2, apresenta uma interpretação da localização das variáveis em células no contorno do domínio estudado quando usada a metodologia de células fantasmas.

A condição de contorno de Dirichlet, também conhecida como condição de valor prescrito, define que os valores das variáveis a serem resolvidas são conhecidos no contorno e independentes da solução encontrada. Adicionalmente, os valores no contorno podem estar sujeitos a variação temporal, caso necessário. Esta condição estabelece que o valor da propriedade estudada $\left(\phi_{f}\right)$ é conhecida na fronteira do volume, o que implica na determinação direta de $\phi_{i+1}$ pela equação (2.16). Esta equação é a representação da interpolação, pelo método das diferenças centrais, entre os valores nos 


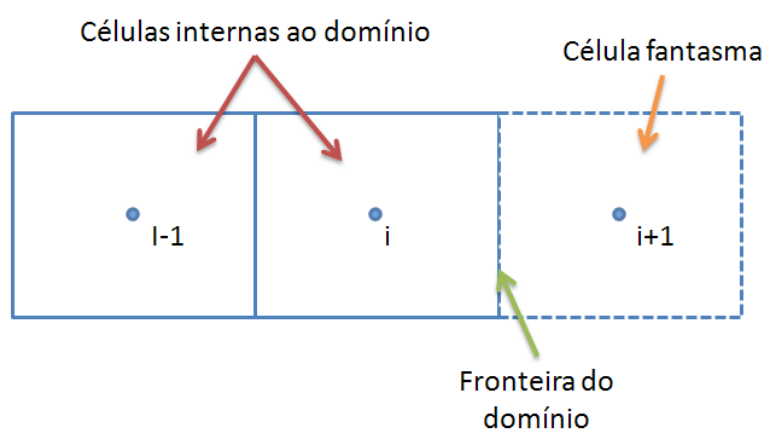

Figura 2.2: Aplicação das condições de contorno para a metodologia das células fantasmas

centróides das células e no contorno.

$$
\phi_{i+1}=2 \phi_{f}-\phi_{i}
$$

Já a condição de contorno de Neumann, conhecida por condição de fluxo definido, implica que o fluxo, ou a primeira derivada direcional das variáveis a serem resolvidas, é conhecido no contorno. Assim, nessa condição, o fluxo $\left(\frac{\partial \phi_{f}}{\partial x}\right)$ é conhecido, permitindo se obter a equação (2.17). Novamente, essa equação é a aplicação do método das diferenças centrais para a derivada na face, entre os dois centróides dos volumes.

$$
\phi_{i+1}=\frac{\partial \phi_{f}}{\partial x} \Delta x+\phi_{i}
$$

Quando um domínio conta apenas com condições de contorno do tipo Neumann para uma variável, verifica-se que o campo calculado pode não ser único, para um sistema de equações elípticas. Assim, pelo menos um volume da malha computacional deve receber uma condição de Dirichlet para aquela variável, garantindo a existência e unicidade das soluções.

Para facilitar a entrada das informações no programa desenvolvido, foram definidos conjuntos de condições de contorno, como a condição de entrada, condição de 
saída e condição de parede, condição de simetria e condição de periódicidade, os quais representam a aplicação das condições de Dirichlet e Neumman para as variáveis no contorno.

\subsubsection{Condição de contorno do tipo de entrada}

Neste trabalho, a condição de entrada adimite que seja conhecido, a priori, a velocidade ou a pressão dos fluidos que entram no domínio analisado. Quando a velocidade é previamente determinada, aplica-se a condição de Dirichlet esta variável e aplica-se a condição de Neumann para a pressão nessa região. Porém, quando a pressão é conhecida, se faz necessária a utilização de uma condição do tipo Neumann para as velocidades. Essa combinação de condições de contorno para o campo de pressão e velocidades é proveniente da equação de Bernoulli, em que, para um escoamento potencial num duto longo sem efeitos da gravidade, define-se a equação (2.18). Nessa equação, verifica-se uma proporcionalidade direta entre os campos de velocidade e pressão, de modo que, ao se definir um destes campos, o outro é automaticamente definido.

$$
\frac{\rho v^{2}}{2}+P=c t e
$$

Caso alguma outra variável necessite ser determinada na condição de entrada, ela pode assumir tanto uma condição de Dirichlet ou Neumann.

\subsubsection{Condições flutuantes na entrada}

Devido à utilização da metodologia de solução das grandes escalas turbulentas, Ilyushin e Krasinsky (2006) e Pitsch e Steiner (2000) sugerem que as condições de contorno na entrada do domínio computacional considerem uma pequena perturbação para melhor representar as propriedades calculadas e, assim, facilitar a transição do escoamento laminar para o turbulento. Essa perturbação, neste trabalho, foi considerada como uma flutuação na velocidade média do fluido na entrada do domínio. 
Quando não existem dados empíricos para se quantificar essas perturbações, uma porcentagem, usualmente de 2 a $10 \%$ do valor médio da velocidade, é aplicada com uma frequência randômica.

\subsubsection{Condição de contorno do tipo de saída}

Neste trabalho, a condição de saída é caracterizada pela aplicação da condição de Neumann para todas as variáveis, exceto para a pressão, a qual é usualmente conhecida nessa região do escoamento físico.

\subsubsection{Região de alta difusividade ou "buffer domain"}

Em escoamentos turbulentos com alta vorticidade são comuns os problemas de convergência na saída do domínio ao se utilizar as condições de Neumann. Isto ocorre devido à grandes instabilidades que podem surgir devido ao uso da discretização por diferenças centrais. Assim, para evitar esse tipo de problema, define-se uma região, que antecede a fronteira de saída do domínio, chamada de "buffer domain", com tamanho de até $10 \%$ do domínio computacional. Neste trabalho, as flutuações da velocidade, na "buffer domain", são minimizadas por um alto coeficiente de difusão, diminuindo sua intensidade e minimizando a possiblidade de geração de instabilidades. Esse tipo de solução deve ser empregado com extrema cautela para que sua influência não perturbe o escoamento original, modificando seu comportamento.

\subsubsection{Condição de contorno do tipo parede}

As condições do tipo parede foram definidas como impermeável e sem escorregamento, ou seja, todas as velocidades, normais e tangenciais, foram prescritas nulas. Entretando, se a parede possuir movimento relativo ao escoamento do fluido, as velocidade tangenciais podem ser definidas como não nulas. As velocidades normais são sempre nulas, não perminindo que a fronteira se mova nesta direção.

A condição de Neumann com fluxo nulo é, geralmente, aplicada para a pressão e outros escalares na região de perede do domínio. 


\subsubsection{Condições de contorno de simetria e periodicidade}

Condições de simetria e periodicidade dependem, diretamente, da geometria do domínio e do escoamento a ser calculado, isto porque, mesmo que o escoamento médio temporal e a geometria estudada apresentem alguma simetria ou periodicidade, no método LES, as flutuações devido às interações das estruturas turbulentas não apresentam tais características, o que impede a utilização desse tipo de condição de contorno. Assim, extrema cautela deve ser tomada ao se utilizar essas condição no contorno do domínio estudado.

Para a condição de simetria, utiliza-se a condição de Dirichlet nula para as velocidades normais à face e, para as velocidades tangenciais, bem como para a pressão e escalares, aplica-se a condição de Neumann com valor nulo.

Para a condição de periodicidade, definem-se todas as propriedades por Dirichlet, de forma que as variáveis possuam os mesmo valores nas faces periódicas previamente definidas.

\subsubsection{Condições iniciais do escoamento}

As condições inicias são aplicadas na solução dos campos estudados e, usualmente, aceleram a convergência de um determinado escoamento, quando bem definidas. Em sistemas iterativos em regime permanente, é usual definir um valor qualquer próximo do escoamento real, pois a influência desses valores é minimizada conforme a solução evolui e se aproxima do valor real.

Já em escoamento transientes com métodos de solução não iterativos, é necessário que o valor inicial das variáveis seja muito próximo do valor real, além de respeitarem a restrição de conservação da massa. Assim, neste trabalho, ou partiu-se de campos nulos para todas as variáveis ou campos previamente resolvidos.

Devido à utilização da discretização temporal pelo método de Adams-BashforthMoulton, neste trabalho, a condição inicial foi sempre nula para todas as variáveis localizadas no interior do domínio computacional. 


\subsection{Modelagem dos efeitos da turbulência pela me- todologia LES}

$\mathrm{Na}$ natureza ou em sistemas de engenharia podem ser encontrados escoamentos turbulentos, os quais são caracterizados por movimentos aleatórios, tridimensionais, irregulares, transientes, caóticos e dissipativos, de acordo com Pope (2000).

A figura 2.3 apresenta o escoamento instantâneo de um jato turbulento totalmente desenvolvido na qual se observam estruturas turbulentas com escalas de movimento que excedem 2 vezes o diâmetro de saída do jato até o limite de resolução da câmera utilizada na foto. Em escoamentos turbulentos, resolvidos pela metodologia LES, o valor de uma propriedade num determinado ponto é decomposto num valor resolvido e um resíduo submalha, como apresentado na figura (2.4).

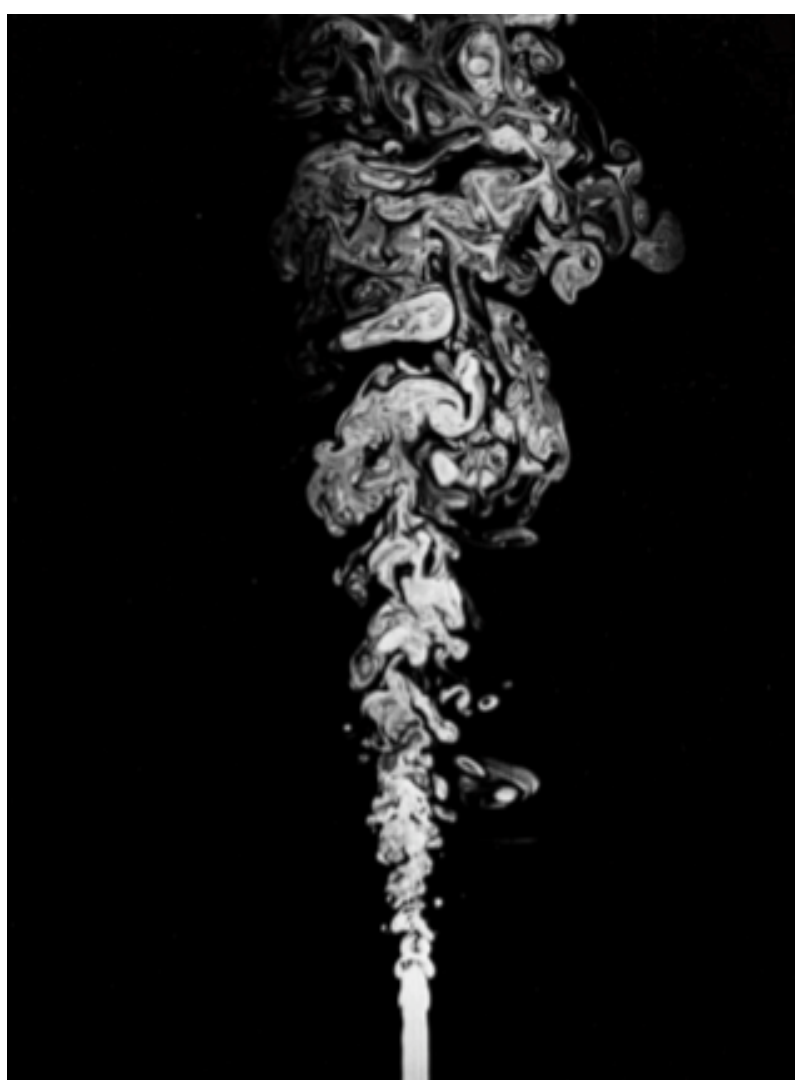

Figura 2.3: Exemplo de jato turbulento: escalas do movimento. Dimotakis, Lye e Papantoniou (1981)

De acordo com Pope (2000), escoamentos com alto número de Reynolds apre- 


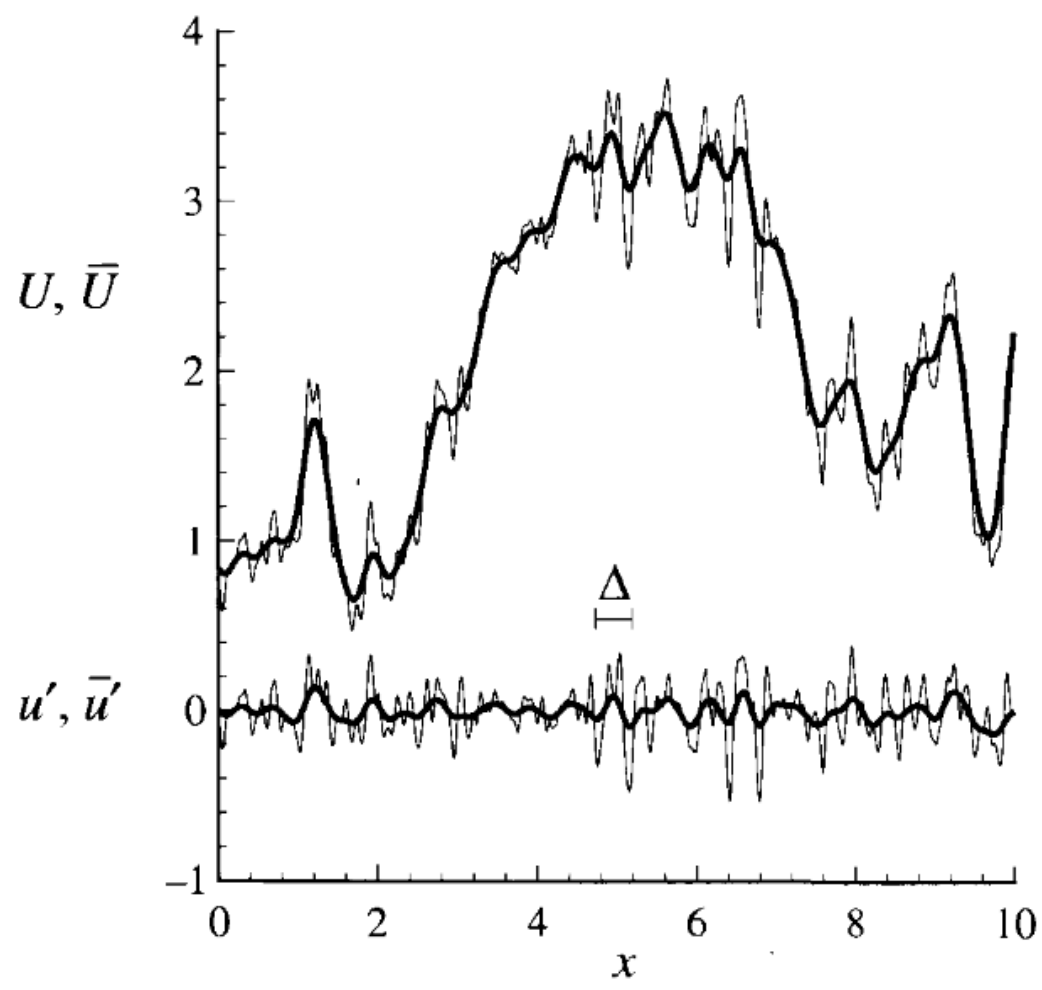

Figura 2.4: Decomposição do sinal turbulento num dado ponto do escoamento: valor real $(U)$, filtrado $(\bar{U})$, resíduo submalha $\left(u^{\prime}\right)$ e resíduo filtrado $\left(\bar{u}^{\prime}\right)$. Fonte: Pope $(2000)$

sentam uma separação no tamanho das escalas turbulentas: as grandes e as pequenas escalas. As grandes escalas são diretamente influenciadas pela geometria do escoamento, governando globalmente o transporte e a mistura de espécies. Já as pequenas escalas são dependentes apenas da taxa de energia que recebem das grandes escalas e da viscosidade do meio, apresentando, assim, características locais e universais, independentes do escoamento global.

Dada essa separação entre as escalas turbulentas, verifica-se que as pequenas escalas são responsáveis pela dissipação da energia turbulenta produzida pelas grandes escalas. Esse transporte de energia, idealizado na figura 2.5 por Frisch (1996), é denominado cascata de energia de Kolmogorov. Essa cascata é representada na figura 2.6, em termos da energia cinética turbulenta em função do número de onda, na qual se distinguem três regiões principais: produção de energia nas grandes escalas, transporte inercial nas escalas intermediárias e dissipação dessa energia pelas pequenas escalas, para escoamentos homogêneos e isotrópicos, em que o decaimento na região inercial é 
proporcional a $K^{-\frac{5}{3}}$.

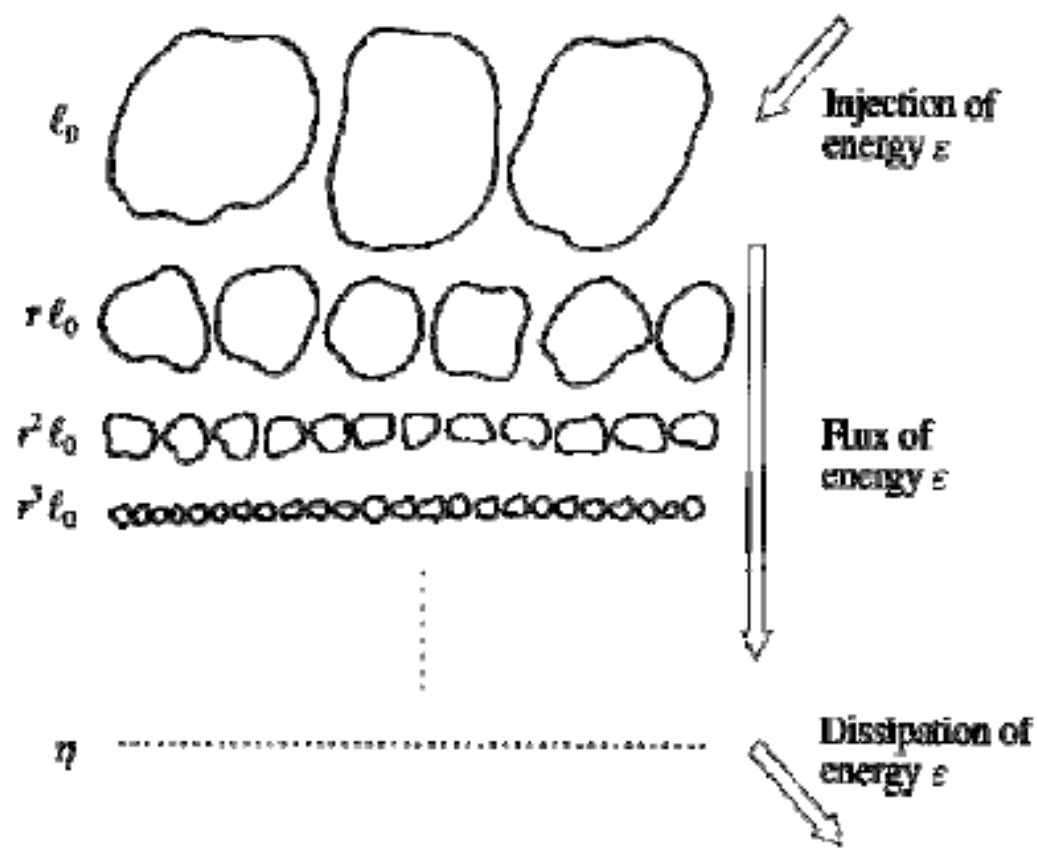

Figura 2.5: Transporte idealizado da energia cinética turbulenta pelas escalas do movimento. Fonte: Frisch (1996)

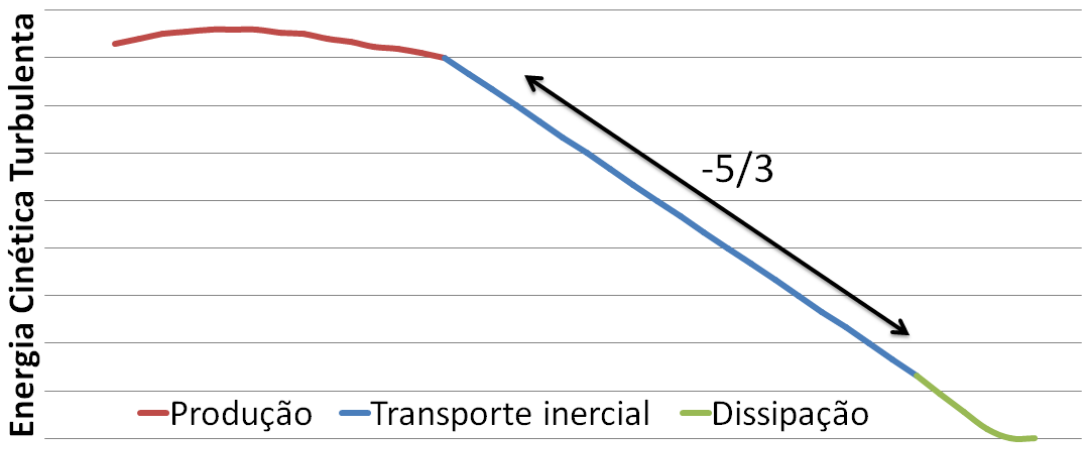

Número de Onda

Figura 2.6: Representação da densidade de energia na cascata de Kolmogorov: distribuição de energia pelas escalas do movimento turbulento

Segundo Pope (2000), as menores escalas do movimento turbulento encontradas num escoamento, denominadas escalas de Kolmogorov, são definidas pelas equações (2.19), (2.20) e (2.21), as quais representam, respectivamente, as escalas de compri- 
mento $\left(\eta^{K}\right)$, tempo $\left(\tau_{\eta}^{K}\right)$ e velocidade $\left(u_{\eta}^{K}\right)$. A equação (2.22) apresenta o conceito de número de onda $(K)$.

$$
\begin{aligned}
& \eta^{K} \equiv\left(\frac{\nu^{3}}{\varepsilon}\right)^{\frac{1}{4}} \\
& \tau_{\eta}^{K} \equiv\left(\frac{\nu}{\varepsilon}\right)^{\frac{1}{2}} \\
& u_{\eta}^{K} \equiv(\nu \varepsilon)^{\frac{1}{4}} \\
& K \equiv 2 \pi l
\end{aligned}
$$

Pope (2000) demonstra que, em escoamentos homogêneos e isotrópicos, a energia cinética turbulenta e sua taxa de dissipação são proporcionais a $\left(K^{-\frac{2}{3}}\right)$ e $\left(K^{\frac{4}{3}}\right)$, ou seja, a energia cinética turbulenta diminui conforme o tamanho das escalas turbulentas diminui, sendo o tamanho dessas escalas inversamente proporcional ao número de onda. Consequentemente, a taxa de dissipação dessa energia aumenta com o aumento do número de onda.

Segundo Hoffmann e Chiang (2000), Pope (2000) entre outros, definem-se três métodos para o estudo numérico dos efeitos da turbulência em escoamentos: RANS, LES e DNS. O metodo RANS ou "Reynolds Averaged Navier-Stokes" necessita da modelagem completa dos efeitos da turbulência em todas as escalas do movimento, além de resolver apenas escoamentos médios ou em regime estatísticamente estacionário. No outro extremo está o DNS ou "Direct Numerical Simulation", o qual resolve as equações instantâneas de Navier-Stokes sem a necessidade de qualquer modelagem matemática para os efeitos da turbulência, ou seja, nesta metodologia, todas as escalas do movimento são calculadas e seus efeitos sobre o escoamento são incluídos diretamente.

A metodologia LES ou "Large Eddy Simulation" se encontra no meio termo entre a RANS e DNS, em que as grandes escalas turbulentas são resolvidas e modelamse apenas as pequenas escalas. Essa metodologia exita a necessidade de se discretizar 
o espaço e o tempo abaixo do comprimento das escalas de kolmogorov, como no DNS, ao mesmo tempo que resolve os efeitos de transporte e mistura devido a anisotropia das grandes escalas, o que não pode ser feito na metodologia RANS.

Como um dos objetivos deste trabalho é melhor entender escoamentos turbulentos reativos, a metodologia RANS foi descartada por se basear apenas e diretamente em escoamentos médios. Devido ao alto custo computacional exigido pela metodologia DNS, o método da simulação das grandes escalas turbulentas, ou LES, foi estudado e implementado neste trabalho.

\subsubsection{Metodologia LES}

De acordo com Hoffmann e Chiang (2000), Pope (2000), Tennekes e Lumley (1972), entre outros, a metodologia LES se baseia na solução das equações filtradas de Navier-Stokes. O comprimento do filtro utilizado define o limiar entre as escalas a serem resolvidas e as modeladas.

A metodologia LES se baseia em quatro conceitos, de acordo com Pope (2000): filtragem dos campos das variáveis estudadas, filtragem das equações de Navier-Stokes, fechamento do sistema equações pela modelagem das tensões residuais e solução numérica do campo filtrado.

A filtragem dos campos das variáveis estudadas se dá, de acordo com a equação (2.23), pela decomposição destes campos em duas parcelas: os campos resolvidos diretamente $(\bar{\phi})$ e os residuais $\left(\phi^{\prime}\right)$. Apesar dessa decomposição apresentar semelhanças com a de de Reynolds, a principal diferença, segundo Pope (2000), é que a média temporal das flutuações residuais $\left(\phi^{\prime}\right)$, geralmente, não é nula.

$$
\phi=\bar{\phi}+\phi^{\prime}
$$

A filtragem das equações de Navier-Stokes ocorre aplicando-se a equação (2.23) na equação de conservação de quantidade de movimento, equação (2.2), obtendo-se a 
equação (2.24). A equação (2.25) apresenta o termo das tensões residuais devido à aplicação do filtro.

$$
\begin{aligned}
& \frac{\partial}{\partial t}\left(\rho \bar{u}_{i}\right)+\frac{\partial}{\partial x_{j}}\left(\rho \bar{u}_{i} \bar{u}_{j}\right)=-\frac{\partial \bar{P}}{\partial x_{i}}+\frac{\partial}{\partial x_{j}}\left(\mu \frac{\partial \bar{u}_{i}}{\partial x_{j}}\right)+\rho g_{i}+S_{\bar{u}_{i}}-\frac{\partial \tau_{i j}}{\partial x_{j}} \\
& \tau_{i j}=\overline{u_{i} u_{j}}-\bar{u}_{i} \bar{u}_{j}
\end{aligned}
$$

Na metodologia LES existem duas formas de se fazer a filtragem das equações: implícita e explícita. A metodologia implícita considera que a própria malha utilizada acoplado ao método numérico implementado, representam o filtro a ser empregado nas equações a serem resolvidas. Já na metodologia com filtragem explícita, o comprimento do filtro a ser utilizado é explicitamente definido e, usualmente, é maior que o comprimento utilizado na metodologia implícita. Segundo Lund (2003), a filtragem explícita é utilizada para controlar o erro númerico devido a operação de filtragem e, apesar de trazer melhores resultados, esta metodologia é extremamente custosa computacionalmente quando comparada ao metodologia implícita. Assim, neste trabalho, foi empregada a metodologia implícita, de modo a associar o comprimento do filtro ao volume das células que discretizam espacialmente o domínio analisado. O comprimento do filtro é calculado pela equação (2.26).

$$
\Delta=V_{c}^{\frac{1}{3}}
$$

Aplicando a equação (2.23) na (2.25), encontra-se a equação (2.27), a qual apresenta os termos que são resolvidos diretamente, equação (2.28), e os que devem ser modelados, equação (2.29).

$$
\tau_{i j}=L_{i j}+C_{i j}+R_{i j}
$$




$$
\begin{aligned}
& L_{i j}=\overline{\bar{u}_{i} \bar{u}_{j}}-\overline{\bar{u}}_{i} \overline{\bar{u}}_{j} \\
& C_{i j}+R_{i j}=\overline{\bar{u}_{j} u_{i}^{\prime}}+\overline{\bar{u}_{i} u_{j}^{\prime}}+\overline{u_{i}^{\prime} u_{j}^{\prime}}
\end{aligned}
$$

Subtraindo-se a energia cinética turbulenta residual do tensor das tensões residuais, encontra-se o tensor anisotrópico das tensões residuais, equação (2.30). Essas tensões residuais isotrópicas são, então, incluidas no campo modificado das pressões filtradas, equação (2.31). Com as equações (2.30) e (2.31), obtem-se a equação (2.32).

$$
\begin{aligned}
& \tau_{i j}^{+}=\tau_{i j}-\frac{1}{3} \tau_{i i} \delta_{i j} \\
& \bar{P}^{+}=\bar{P}+\frac{1}{3} \tau_{i i} \\
& \frac{\partial}{\partial t}\left(\rho \bar{u}_{i}\right)+\frac{\partial}{\partial x_{j}}\left(\rho \bar{u}_{i} \bar{u}_{j}\right)=-\frac{\partial \bar{P}^{+}}{\partial x_{i}}+\frac{\partial}{\partial x_{j}}\left(\mu \frac{\partial \bar{u}_{i}}{\partial x_{j}}\right)+\rho g_{i}+S_{\bar{u}_{i}}-\frac{\partial \tau_{i j}^{+}}{\partial x_{j}}
\end{aligned}
$$

Para a solução da equação (2.32), é necessário um modelo de fechamento que resolva os termos da equação (2.30). Para tanto, Smagorinsky (1963) propôs uma abordagem, baseada na hipótese de Boussinesq, que define uma viscosidade turbulenta proporcional ao tensor das taxas de deformações do fluido, para modelar a dissipação na pequena escala, menores que o filtro utilizado, em forma de energia interna.

Existem diversos modelos sub-malha que fazem uma adaptação ao proposto originalmente por Smagorinsky, o mais conhecido é chamado por modelo dinâmico, apresentado por Germano et al. (1991) e modificado por Lilly (1991). Entretanto, apesar de existirem modelos submalha mais complexos, Boersma, Brethouwer e Nieuwstadt (1998), Pitsch e Steiner (2000), Branley e Jones (2001), Ilyushin e Krasinsky (2006), entre outros, obtiveram bons resultados com o modelo original proposto por Smagorinsky (1963). Assim este modelo será estudado e implementado neste trabalho. 


\subsubsection{Modelo de Smagorinsky para a modelagem dos efeitos de dissipação submalha}

O modelo proposto por Smagorinsky (1963) para capturar os efeitos de dissipação viscosa sub-malha se baseia, fundamentalmente, no conceito de equilíbrio entre produção e dissipação de energia cinética turbulenta. Este conceito é nítido quando se estuda o escoamento a jusante de uma grelha, o qual apresenta turbulência homogênea e isotrópica.

Este modelo é baseado na aproximação de Boussinesq, apresentada pela equação (2.33), de acordo com Hoffmann e Chiang (2000). Nela, o tensor das tensões anisotrópicas residuais é proporcional à taxa de deformação das grandes escalas turbulentas, apresentada pela equação (2.34). Define-se, então, um escalar, chamado viscosidade turbulenta $\left(\mu_{t}\right)$, que torna a proporcionalidade em igualdade. A equação (2.35) representa a taxa de deformação característica do escoamento.

$$
\begin{aligned}
& \tau_{i j}^{+}=2 \mu_{t} \bar{S}_{i j} \\
& \bar{S}_{i j}=\frac{1}{2}\left(\frac{\partial \overline{u_{i}}}{\partial x_{j}}+\frac{\partial \overline{u_{j}}}{\partial x_{i}}\right) \\
& \bar{S}=\left(2 \bar{S}_{i j} \bar{S}_{i j}\right)^{\frac{1}{2}}
\end{aligned}
$$

De acordo com Pope (2000), o modelo de Smagorinsky é análogo ao modelo de comprimento de mistura, o qual define a viscosidade turbulenta em função de um comprimento de mistura característico $\left(l_{s}\right)$ do escoamento e da taxa de deformação característica, como mostrado pela equação (2.36). Esse comprimento característico $\left(l_{s}\right)$ é associado ao comprimento do filtro $(\Delta)$ utilizado pela constante de Smagorinsky $\left(C_{s}\right)$. Logo, a equação (2.37) apresenta o cálculo da viscosidade turbulenta para este modelo. 


$$
\begin{aligned}
& \mu_{t}=l_{s}^{2} \bar{S} \\
& \mu_{t}=\left(C_{s} \Delta\right)^{2} \bar{S}
\end{aligned}
$$

A constante de Smagorinsky varia entre 0,1 e 0,24, não sendo universal para todos os tipos de escoamento. De acordo com Pope (2000), Branley e Jones (2001) entre outros, adota-se o valor entre 0,1 e 0,17 para escoamentos de jatos turbulentos. Entretanto, de acordo com Ilyushin e Krasinsky (2006), a escolha do valor desta constante está diretamente associada ao comprimento do núcleo do jato e à dissipação númerica do código, de forma que quanto menor for esta constante, menor será o núcleo do jato turbulento e a difusividade turbulenta. Assim, para este trabalho, adotou-se o valor de 0,1 para as análises, como utilizado por Branley e Jones (2001) e indicado por Ilyushin e Krasinsky (2006).

\subsection{Modelagem dos efeitos de combustão pelo mo- delo "Flamesheet"}

Os modelos de combustão são empregados para, dado o transporte das espécies químicas no escoamento, transformar as concentrações dos reagentes em produtos. Esses modelos consideram os efeitos das reações químicas de modo a permitir a análise do processo de combustão devido à mistura dos reagentes, bem como as concentrações finais das espécies.

Nos modelos de combustão, é usual definir equações de transporte para as espécies químicas, equação (2.38), e para a a entalpia, equação (2.39), de acordo com Versteeg e Malalasekera (2007). O sub-índice $(k)$ indica a espécie transportada e $\left(Y_{k}\right)$

a fração mássica dessa espécie.

$$
\frac{\partial}{\partial t}\left(\rho Y_{k}\right)+\frac{\partial}{\partial x_{i}}\left(\rho u_{i} Y_{k}\right)=\frac{\partial}{\partial x_{i}}\left(\rho D_{k} \frac{\partial Y_{k}}{\partial x_{i}}\right)+\dot{\omega}_{k}
$$




$$
\begin{array}{r}
\frac{\partial}{\partial t}(\rho h)+\frac{\partial}{\partial x_{i}}\left(\rho u_{i} h\right)=\frac{\partial}{\partial x_{i}}\left(\frac{\mu}{\sigma_{h}} \frac{\partial h}{\partial x_{i}}+\mu\left(\frac{1}{S_{c_{k}}}+\frac{1}{\sigma_{h}}\right) \sum_{k}^{n}\left(h_{k} \frac{\partial Y_{k}}{\partial x_{i}}\right)\right)+ \\
+\frac{\partial P}{\partial t}+S_{\text {rad }}
\end{array}
$$

Definem-se, ainda, os números de Prandtl $\left(\sigma_{h}\right)$, Lewis $(L e)$ e $\operatorname{Schmidt}\left(S_{c_{k}}\right)$ pelas equações $(2.40),(2.41)$ e (2.42). A relação entre esses números é dada pela equação (2.43). Nestas equações, $\left(c_{p}\right)$ é o calor específico a pressão constante, $(\mu)$ é a viscosidade molecular, $(k)$ é a condutividade térmica e $\left(D_{k}\right)$ é o coeficiente de difusão binária das espécies.

$$
\begin{aligned}
& \sigma_{h}=\frac{c_{p} \mu}{k} \\
& L e=\frac{k}{\rho c_{p} D_{k}} \\
& S_{c_{k}}=\frac{\mu}{\rho D_{k}}=L e \sigma_{h} \\
& S_{c_{k}}=\sigma_{h} L e
\end{aligned}
$$

Cook, Riley e Kosály (1997), Kempf, Lindstedt e Janicka (2005), Mustata et al. (2006), entre outros, utilizam modelos avançados, tais como o modelo "Flamelet", modelos estatísticos, modelos com cinética completa das reações, etc. Entretanto, modelos mais simples, como o baseado no equilíbrio das reações químicas, usado por Branley e Jones (2001), apresentam bons resultados. Assim, nesse trabalho, optou-se por se estudar e implementar um modelo de combustão simplificado, conhecido por "Flamesheet model" ou modelo de folha de chama. 


\subsubsection{Modelo de folha de chama ou "Flamesheet"}

Este modelo é usualmente aplicado em escoamentos em que ocorre a combustão não pré-misturada, em que o combustível e o oxidante não estão misturados antes do processo de combustão. Entretanto, a principal restrição desse modelo, segundo Griffiths e Barnard (1995), é a hipótese de combustão com reação extremamente rápida, de modo a não representar fenômenos determinados pela cinética química dos componentes, como ignição, extinção ou reações extremamente lentas, como a formação de óxidos de nitrogênio (NOx).

De acordo com Versteeg e Malalasekera (2007), Turns (2000), Griffiths e Barnard (1995), outras hipóteses desse modelo são: não consideração de cinética química detalhada, reação completa dos reagentes formando produtos, consideração de apenas três espécies para reação (combustível, oxidante e produto), restrição de existência de apenas um reagente de cada lado da folha de chama, desconsideração dos efeitos de transferência de calor por radiação, reação química descrita por apenas uma equação, reação irreversível, tansporte molecular das espécies regido pela lei de Fick para sistemas binários e restrição da difusividade da energia interna igual a difusividade das espécies, isto é, número de Lewis unitário.

Com essas restrições e a hipótese de escoamento de baixo número de Mach, a equação de transporte de entalpia se resume à equação (2.44).

$$
\frac{\partial}{\partial t}(\rho h)+\frac{\partial}{\partial x_{i}}\left(\rho u_{i} h\right)=\frac{\partial}{\partial x_{i}}\left(\frac{\mu}{\sigma_{h}} \frac{\partial h}{\partial x_{i}}\right)
$$

Para o sistema em que apenas um combustível e um oxidante estão presentes como reagentes, as equações de transporte da fração mássica para o combustível $\left(Y_{c}\right)$ e para o oxidante $\left(Y_{o} x\right)$ são dadas pelas equações (2.45) e (2.46), respectivamente.

$$
\frac{\partial}{\partial t}\left(\rho Y_{c}\right)+\frac{\partial}{\partial x_{i}}\left(\rho u_{i} Y_{c}\right)=\frac{\partial}{\partial x_{i}}\left(\rho D_{c} \frac{\partial Y_{c}}{\partial x_{i}}\right)+\dot{\omega}_{c}
$$




$$
\frac{\partial}{\partial t}\left(\rho Y_{o x}\right)+\frac{\partial}{\partial x_{i}}\left(\rho u_{i} Y_{o x}\right)=\frac{\partial}{\partial x_{i}}\left(\rho D_{o x} \frac{\partial Y_{o x}}{\partial x_{i}}\right)+\dot{\omega}_{o x}
$$

Neste trabalho, estudou-se o sistema metano/ar, cuja equação (2.47) representa a reação química utilizada. Para este sistema, em que apenas essa reação descreve o processo de combustão, verifica-se que a taxa de consumo de combustível é igual a taxa de consumo do oxidante multiplicado pelo inverso do coeficiente estequiométrico da parcela oxidante, isto é, a relação entre as taxas de consumo de combustível e oxidante é dada pela equação (2.48), na qual, $s=2$ para o sistema metano/ar.

$$
\begin{aligned}
& \mathrm{CH}_{4}+2 \mathrm{O}_{2}+7,53 \mathrm{~N}_{2} \Longrightarrow \mathrm{CO}_{2}+2 \mathrm{H}_{2} \mathrm{O}+7,53 \mathrm{~N}_{2} \\
& \dot{\omega}_{c}=\frac{1}{s} \dot{\omega}_{o x}
\end{aligned}
$$

De acordo com Versteeg e Malalasekera (2007), ao se definir o escalar da equação (2.49), e operar algebricamente as equações (2.45), (2.46) e (2.49), obtémse a equação (2.50). Essa equação representa o transporte do escalar conservativo $\left(\phi_{c}\right)$.

$$
\begin{aligned}
& \phi_{c}=s Y_{c}-Y_{o x} \\
& \frac{\partial}{\partial t}\left(\rho \phi_{c}\right)+\frac{\partial}{\partial x_{i}}\left(\rho u_{i} \phi_{c}\right)=\frac{\partial}{\partial x_{i}}\left(\Gamma_{\phi_{c}} \frac{\partial \phi_{c}}{\partial x_{i}}\right)
\end{aligned}
$$

Define-se, então, o escalar fração de mistura, equação (2.51), o qual representa uma normalização linear entre as frações mássicas de combustível e oxidante. Nessa equação, o superíndice "0" representa o escoamento de apenas oxidante e "1" o escoamento de apenas combustível. Devido à relação linear entre a fração de mistura e a propriedade $\left(\phi_{c}\right)$, é possível obter a equação (2.52), segundo Versteeg e Malalasekera (2007). 


$$
f=\frac{\phi_{c}-\phi_{c}^{0}}{\phi_{c}^{1}-\phi_{c}^{0}}
$$

$$
\frac{\partial}{\partial t}(\rho f)+\frac{\partial}{\partial x_{i}}\left(\rho u_{i} f\right)=\frac{\partial}{\partial x_{i}}\left(\Gamma_{f} \frac{\partial f}{\partial x_{i}}\right)
$$

Com a definição da fração de mistura pela equação (2.51) e solução da equação (2.52), é possível determinar o lugar geométrico em que as concentrações de combustível e oxidante alcançam a relação estequiométrica.

Neste trabalho, o sistema estudado é baseado na chama D, proposta pelo laboratório SANDIA nos EUA, a qual considera a mistura de $75 \%$ de oxidante e $25 \%$ de metano como combustível na saída do jato. Assim, o valor da fração de mistura na razão estequiométrica dos reagentes é dado pela equação (2.53) e para esse sistema vale, aproximadamente, 0,368. A figura (2.7) apresenta a distribuição das frações mássicas dos reagentes e dos produtos em função da fração de mistura para este sistema. Já a figura (2.8) apresenta a relação entre a fração de mistura, a temperatura e a densidade das espécies, para esse mesmo sistema.

$$
f_{s t}=\frac{\phi_{c}^{0}}{\phi_{c}^{1}+\phi_{c}^{0}}
$$

A figura (2.7) é construída em duas partes, isto é, para $0 \leq f<f_{s t}$ as relações, para os reagentes, são dadas pelas equações (2.54) e (2.55). Já para $f_{s t} \leq f \leq 1$, as relações são dadas pelas equações (2.56) e (2.57). Devido a não participação das espécies inertes na reação química de combustão, a relação entre a sua fração mássica e a fração de mistura é dada pela equação (2.58). Assim, a equação (2.59) define a relação para os produtos gerados em função das frações calculadas anteriormente.

$$
Y_{o x}=\frac{f_{s t}-f}{f_{s t}} Y_{o x}^{0}
$$




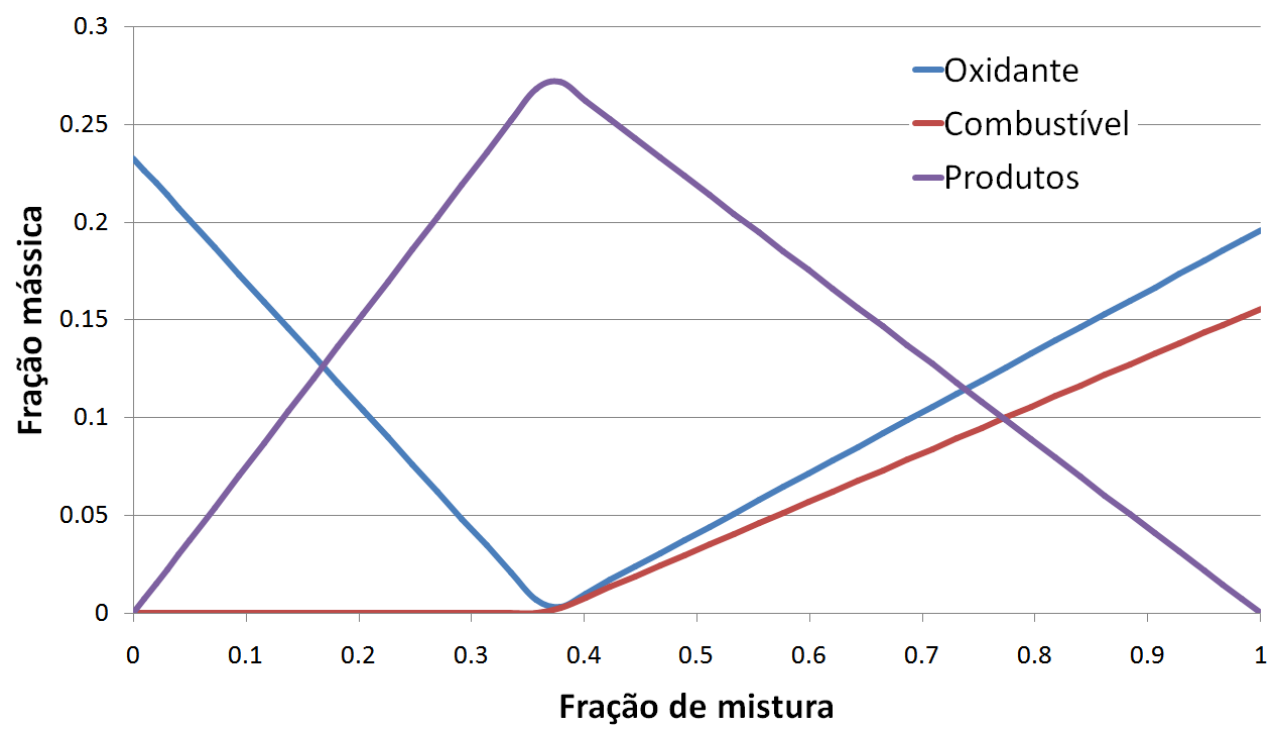

Figura 2.7: Gráfico da fração mássica dos reagentes e produtos em função da fração de mistura

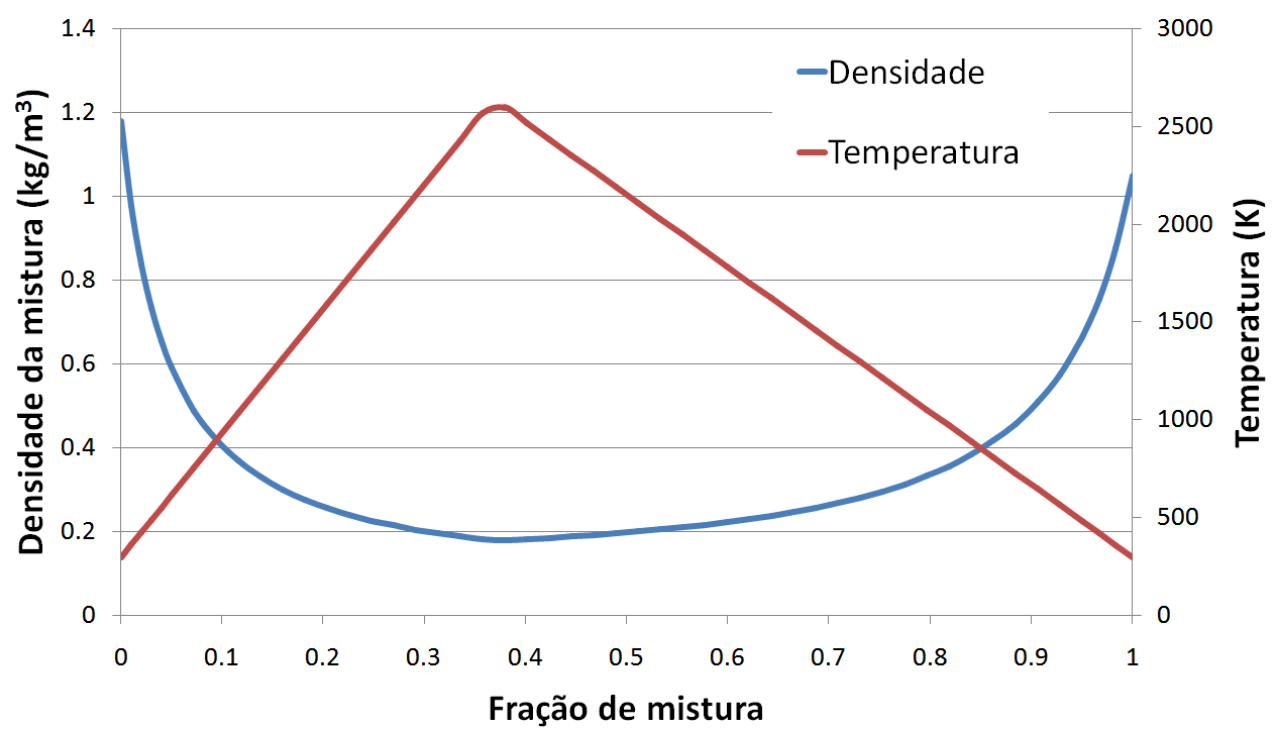

Figura 2.8: Gráfico da distribuição de temperatura e da densidade da mistura em função da fração de mistura

$$
\begin{aligned}
& Y_{c}=0 \\
& Y_{o x}=0 \\
& Y_{c}=\left(\frac{f-f_{s t}}{1-f_{s t}}\right) Y_{c}^{1}
\end{aligned}
$$




$$
Y_{i n}=Y_{i n}(1-f)+Y_{i n} f
$$

$$
Y_{p r}=1-\left(Y_{c}+Y_{o x}+Y_{i n}\right)
$$

As condições de contorno para a solução da equação de transporte da fração de mistura são definidas como: fração de mistura unitária para a região de entrada do combustível $\left(f^{1}=1\right)$ e fração de mistura nula para a região de entrada de oxidante $\left(f^{0}=0\right)$. Essas condições respeitam a restrição de apenas dois reagentes (combustível e oxidante) e a normalização realizada pela equação (2.51).

Utilizando-se o conceito definido na equação (2.51), define-se a equação para a normalização da entalpia (2.60). Admitindo-se a hípotese de que o número de Lewis é unitário, verifica-se que $\frac{\mu}{\sigma_{h}}=\rho D_{k}=\Gamma_{f}$, e que, devido a normalização da equação (2.60), as condições de contorno para a equação de transporte da entalpia são idênticas as da fração de mistura. Assim, ao se resolver a equação de transporte da fração de mistura, equação (2.52), resolve-se, também, a equação de transporte da entalpia, equação (2.44).

Com as equações $(2.55),(2.57)$ e (2.60) e a adoção da hipótese de gás perfeito, é possível obter o campo das temperaturas do escoamento, dado pela equação (2.61) e, consequentemente, a densidade do fluido pela equação (2.62).

$$
\begin{gathered}
f=h^{*}=\frac{h-h_{o x}^{0}}{h_{c}^{1}-h_{o x}^{0}} \\
T=\frac{h-Y_{c}\left(\Delta h_{c}\right)}{\bar{c}_{p}} \\
\rho=\frac{p}{R_{u} T \sum_{k}^{n} \frac{Y_{k}}{M W_{k}}}
\end{gathered}
$$




\subsubsection{Modelo "Flamesheet" para escoamentos turbulentos}

Para escoamentos turbulentos e em que a densidade é função apenas da temperatura, se faz necessária a aplicação do filtro de Favre para o cálculo das grandezas vertoriais e escalares. A equação (2.63) apresenta o conceito da filtro de Favre para a velocidade. As equações (2.64), (2.65), (2.66) e (2.67) apresentam as equações filtradas de Favre para a conservação da massa, quantidade de movimento, energia e fração de mistura, respectivamente, de acordo com Versteeg e Malalasekera (2007).

$$
\begin{aligned}
& \tilde{u}_{i}=\frac{\rho \bar{u}_{i}}{\bar{\rho}} \\
& \frac{\partial}{\partial t}(\bar{\rho})+\frac{\partial}{\partial x_{i}}\left(\bar{\rho} \tilde{u}_{i}\right)=0 \\
& \frac{\partial}{\partial t}\left(\bar{\rho} \tilde{u}_{i}\right)+\frac{\partial}{\partial x_{j}}\left(\bar{\rho} \tilde{u}_{i} \tilde{u}_{j}\right)=-\frac{\partial \bar{P}}{\partial x_{i}}+\frac{\partial}{\partial x_{i}}\left(\mu_{e} \frac{\partial \tilde{u}_{i}}{\partial x_{j}}\right)+\bar{\rho} g_{i}+S_{\tilde{u}_{i}} \\
& \frac{\partial}{\partial t}(\bar{\rho} \tilde{h})+\frac{\partial}{\partial x_{i}}\left(\bar{\rho} \tilde{u}_{i} \tilde{h}\right)=\frac{\partial}{\partial x_{i}}\left(\frac{\mu_{e}}{\sigma_{h}} \frac{\partial \tilde{h}}{\partial x_{i}}\right) \\
& \frac{\partial}{\partial t}(\bar{\rho} \tilde{f})+\frac{\partial}{\partial x_{i}}\left(\bar{\rho} \tilde{u}_{i} \tilde{f}\right)=\frac{\partial}{\partial x_{i}}\left(\Gamma_{f} \frac{\partial \tilde{f}}{\partial x_{i}}\right)
\end{aligned}
$$

Ao utilizar o conceito do filtro de Favre, as equações (2.66) e (2.67) resolvem a entalpia e fração de mistura filtradas. Como as relações do modelo "Flamesheet" são para os valores instantâneos, se faz necessário o uso da metodologia " $\beta$-PDF" para se encontrar as estatísticas da temperatura, densidade e fração mássica das espécies e assim correlacionar com os valores das propriedades transportadas pelo escoamento. 


\subsubsection{Método " $\beta$-PDF"}

O método " $\beta$-PDF" utiliza uma função de densidade de probabilidade ou PDF com forma pré-definida para se estimar os valores filtrados das propriedades do modelo de combustão de forma a se correlacionar com as propriedades transportadas pelo escoamento. De acordo com Versteeg e Malalasekera (2007), dada uma função de probabilidade $F_{\phi}(\psi)=\operatorname{Prob}\{\phi<\psi\}$, em que $\left(F_{\phi}\right)$ é a probabilidade de $(\phi)$ ser menor que $(\psi)$, a função densidade de probabilidade é definida pela equação (2.68). Essa função PDF possui as características dadas pelas equações (2.69) e (2.70).

$$
\begin{aligned}
& P_{\phi}(\psi)=\frac{d F_{\phi}(\psi)}{d \psi} \\
& P_{\phi}(\psi) \geq 0 \\
& \int_{-\infty}^{+\infty} P_{\phi}(\psi) d \psi=1
\end{aligned}
$$

A equação (2.71) representa a filtragem de uma propriedade qualquer $(\phi)$ pelo filtro $(P(\psi))$. Aplicando a relação dada pela equação (2.72) na equação (2.71) encontrase o valor da densidade filtrada da mistura, dada pela equação (2.73), segundo Versteeg e Malalasekera (2007).

$$
\begin{aligned}
& \bar{\phi}=\int_{-\infty}^{+\infty} \phi(\psi) P(\psi) d \psi \\
& \tilde{P}(f)=\frac{\rho(f)}{\bar{\rho}} P(f) \\
& \bar{\rho}=\left(\int_{0}^{1} \frac{\tilde{P}(f)}{\rho(f)} d f\right)^{-1}
\end{aligned}
$$


A equação (2.74) apresenta a quantidade $(\tilde{\phi})$ devido à aplicação do filtro de favre para uma propriedade qualquer $(\phi)$.

$$
\tilde{\phi}=\int_{0}^{1} \phi(f) \tilde{P}(f) d f
$$

A forma da função densidade de probabilidade varia para diferentes escoamentos. Bilger (1980) observou, em diversos pontos espaciais, que a forma desta função num jato turbulento reativo é bem representada pela distribuição $\beta$. A figura (2.9) apresenta um esboço da distribuição encontrada em diversos pontos de um jato turbulento reativo. A distribuição " $\beta$-PDF" é utilizada por Branley e Jones (2001), Pitsch e Steiner (2000), entre outros, apresentando resultados compatíveis com os dados experimentais.

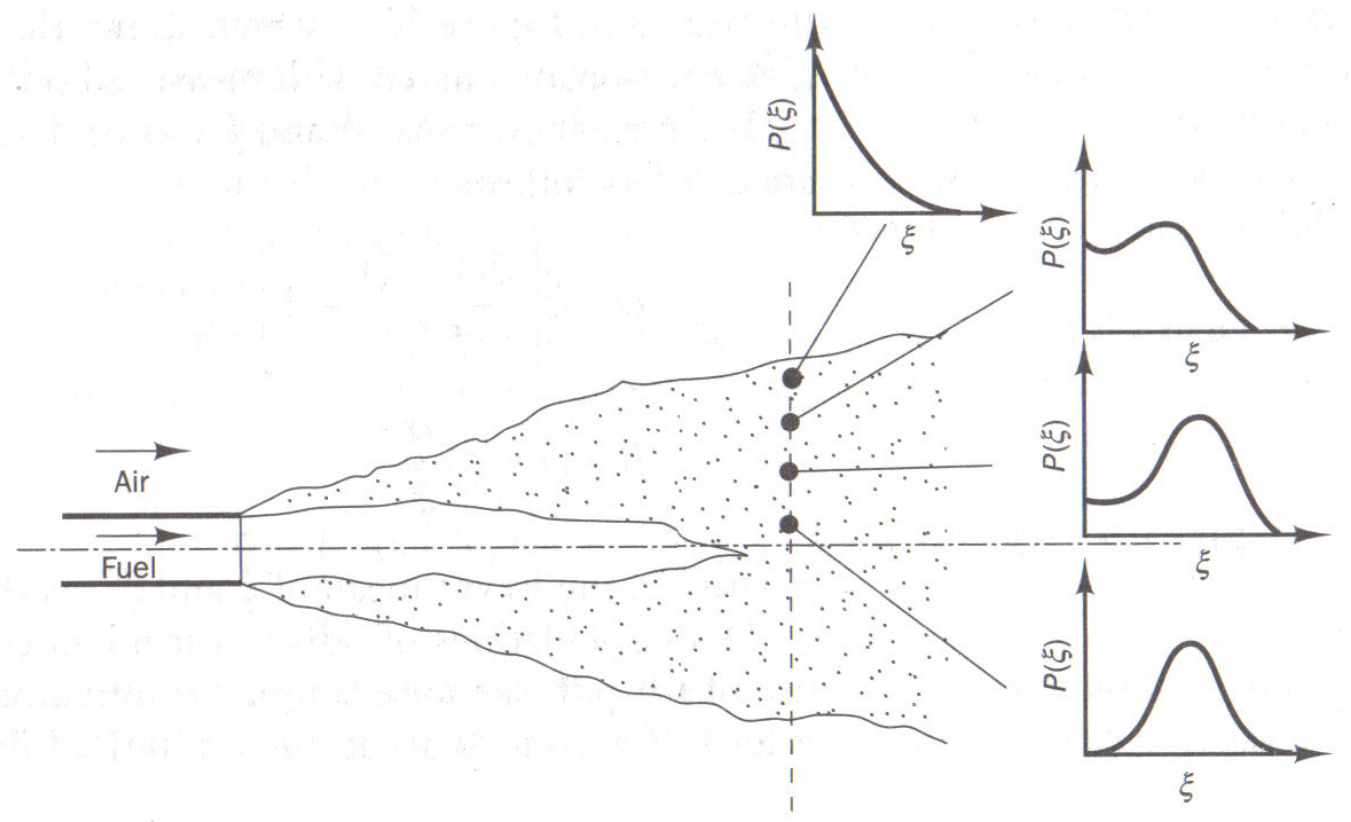

Figura 2.9: Esboço das distribuições PDF em um jato turbulento reativo. Fonte: Versteeg e Malalasekera (2007)

A distribuição " $\beta$-PDF" é definida pela equação (2.75 em que os parâmetros $(\alpha)$ e $(\beta)$ são definidos pelas equações $(2.76)$ e (2.77). A figura (2.10) apresenta as 
diferentes distribuições da função $(\beta)$ para alguns valores de $(\alpha)$ e $(\beta)$. Na equação (2.75), $\left(\Gamma^{\phi}(\zeta)\right)$ é a função gama definida por Evans et al. (2000), Pope (2000), entre outros.

$$
\begin{aligned}
& \tilde{P}(f)=f^{\alpha-1}(1-f)^{\beta-1}\left(\frac{\Gamma^{\phi}(\alpha+\beta)}{\Gamma^{\phi}(\alpha) \Gamma^{\phi}(\beta)}\right) \\
& \alpha=\tilde{f}\left(\frac{\tilde{f}(1-\tilde{f})}{\tilde{f}^{\prime \prime 2}}-1\right) \\
& \beta=(1-\tilde{f})\left(\frac{\tilde{f}(1-\tilde{f})}{\tilde{f}^{\prime \prime 2}}-1\right)
\end{aligned}
$$

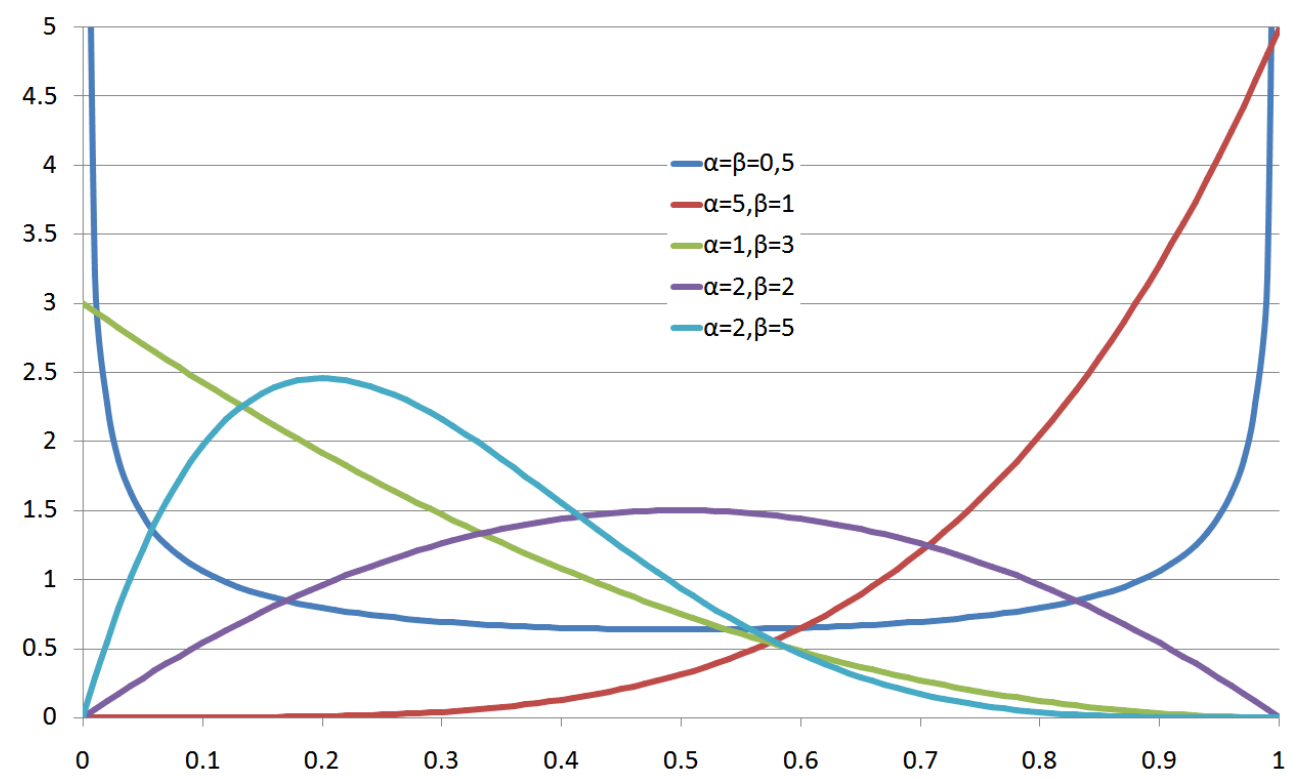

Figura 2.10: Distribuição da densidade de probabilidade pela função " $\beta$-PDF" para diversos valores de $(\alpha)$ e $(\beta)$

A variância da fração de mistura pode ser obtida por uma equação de transporte, como apresentado por Versteeg e Malalasekera (2007) ou calculada algebricamente como feito por Pitsch e Steiner (2000). O primeiro método é usual para escoamentos que aplicam a metodologia RANS para resolver os efeitos de turbulência. 
Já o segundo método é usual quando a metodologia LES é empregada. Assim, neste trabalho, optou-se pelo cálculo realizado pela equação (2.78), utilizada por Pitsch e Steiner (2000) ente outros.

$$
\tilde{f}^{\prime \prime 2}=C_{s} \Delta^{2}\left|\frac{\partial \tilde{f}}{\partial x_{i}}\right|^{2}
$$




\section{Capítulo 3}

Solução das equações de

Navier-Stokes para escoamentos

baixo Mach 
A densidade de um fluido é definida, pela termodinâmica, como sendo função de seu estado, definido pela pressão e temperatura deste fluido. Assim, é possível identificar uma equação que relacione as variações de densidade com as variações de pressão e/ou temperatura.

Versteeg e Malalasekera (2007), Ferziger e Peric (2002), Maliska (2004), Hoffmann e Chiang (2000), Turns (2000) entre outros, verificam que, em escoamentos com baixos valores para o número de Mach $\left(M_{a}\right)$, equação (3.1), a densidade é fracamente acoplada à pressão, isto é, variações no campo das pressões não induzem variações na densidade. Este tipo de escoamento é denominado incompressível. Na equação (3.1), (c) é a velocidade do som no meio analisado.

$$
M_{a}=\frac{\max \left(u_{i}\right)}{c}
$$

Em escoamentos incompressíveis, para se evitar problemas convergência numérica, a equação da conservação da massa não é resolvida diretamente, mas sim acoplada à equação de conservação da quantidade de movimento. A fusão destas duas equações origina uma equação para a solução do campo de pressões do escoamento. Esse método de solução é denominado acoplamento pressão-velocidade (P-V), de acordo com Versteeg e Malalasekera (2007), Ferziger e Peric (2002), Maliska (2004) entre outros.

Os acoplamentos P-V são, usualmente, divididos em duas categorias: os iterativos e os diretos ou não iterativos. O método SIMPLE ou "Semi-Implicit Method for Pressure-Linked Equation", amplamente difundido, apresentado por Versteeg e Malalasekera (2007), e o método PRIME ou "Pressure Implicit Momentum Explicit", idealizado por Maliska (2004), são exemplos de acoplamentos iterativos. Já o método "Fractional Steps", idealizado e discutido por Choi e Moin (1993) e reapresentado por Ferziger e Peric (2002), e o método Adams-Bashforth-Moulton, aplicado por Boersma, Brethouwer e Nieuwstadt (1998) e Pitsch e Steiner (2000), são exemplos de métodos não-iterativos.

Neste trabalho optou-se, inicialmente, pela utilização do método PRIME, discutido por Maliska (2004). Entretanto, verificou-se que métodos iterativos são extrema- 
mentes custosos computacionalmente quando utilizados para a solução de escoamentos transientes. Assim, na busca de métodos não iterativos, observou-se que os métodos "Fractional Steps" e Adams-Bashforth-Moulton eram os mais utilizados pela bibliografia especializada.

Ao se implementar o método "Fractional Steps" na forma apresentada por Ferziger e Peric (2002), verificou-se que este método não era adequado para a soução de escoamentos reativos. A discussão completa deste método pode ser encontrada no apêndice B.

Por fim, implementou-se o método Adams-Bashforth-Moulton como aplicado por Boersma, Brethouwer e Nieuwstadt (1998) para escoamentos não reativos. No caso em que a combustão foi estudada, modificações foram feitas neste método inicial, como proposto por Pitsch e Steiner (2000).

\subsection{Método Adams-Bashforth-Moulton para esco- amentos turbulentos e isotérmicos}

O método Adams-Bashforth-Moulton consiste, de forma simplificada, na solução em sequência das discretizações temporais de Adams-Bashforth e Adams-Moulton. Essa solução sequenciada é conhecida por método preditor-corretor, em que se resolve o método Adams-Bashforth para se obter uma estimativa do campo de velocidades e pressão e, com essa estimativa, resolve-se o método Adams-Moulton para se obter o campo final. Segundo Boersma, Brethouwer e Nieuwstadt (1998), esta metodologia apresenta decaimento de segunda ordem para o erro, compatível com os decaimentos das discretizações espacial e temporal.

Aplicando-se a discretização temporal de Adams-Bashforth no método dos volumes finitos, equação (A.12), encontra-se a equação (3.2). Nessa equação, $A$ e $D$ representam os termos advectivos e difusivos da equação de transporte. Verifica-se que os termos da gravidade e da pressão não estão presentes, o que, segundo Boersma, Brethouwer e Nieuwstadt (1998), resolve-se o campo de velocidades garantindo, apenas, 
a conservação da energia cinética. O termo $\left(\tau_{P V}\right)$ é dado pela equação (3.3). Na equação (3.2), o termo $\left(S_{u_{i}}\right)$ representa apenas as contribuições das condições de contorno.

$$
\begin{aligned}
& \frac{\left(\rho V u_{i}\right)^{n^{*}}-\left(\rho V u_{i}\right)^{n}}{\Delta t^{n}}=\left(1+\tau_{P V}\right)(A+D)^{n}-\tau_{P V}(A+D)^{n-1}+\left(S_{u_{i}} V\right)^{n} \\
& \tau_{P V}=\frac{1}{2}\left(\frac{\Delta t_{n}}{\Delta t_{n-1}}\right)
\end{aligned}
$$

Esse método se encontra na categoria dos métodos de projeção e correção, em que, inicialmente, o campo de velocidades é projetado num domínio que respeita a conservação da energia cinética do escoamento, solução da equação (3.2), e, em seguida, corrigido para um domínio em que a conservação da massa também é respeitada, solução da equação (3.4).

$$
\frac{\left(\rho u_{i}\right)^{n^{* *}}-\left(\rho u_{i}\right)^{n^{*}}}{\Delta t^{n}}=-\left(\frac{\partial P}{\partial x_{i}}\right)^{n^{* *}}
$$

Para satisfazer a conservação da massa, aplica-se o operador divergente na equação (3.4) e, utilizando a equação da continuidade, equação (2.1), encontra-se a equação (3.5) conhecida por equação de Poisson da pressão.

$$
\left(\frac{\partial^{2} P}{\partial x_{i} x_{j}}\right)^{n^{* *}}=\frac{1}{\Delta t^{n}}\left(\frac{\partial}{\partial x_{i}}\left(\rho u_{i}\right)^{n^{*}}\right)
$$

Apesar do método Adams-Bashforth ser explícito no tempo, em que a variável a ser resolvida $\left(u_{i}{ }^{n^{* *}}\right)$ depende apenas das propriedades do fluido e do escoamento já calculadas em instantes anteriores $\left(u_{i}{ }^{n-1}\right)$ e $\left(u_{i}^{n-2}\right)$, a solução da equação da Poisson da pressão precisa ser resolvida implicitamente, ou seja, a solução do campo de pressões é função apenas do campo a ser resolvido $\left(P^{n^{* *}}\right)$ e de seu termo fonte. Para tanto, um 
solucionador numérico iterativo foi empregue. O apêndice D apresenta os métodos iterativos para a solução de sistemas algébricos que foram implementados neste trabalho.

Com o campo estimado das velocidades $u_{i}^{n^{* *}}$ respeitando a conservação da massa e da quantidade de movimento, aplica-se a discretização de Adams-Moulton para se obter as velocidades no final do incremento de tempo $u_{i}^{n+1}$. A equação (3.6) apresenta esta discretização aplicada ao método dos volumes finitos.

$$
\frac{\left(\rho V u_{i}\right)^{n^{* * *}}-\left(\rho V u_{i}\right)^{n^{* *}}}{\Delta t^{n}}=\tau_{P V}(A+D)^{n^{* *}}+\tau_{P V}(A+D)^{n}+\left(S_{u_{i}} V\right)^{n}
$$

Para a solução das velocidades $u_{i}^{n+1}$, aplica-se a equação (3.7). Esta equação necessita do campo de pressões da Poisson da pressão, equação (3.8), definida no final do incremento de tempo.

$$
\begin{gathered}
\frac{\left(\rho u_{i}\right)^{n+1}-\left(\rho u_{i}\right)^{n^{* * *}}}{\Delta t^{n}}=-\left(\frac{\partial P}{\partial x_{i}}\right)^{n+1} \\
\left(\frac{\partial^{2} P}{\partial x_{i} x_{j}}\right)^{n+1}=\frac{1}{\Delta t^{n}}\left(\frac{\partial}{\partial x_{i}}\left(\rho u_{i}\right)^{n^{* * *}}\right)
\end{gathered}
$$

\subsection{Método Adams-Bashforth-Moulton para esco- amentos reativos}

Em escoamentos reativos, Pitsch e Steiner (2000) propõem mudanças no algorítmo utilizado por Boersma, Brethouwer e Nieuwstadt (1998), de forma a considerar variações da densidade do fluido, devido aos efeitos da combustão, na solução das equações de Navier-Stokes.

Ao se aplicar o modelo "Flamesheet" no método Adams-Bashforth-Moulton para o acoplamento pressão-velocidade, os efeitos do processo de combustão sobre a variação da densidade devem ser incluidos na conservação da massa do sistema. Assim, 
de forma a contemplar tais efeitos, as equações (3.5) e (3.8) se tornam (3.9) e (3.10), respectivamente.

$$
\begin{aligned}
& \left(\frac{\partial^{2} P}{\partial x_{i} x_{j}}\right)^{n^{* *}}=\frac{1}{\Delta t^{n}}\left(\left(\frac{\partial \rho}{\partial t}\right)^{n^{* *}}+\frac{\partial}{\partial x_{i}}\left(\rho u_{i}\right)^{n^{*}}\right) \\
& \left(\frac{\partial^{2} P}{\partial x_{i} x_{j}}\right)^{n+1}=\frac{1}{\Delta t^{n}}\left(\left(\frac{\partial \rho}{\partial t}\right)^{n+1}+\frac{\partial}{\partial x_{i}}\left(\rho u_{i}\right)^{n^{* *}}\right)
\end{aligned}
$$

Nas equações (3.9) e (3.10), a variação da densidade no tempo $\left(\frac{\partial \rho}{\partial t}\right)$ é calculada pelas equações (3.11) e (3.12), respectivamente.

$$
\begin{aligned}
& \left(\frac{\partial \rho}{\partial t}\right)^{n^{* *}}=\frac{\rho^{n^{* *}}-\rho^{n}}{\Delta t^{n}} \\
& \left(\frac{\partial \rho}{\partial t}\right)^{n+1}=\frac{\rho^{n+1}-\rho^{n}}{\Delta t^{n}}
\end{aligned}
$$

Com a inclusão do modelo "Flamesheet", faz-se necessária a solução da equação de transporte da fração de mistura, equação (2.52). O transporte deste escalar é realizado pela solução das equações (3.13) e (3.14) para a solução do campo projetado $\left(f^{n^{* *}}\right)$ e para o campo corretor $\left(f^{n+1}\right)$, respectivamente. Estas equações representam a solução do transporte deste escalar pelo método semi-implícito de Crank-Nicholson.

$$
\begin{aligned}
& \frac{(\rho V f)^{n^{* *}}-(\rho V f)^{n}}{\Delta t^{n}}=\frac{\left(A_{f}+D_{f}\right)^{n^{* *}}+\left(A_{f}+D_{f}\right)^{n}}{2}+\left(S_{f} V\right)^{n} \\
& \frac{(\rho V f)^{n+1}-(\rho V f)^{n^{* *}}}{\Delta t^{n}}=\frac{\left(A_{f}+D_{f}\right)^{n+1}+\left(A_{f}+D_{f}\right)^{n^{* *}}}{2}+\left(S_{f} V\right)^{n}
\end{aligned}
$$

Vale ressaltar que não aparecem termos fontes de geração de massa, uma vez que para este modelo, a massa dos reagentes se transforma nas massas dos produtos, conservando-se a massa global do sistema. 


\subsection{Fluxo de informações no método Adams-Bashforth- Moulton}

De forma resumida, o método Adams-Bashforth-Moulton é implementado com a seguinte estrutura:

Passo 1 : Definição do campo Inicial ou avançado no tempo para as velocidades e pressão: $\left(u_{i}^{n}\right),\left(u_{i}^{n-1}\right),\left(P^{n}\right)$ e $\left(f^{n}\right)$;

Passo 2 : Cálculo do campo de velocidades sem considerar os gradientes de pressão $\left(u_{i}^{n^{*}}\right)$, baseado nos campos $\left(u_{i}^{n}\right)$ e $\left(u_{i}^{n-1}\right)$;

Passo 3 : Transporte semi-implícito da fração da mistura e cálculo dos efeitos de combustão para $\left(f^{n^{* *}}\right)$, com o campo $\left(f^{n}\right)$;

Passo 4 : Solução implícita da Poisson da pressão para se obter $\left(P^{n^{* *}}\right)$;

Passo 5 : Correção do campo de velocidades $\left(u_{i}{ }^{n^{*}}\right)$ para garantir conservação da massa $\left(u_{i}^{n^{* *}}\right)$;

Passo 6 : Cálculo do campo de velocidades $\left(u_{i}^{n^{* * *}}\right)$, com o campo calculado, $\left(u_{i}^{n^{* *}}\right)$, sem os gradientes de pressão;

Passo 7 : Transporte semi-implícito da fração da mistura e cálculo dos efeitos de combustão para $\left(f^{n+1}\right)$, com o campo $\left(f^{n^{* *}}\right)$;

Passo 8 : Solução implícita da poisson da pressão para se obter $\left(P^{n+1}\right)$;

Passo 9 : Correção do campo de velocidades $\left(u_{i}{ }^{* * *}\right)$ para garantir conservação da massa no final da integração $\left(u_{i}^{n+1}\right)$;

Passo 10 : Avanço no tempo.

Os passos de 1 a 5 correspondem ao método preditor Adams-Bashforth. Já os passos de 7 a 9 correspondem ao método corretor Adams-Moulton. Os passos 3 e 7 são realizado apenas quando o escoamento é reativo. 
Capítulo 4

Implementação do código "Large Eddy Combustion Simulator" LECS 
Definidos os modelos matemáticos para a solução dos problemas de escoamentos turbulentos de fluidos reativos, estes foram implementados no código numérico LECS ou "Large Eddy Combustion Simulator". A codificação deste programa foi realizada em linguagem $\mathrm{C}++$ e utilizado o compilador Intel ${ }^{\circledR}$ na versão 11 . O código gerado foi baseado em rotinas disponíveis em qualquer implementação da linguagem $\mathrm{C}++$, possibilitando o seu uso em sistemas Linux ${ }^{\circledR}$, Mac OS $^{\circledR}$ e MS-Windows ${ }^{\circledR}$.

A visualização dos campos escalares e vetoriais calculados foi realizada com o auxílio do programa TecPlot ${ }^{\circledR}$.

\subsection{Histórico de desenvolvimento}

O código numérico LECS, desenvolvido neste trabalho, surgiu, inicialmente, como a continuação ao trabalho de Araujo (2006), o qual havia desenvolvido um código semelhante em objetivo, porém, diferente em implementação. Como este código não pôde ser bem explorado neste trabalho, devido a restrições de implementação, um novo código foi desenvolvido, denominado LECS.

Assim como o código de Araujo (2006), a primeira implementação do LECS foi baseada no método PRIME de solução do acoplamento pressão-velocidade, além da utilização de células fastasmas para aplicação das condições de contorno. Foram implementados, ainda, o modelo sub-malha de Smagorinsky (1963) e o método de Jacobi para a solução de sistemas lineares.

Logo se verificou que o método PRIME, por ser iterativo, apresentava grande custo computacional para a solução de escoamentos turbulentos transientes, assim, este método foi substituído pelo "Fractional Steps", apresentado por Ferziger e Peric (2002) e no apêndice $\mathrm{B}$ deste trabalho.

Para se maximizar o desempenho do código numérico, as condições de contorno passaram a ser implementadas diretamente na solução das equações algébricas, abolindo o uso das células fantasmas. Essa mudança possibilitou o uso de malhas não estruturadas com volumes hexaédricos ortogonais. 
De forma a permitir a vizualização dos resultados obtidos, foi implementada a utilização de um arquivo de saída no formato TecPlot ${ }^{\circledR}$. Nesta mesma época, foi criado um formato de arquivo de recuperação de resultados para reinício de simulações.

Devido ao alto custo computacional da solução de escoamentos turbulentos pelo método LES, foi desenvolvido e implementado o método de paralelização OpenMP ${ }^{\circledR}$, o que representou um granho no tempo de realização das simulações numéricas.

Com a evolução do LECS, foram implementados o transporte de escalares passivos e novos métodos de solução de sistemas lineares. Este último se deu pela necessidade de se encontrar um melhor solucionador numérico. Foram implementados os métodos de Gauss-Siedel, Gradientes Conjugados, Gradientes Bi-Conjugados, e Gradientes Bi-Conjugados Estabilizado. O melhor método implementado e escolhido foi baseado numa variante do método de Gauss-Siedel, apresentado no apêndice D.

Foi realizada uma tentativa de implementação do método multigrid, porém, devido a sua complexidade, este foi rapidamente desconsiderado.

Para se verificar a implementação do modelo submalha de Smagorinsky (1963), implementou-se o modelo Dinâmico de Germano (1991). Obtendo-se os mesmo resultados. Assim, na tentativa de se encontrar possíveis erros de programação no LECS, o método de soluções manufaturadas foi aplicado.

Com este método, foi possível encontrar e solucionar pequenos erros de programação e implementação dos modelos, permitindo a verificação do código desenvolvido.

Com o LECS verificado, definiu-se que o modelo padrão de Smagorinsky (1963) estava correto e deveria satisfazer a solução dos casos estudados. Ainda, nesta etapa, foi desenvolvido e implementado o modelo de combustão "FlameSheet". A tabela utilizada para determinar as propriedades deste modelo foi, inicialmente, obtida pelo programa Fluent ${ }^{\circledR}$ da Fluent Inc..

Assim, com os modelos matemáticos verificados, realizou-se a tentativa de solução da chama D apresentada pelo Laboratório Sandia dos EUA. Os resultados obtidos, quando comparados com os dados experimentais disponíveis, não apresentavam 
boa correlação. Assim, a solução encontrada foi a substituição do método "Fractional Steps" pelo método Adams-Bashforth-Moulton, utilizado por Pitsch e Steiner (2000) na solução desta mesma chama D.

Optou-se, então, por realizar diretamente os cálculo das propriedades utilizadas pelo modelo de combustão, não sendo necessário o uso de dados externos, como os iniciamentes obtidos. Para tanto, foi implementado o método " $\beta$-PDF" que permite a correlação de dados não filtrados com os filtrados vindos das simulações pelo método LES.

Foi implementada ainda uma sub-realaxação no cálculo da densidade para se melhorar a convergência da solução do sistema algébrico da Poisson da pressão.

Como os resultados do transporte da fração de mistura se apresentavam bem distintos dos dados da literatura, optou-se por resolver o transporte deste escalar pelo método semi-implícito de Crank-Nicholson.

Por fim, aplicando-se esta metodologia na solução numérica da chama D, foram obtidas boas correlações entre os campos simulados e experimentais.

\subsection{Organização do programa}

O programa LECS foi dividido em módulos que facilitam o entendimento de cada rotina, isto é, foram definidos módulos que agregaram as rotinas básicas de leitura e gravação de arquivos, cálculo das funções de combustão, cálculo dos modelos submalha de tubulência, etc. Cada módulo foi separado em um arquivo tipo "header". Os principais arquivos são:

- main.cpp: arquivo base do programa, o qual chama as rotinas de leitura da malha e inicialização do domínio, aplicação das condições de contorno e solução do escoamento.

- adams.h: arquivo com as rotinas para a solução dos campos de velocidade, pressão e fração de mistura pelo acoplamento Adams-Bashforth-Moulton. 
- fscn.h: arquivo com as rotinas para a solução dos campos de velocidade, pressão e fração de mistura pelo acoplamento "Fractional Steps".

- prime.h: arquivo com as rotinas para a solução dos campos de velocidade e pressão pelo método PRIME.

- combustion.h: arquivo com as rotinas de cálculo dos efeitos da combustão pelo método "Flamesheet".

- turbulence.h: arquivo com as rotinas para o cálculo dos modelos submalha para o método LES.

- Domaincart3D.h: arquivo com as rotinas para leitura de malha, aplicação das condições de contorno, solução do escoamento, gravação dos arquivos com resultados, entre outras funções vitais para a execução do LECS. Esse arquivo contém as rotinas base para o sistema de coordenadas cartesianas 3D.

- Volumecart3D.h: arquivo com as definições das variáveis utilizadas e a serem resolvidas do escoamento. Este arquivo foi implementado para a utilização de malhas tri-dimensionais com sistema de coordenadas cartesianas.

- system_solvers.h: arquivo com as rotinas dos solucionadores de sistemas algébricos lineares.

- manufaturadas.h: arquivo com os termos forçantes da soluções analíticas do método de verificações por soluções manufaturadas.

- prob.cpp: arquivo com as rotinas para o cálculo das densidade de probabilidade pelo método " $\beta$-PDF".

- Entrada.cfd: arquivo com as definições das propriedades do escoamento e dos modelos a serem utilizados.

Para melhorar o desempenho do LECS, foi utilizado o método de paralelização OpenMP ${ }^{\circledR}$, o qual divide certas tarefas em mais de um processador. As tarefas que apresentam os melhores desempenhos com esse método são os ciclos "while" e "for" 
por se tratarem de operações repetitivas. No caso da implementação do LECS, ganhos consideráveis foram obtidos ao se paralelizar ciclos "for" que varriam todos os volumes do domínio computacional, como os solucionadores de sistemas lineares.

A figura 4.1 apresenta o diagrama funcional do código implementado.

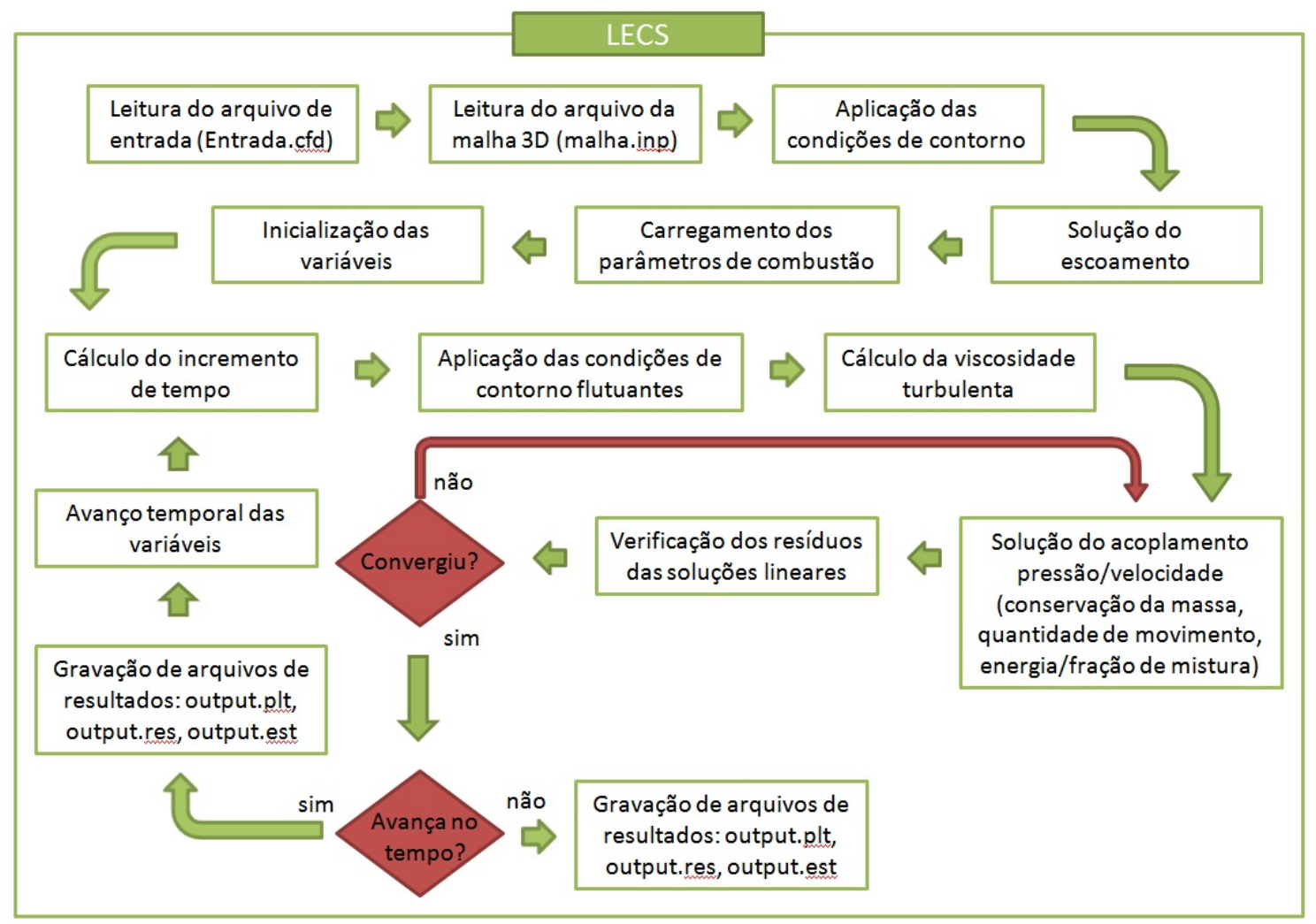

Figura 4.1: Diagrama funcional do programa LECS

\subsection{Organização das informações}

As informações são, primariamente, organizadas em três principais estruturas: Grid, coefs e prop. Toda informação é armazenada nos centróides das células, exceto as velocidades nas faces do volume.

A estrutura Grid guarda as informações espaciais do domínio computacional, bem como os valores das variáveis calculadas. As variáveis da estrutura Grid são:

- dx, dy e dz: comprimentos da célula nos eixos coordenados. 
- centerx, centery e centerz: coordenadas do centróide da célula.

- areae, areaw, areat, areab, arean e areas: tamanho das áreas de cada face da célula.

- vol: volume da célula.

- $\mathrm{u}, \mathrm{v}$ e w: velocidades filtradas nos eixos coordenados.

- mu, mv e mw: média temporal das velocidades filtradas paralelas eixos coordenados.

- ru, rv e rw: resíduo da solução dos sistema linear algébrico do campo das velocidades.

- ub, ut, uw, ue, us e un: velocidades paralelas ao eixo X nas faces da célula.

- vb, vt, vw, ve, vs e vn: velocidades paralelas ao eixo Y nas faces da célula.

- wb, wt, ww, we, ws e wn: velocidades paralelas ao eixo Z nas faces da célula.

- uaprox, vaprox e waprox: velocidades auxiliares.

- uold, vold e wold: velocidades filtradas no instante $t-1$, paralelas aos eixos coordenados.

- vold2, vold2 e wold2: velocidades filtradas no instante $t-2$, paralelas aos eixos coordenados.

- uexact, vexact e wexact: velocidades exatas oriundas do método das soluções manufaturadas quando ativado.

- ro, roold e roold2: densidade média do fluido nos instantes $t, t-1$ e $t-2$.

- dif: coeficiente de difusão da equação de transporte de quantidade de movimento.

- dynviscmol: viscosidade molecular do fluido.

- dynviscturb: viscosidade turbulenta calculada pelos modelos submalha.

- P e Pold: pressão nos instantes $t$ e $t-1$. 
- e[i]: escalares passivos; i é o número de escalares a serem transportados.

- me[i]: média temporal dos escalares passivos.

- $\operatorname{eold}[\mathrm{i}]$ e eold2[i]: escalares passivos nos instantes $t-1$ e $t-2$.

- T: temperatura do fluido.

- Cs: coeficiente de Smagorinsky.

- Mpsdt e Mpsdt0: coeficientes auxiliares para a conservação da massa.

- Fb, Ft, Fw, Fe, Fs e Fn: fluxos advectivos nas faces da célula.

- Db, Dt, Dw, De, Ds e Dn: fluxos difusivos nas faces da célula.

- adamsun e adamsunold: coeficientes auxiliares do acoplamento Adams-BashforthMoulton.

- n1, n2, n3, n4, n5, n6, n7 e n8: número de identificação do nó em cada vértice da célula.

- elw, ele, elb, elt, els e eln: elementos adjacentes a cada face da célula.

- gid: identificador da célula.

- gidbcb, gidbct, gidbcw, gidbce, gidbcs e gidbcn: identificadores das células adjacentes as faces do volume, representando a existência ou não de condições de contorno em cada face.

- discret: modelo de discretização a ser utilizado na célula.

- BDoutflow: identificador do uso de "Buffer Domain".

A estutura coefs armazena, basicamente, os coeficientes dos sistemas lineares a serem resolvidos. Essa estrutura foi desenvolvida para permitir seu uso em métodos multigrid geométricos, caso necessário. As variáveis da estrutura coefs são:

- Awu, Aeu, Asu, Anu, Abu, Atu e Apu: coeficientes da equação de transporte da quantidade de movimento na direção X. 
- Awv, Aev, Asv, Anv, Abv, Atv e Apv: coeficientes da equação de transporte da quantidade de movimento na direção Y.

- Aww, Aew, Asw, Anw, Abw, Atw e Apw: coeficientes da equação de transporte da quantidade de movimento na direção Z.

- AwP, AeP, AsP, AnP, AbP, AtP e ApP: coeficientes da equação da poisson da pressão.

- Suu, Suv, Suw e Sup: termos fontes das equações de transporte da quantidade de movimento nas direções X, Y e Z e da poisson da pressão.

- Awe[i], Aee[i], Ase[i], Ane[i], Abe[i], Ate[i] e Ape[i]: coeficientes da equação de transporte dos escalares passivos.

- Sue[i]: termo fonte da equação de transporte dos escalares passivos.

- X e R: variáveis auxiliares para a solução dos sistemas lineares.

- el1, el2, el3, el4, el5, el6, el7 e el8, mg, elms, gid, calc: variáveis auxiliares para uso do solucionador multigrid.

A estrutura prop guarda as informações referentes às condições de contorno do domínio, os modelos a serem utilizados para o cálculo dos efeitos de turbulência, de combustão, o solucionador numérico a ser utilizado para a solução dos sistemas lineares entre outras informações. Maiores detalhes podem ser encontrados no apêndice E, o qual trata dos parâmetros do arquivo de entrada. 
Capítulo 5

Verificação e validação do código computacional desenvolvido (LECS) 
Após a implementação do código numérico, se faz necessária a validação do mesmo para se garantir os resultados obtidos além de se verificar possíveis erros de implementação. Para tanto, dois métodos foram utilizados: método das soluções manufaturadas e das soluções de engenharia.

Nesta parte do trabalho apenas serão validados os escoamentos laminares isotérmicos. No capítulo 6, seção 6.2, será resolvido um jato turbulento isotérmico para se validar a metodologia LES implementada. Já na seção 6.3, será realizada a análise do jato turbulento reativo, o qual permitirá a verificação e validação do modelo de combustão implementado e a interação entre este modelo e a metodologia LES.

\subsection{Método das soluções manufaturadas}

O método das soluções manufaturadas, discutido por Roy et al. (2004) e por Roache (2002), consiste na comparação entre soluções analíticas conhecidas e as variáveis calculadas pelo código implementado, isto é, para cada variável se define uma solução analítica qualquer e resolve-se o campo numérico com os termos forçantes para essa solução. Compara-se então a solução calculada com a analítica, permitindo a verificação da diferença entre os campos. Essa diferença é definida como o erro proveniente da solução das equações com os métodos implementados.

Para a avaliação do erro, são definidas normas numéricas que permitem quantificar esse erro de forma global no domínio computacional. As normas utilizadas neste trabalho foram a norma do infinito $\left(L_{\infty}\right)$ e a norma quadrática $\left(L_{2}\right)$, as quais representam o máximo da função erro alcançado e a média quadrática do erro global, respectivamente. As equações (5.1) e (5.2) apresentam estas normas.

$$
\begin{aligned}
& L_{\infty}=\|E\|_{\infty}=\sup |E(x)| \quad \forall x \in S \\
& L_{2}=\|E\|_{2}=\left[\sum E(x)^{2}\right]^{\frac{1}{2}} \quad \forall x \in S
\end{aligned}
$$




\subsubsection{Soluções analíticas empregadas}

As soluções utilizadas neste trabalho foram dividas em dois casos (1 e 2), ambos baseados em soluções suaves em todo o domínio. Para a solução desses campos, condições de contorno de Dirichlet foram utilizadas para todas as variáveis. A condição inicial para as variáveis foi baseada na própria solução analítica. Entretanto, devido ao método do acoplamento pressão-velocidade utilizado, parte-se da solução nula ao se resolver o sistema algébrico oriundo da equação da poisson da pressão.

Ambos os casos foram definidos com divergente algébrico nulo para o campo de velocidades, ou seja, dados os campos $\left(u_{x}\right)$ e $\left(u_{y}\right)$, o campo de velocidades $\left(u_{z}\right)$ foi determinado pela restrição algébrica da divergência global nula. A solução analítica desses campos, bem como dos termos forçantes das equações de conservação de quantidade de movimento, foram encontrados com o auxílio do programa Mapple ${ }^{\circledR}$.

As equações de (5.3) a (5.9) correspondem, respectivamente, ao campo de velocidades $\left(u_{x}\right),\left(u_{y}\right)$ e $\left(u_{z}\right)$, ao campo de pressão e aos termos forçantes nas equações de conservação de quantidade de movimento nas direções x, y e z para o caso 1. Igualmente, as equações de (5.10) a (5.16) correspondem ao caso 2, ligeiramente mais complexo e genérico. Esse segundo caso é mais genérico por admitir o produto entre as funções seno e cosseno, além de considerar componentes não alinhadas com a direção preferencial da variável, como na equação (5.11), e termos cruzados não lineares como na equação (5.12).

$$
\begin{aligned}
& u_{x}(x, y, z)=\operatorname{sen}(2 \pi x) \\
& u_{y}(x, y, z)=\operatorname{sen}(2 \pi y) \\
& u_{z}(x, y, z)=(-2 \cos (2 \pi x) \pi-2 \cos (2 \pi y) \pi) z \\
& P(x, y, z)=\cos (2 \pi z) \\
& f_{x}(x, y, z)=2 \operatorname{sen}(2 \pi x) \rho \cos (2 \pi x) \pi-\mu\left(-4 \operatorname{sen}(2 \pi x) \pi^{2}\right) \\
& f_{y}(x, y, z)=2 \operatorname{sen}(2 \pi y) \rho \cos (2 \pi y) \pi-\mu\left(-4 \operatorname{sen}(2 \pi y) \pi^{2}\right)
\end{aligned}
$$




$$
\begin{aligned}
& f_{z}(x, y, z)=4 \operatorname{sen}(2 \pi x)^{2} \rho \pi^{2} z+ \\
& +4 \operatorname{sen}(2 \pi y)^{2} \rho \pi^{2} z+ \\
& +(-2 \cos (2 \pi x) \pi-2 \cos (2 \pi y) \pi)^{2} z- \\
& -\mu\left(8 \cos (2 \pi x) \pi^{3} z+\right. \\
& \left.+8 \cos (2 \pi y) \pi^{3} z\right)- \\
& -2 \operatorname{sen}(2 \pi z) \pi \\
& P(x, y, z)=\cos (2 \pi z)
\end{aligned}
$$

$$
\begin{aligned}
f_{x}(x, y, z)= & -4 \operatorname{sen}(2 \cos (2 \pi x) \pi) \rho \cos (2 \cos (2 \pi x) \pi) \operatorname{sen}(2 \pi x) \pi^{2}- \\
& -\mu\left(-16 \operatorname{sen}(2 \cos (2 \pi x) \pi) \operatorname{sen}(2 \pi x) \operatorname{sen}(2 \pi x) \pi^{4}-\right. \\
& \left.-8 \cos (2 \cos (2 \pi x) \pi) \cos (2 \pi x) \pi^{3}\right)
\end{aligned}
$$

$$
f_{y}(x, y, z)=-2 \operatorname{sen}(2 \cos (2 \pi x) \pi) \rho \operatorname{sen}(2 \pi x) \pi-\mu\left(-4 \cos (2 \pi x) \pi^{2}\right)
$$

$$
\begin{aligned}
f_{z}(x, y, z)= & \operatorname{sen}(2 \cos (2 \pi x) \pi)\left(16 \rho \operatorname{sen}(2 \cos (2 \pi x) \pi)(\operatorname{sen}(2 \pi x) \operatorname{sen}(2 \pi x)) \pi^{4} z+\right. \\
& \left.+8 \rho \cos (2 \cos (2 \pi x) \pi) \cos (2 \pi x) \pi^{3} z\right)+ \\
& +16\left(\cos (2 \cos (2 \pi x) \pi)^{2}\right) \operatorname{sen}(2 \pi x) \operatorname{sen}(2 \pi x) \pi^{4} z \rho- \\
& -\mu\left(-64 \cos (2 \cos (2 \pi x) \pi) \operatorname{sen}(2 \pi x) \operatorname{sen}(2 \pi x) \operatorname{sen}(2 \pi x) \pi^{6} z+\right. \\
& +96 \operatorname{sen}(2 * \cos (2 * p i * x) * p i) \operatorname{sen}(2 \pi x) \pi^{5} z \cos (2 \pi x)- \\
& \left.-16 \cos (2 \cos (2 \pi x) \pi) \operatorname{sen}(2 \pi x) \pi^{4} z\right)- \\
& -2 \operatorname{sen}(2 \pi z) \pi
\end{aligned}
$$


As malhas utilizadas foram baseadas na geometria de um cubo de aresta unitária. Foram testadas malhas estruturadas cartesianas, com 8, 16, 32, 64 e 128 volumes em cada aresta, sempre com distribuição uniforme. O critério de parada do solucionador numérico foi o número de iterações ou o máximo resíduo da solução do sistema linear. O tempo final, foi definido como 1 segundo.

As figuras 5.1 e 5.2 apresentam, respectivamente, o erro e a ordem de queda do erro devido ao refino de malha para a solução do problema do caso 1. Já as figuras 5.3 e 5.4 , para o caso 2 .

A ordem de queda do erro é calculada pela equação (5.17), na qual $\left(E_{n}\right)$ e $\left(E_{2 n}\right)$ representam os erros normados para as malhas com $(n)$ e $(2 n)$ volumes, respectivamente.

$$
O_{\text {erro }}=\frac{\ln \left(\frac{E_{n}}{E_{2 n}}\right)}{\ln (2)}
$$

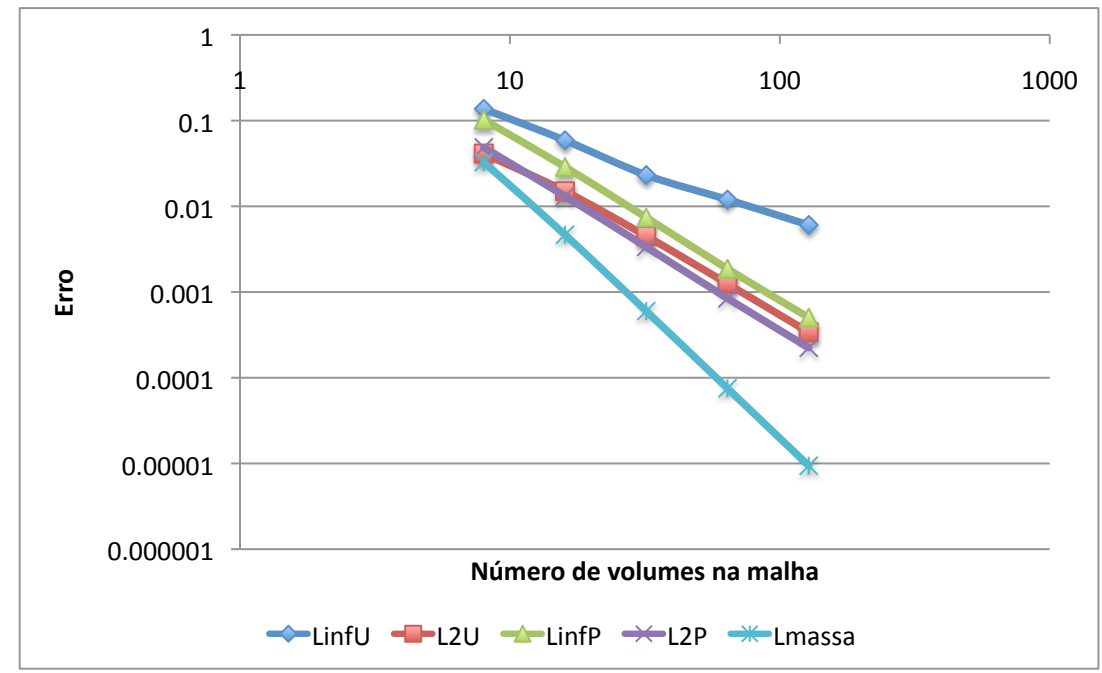

Figura 5.1: Variação do erro de cálculo com o refino da malha

Pelas figuras 5.1 e 5.3 verifica-se que o erro devido a discretização espacial decai com o refino da malha como esperado. Verifica-se, pelas figuras 5.2 e 5.4, que o decaimento do erro tende a $\left(2^{a}\right)$ ordem para as variáveis calculadas e $\left(3^{a}\right)$ ordem para a massa. Entretando, verifica-se na figura 5.2 que o erro normado pela $\left(L_{\infty}\right)$ para as velocidades não decaiu com a ordem esperada. 


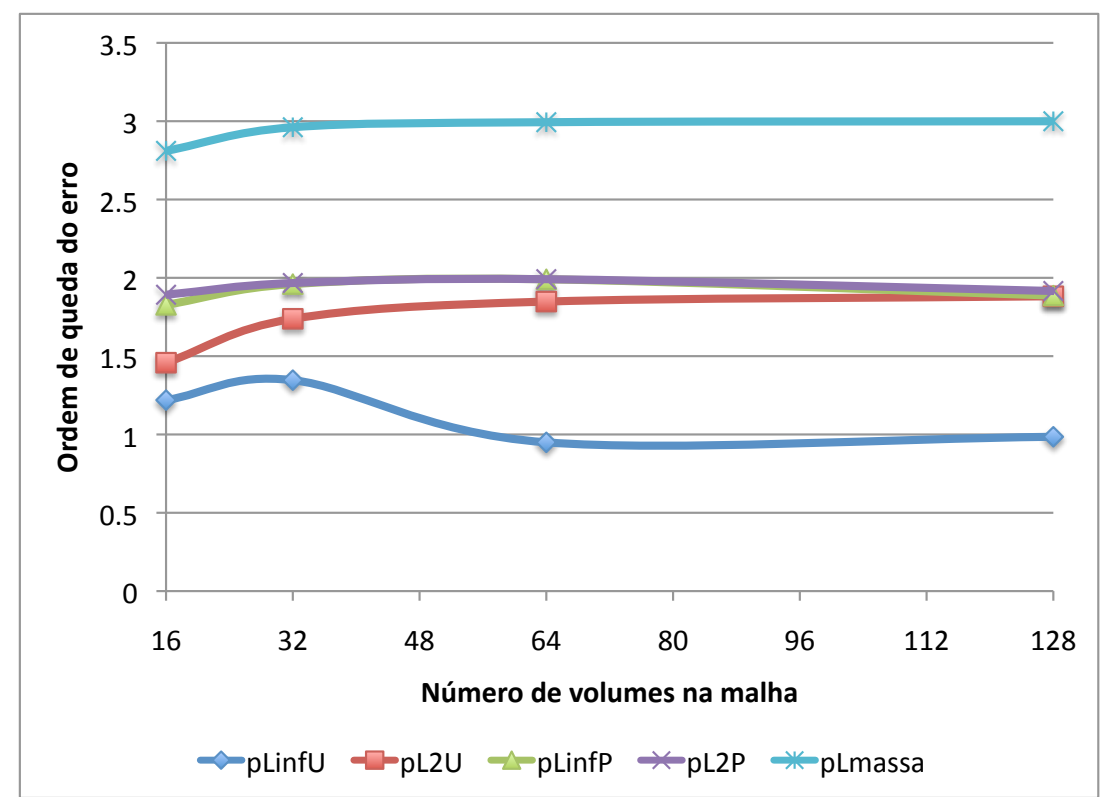

Figura 5.2: Ordem da variação do erro com o refino da malha

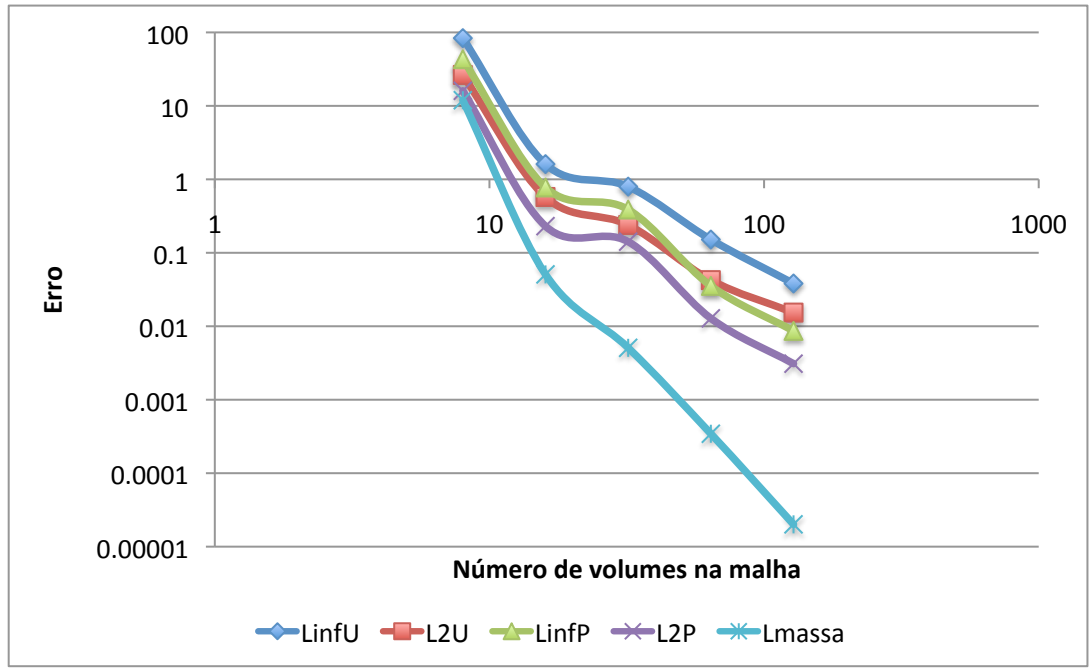

Figura 5.3: Variação do erro de cálculo com o refino da malha

A magnitude elevada do erro no segundo caso é devido, provavelmente, ao cálculo das variáveis extremamente acopladas nas diferentes direções e a efeitos oriundos das não linearidades dos campos algébricos. Entretanto, o comportamento qualitativo do erro com o refino da malha se apresenta de acordo com o esperado, ou seja, com o aumento do número de volumes, obtêm-se uma redução de segunda ordem para o erro. 


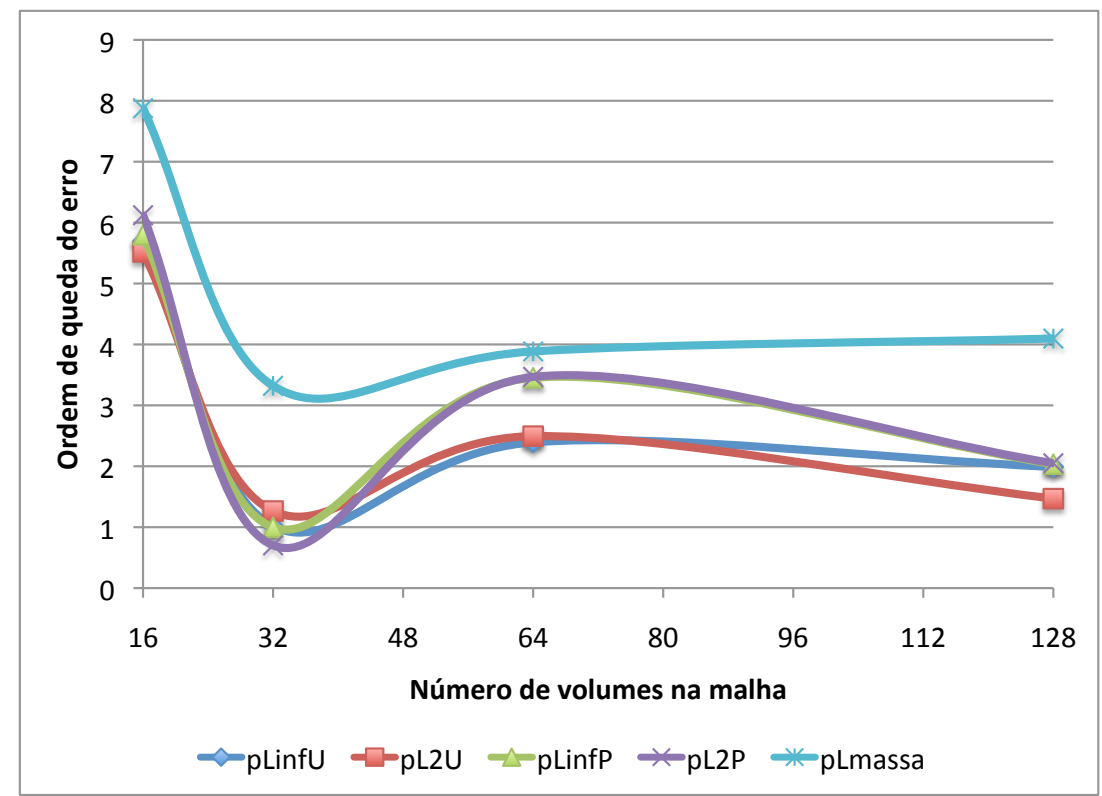

Figura 5.4: Ordem da variação do erro com o refino da malha

\subsection{Validação com escoamentos de engenharia}

Outra forma amplamente utilizada de se validar a implementação de um algorítmo numérico é resolver escoamentos clássicos encontrados na literatura com ou sem solução analítica. Os casos típicos para esse tipo de estudo compreendem escoamentos laminares em cavidades, entre placas planas e jatos de difusão.

\subsubsection{Escoamento laminar em cavidade com tampa móvel}

Escoamentos em cavidades são muito utilizados para a validação de códigos numéricos por serem de simples implementação, além de possuírem características que testam a solução das equações de Navier-Stokes e o acoplamento pressão-velocidade, tais como recirculações, gradientes adversos de pressão e velocidade, etc.

O caso analisado neste trabalho é discutido em Ghia et al (1982), em que um domínio computacional de tamanho unitário foi utilizado. O número de Reynolds com valor de 1000 foi adotado para as comparações. Devido à natureza bi-dimensional do escoamento laminar numa cavidade, três malhas com diferentes refinos foram testadas sem perda de generalidades: 32x32x4, 64x64x4 e 128x128x4 volumes. Em todos 
os casos, foi conduzida uma análise transiente e o critério de parada foi baseado na variação temporal dos campos calculados, de modo a se alcançar a solução em regime permanente das variáveis.

As condições de contorno foram definidas pelo tipo parede para as faces normais ao eixo $\mathrm{X}$ e para a face no sentido negativo de $\mathrm{Y}$. A face no sentido positivo do eixo Y foi definida como parede móvel com movimento apenas no sentido positivo do eixo X. As faces normais ao eixo $\mathrm{Z}$ foram definidas com condições do tipo Neumann para todas as variáveis. A condição inicial foi definida como nula para todas as variáveis analisadas. A figura 5.5 apresenta o domínio computacional e o eixo coordenado utilizado.

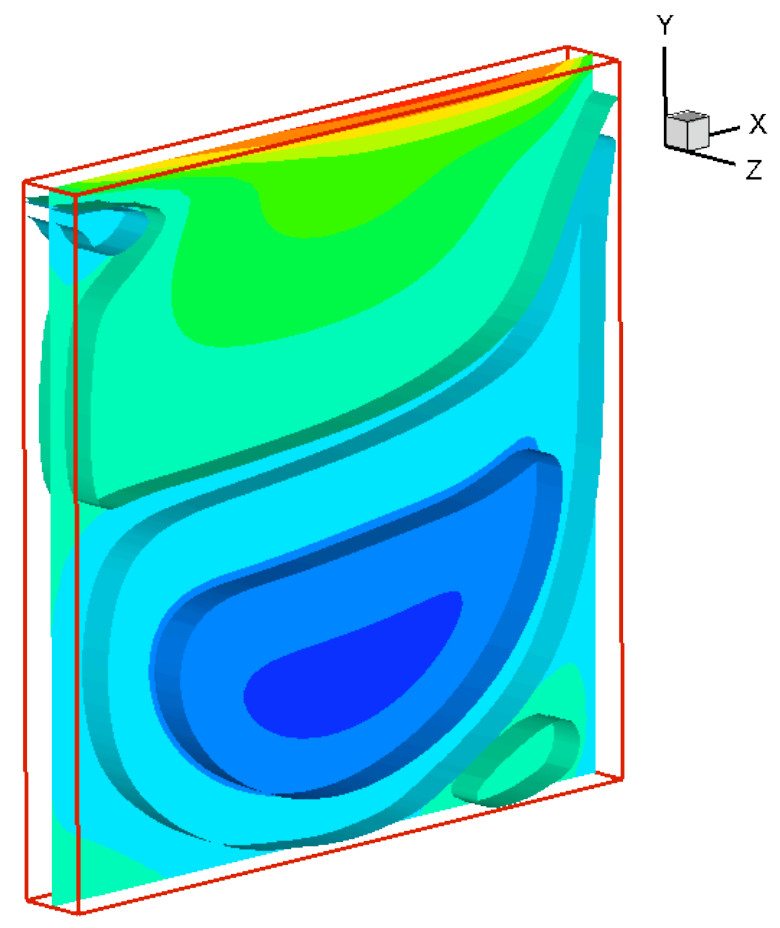

Figura 5.5: Domínio computacional utilizado na validação do código numérico pelo escoamento laminar em cavidades, no sistema coordenado de eixos cartesianos.

A figura 5.6 apresenta os resultados na linha central definida na figura 5.5. Verifica-se boa correlação entre os resultados calculados pelo código implementado neste trabalho com os dados obtidos por Ghia et al (1982). Observa-se ainda que ao se refinar a malha, melhores resultados são obtidos, como esperado.

A figura 5.7 apresenta a distribuição de vorticidade para as malhas analisadas. Na figura 5.8 observam-se características do escoamento como a recirculação próxima 


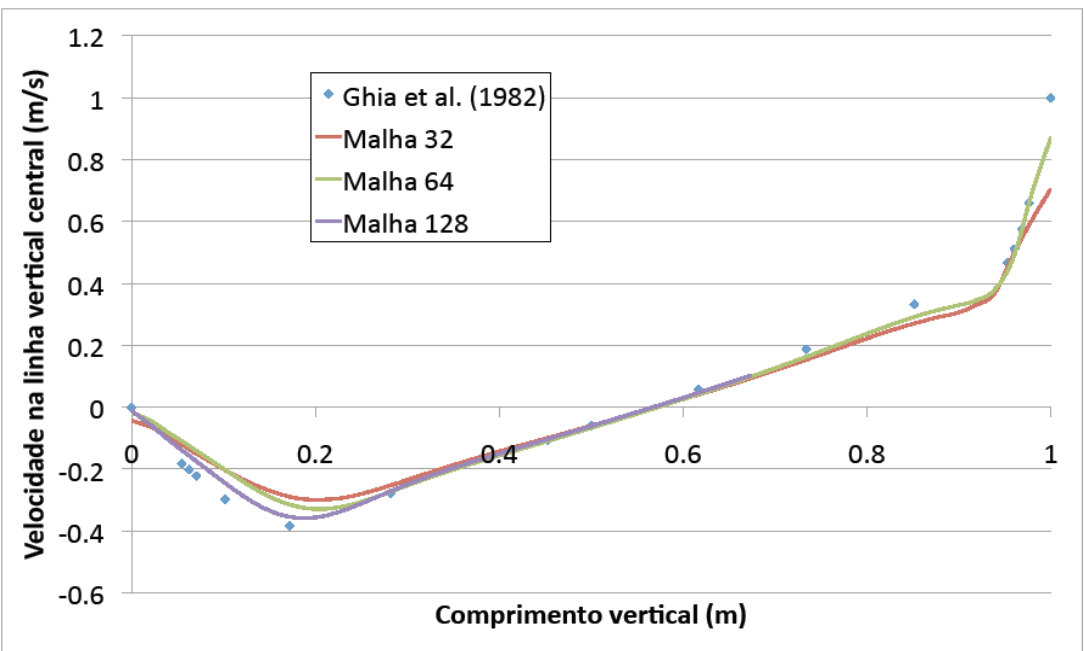

Figura 5.6: Distribuição da componente da velocidade $\left(u_{x}\right)$ na linha central para as diversas malhas utilizadas.

aos vértices inferiores do domínio. Esta figura apresenta a distribuição da componente da velocidade $\left(u_{x}\right)$ e seus vetores não normalizados, isto é, os vetores foram escalados de forma uniforme não mantendo a relação entre as magnitudes.

a)

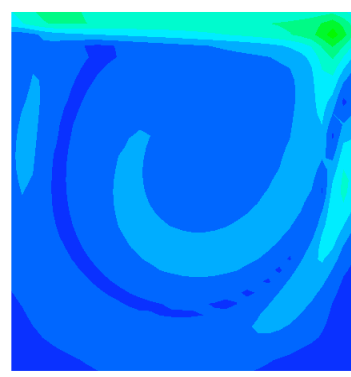

b)

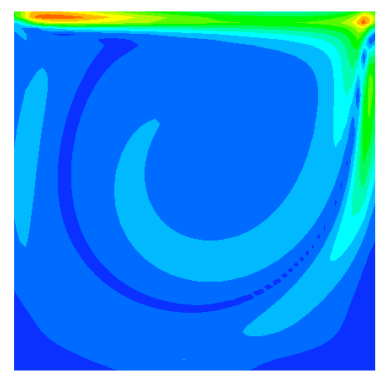

c)

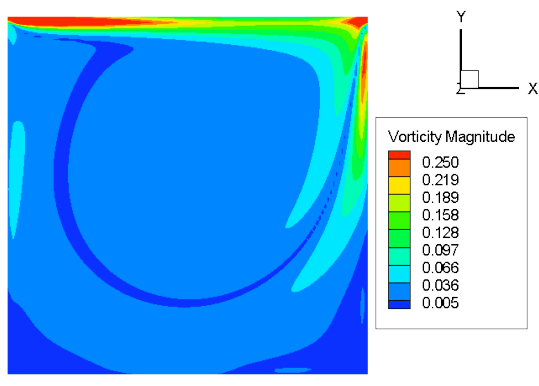

Figura 5.7: Distribuição da magnitude da vorticidade no plano médio do domínio computacional para as malhas analisadas; a) 32x32x4 volumes, b) $64 \times 64 \times 4$ volumes e c) $128 \times 128 \times 4$ volumes. 


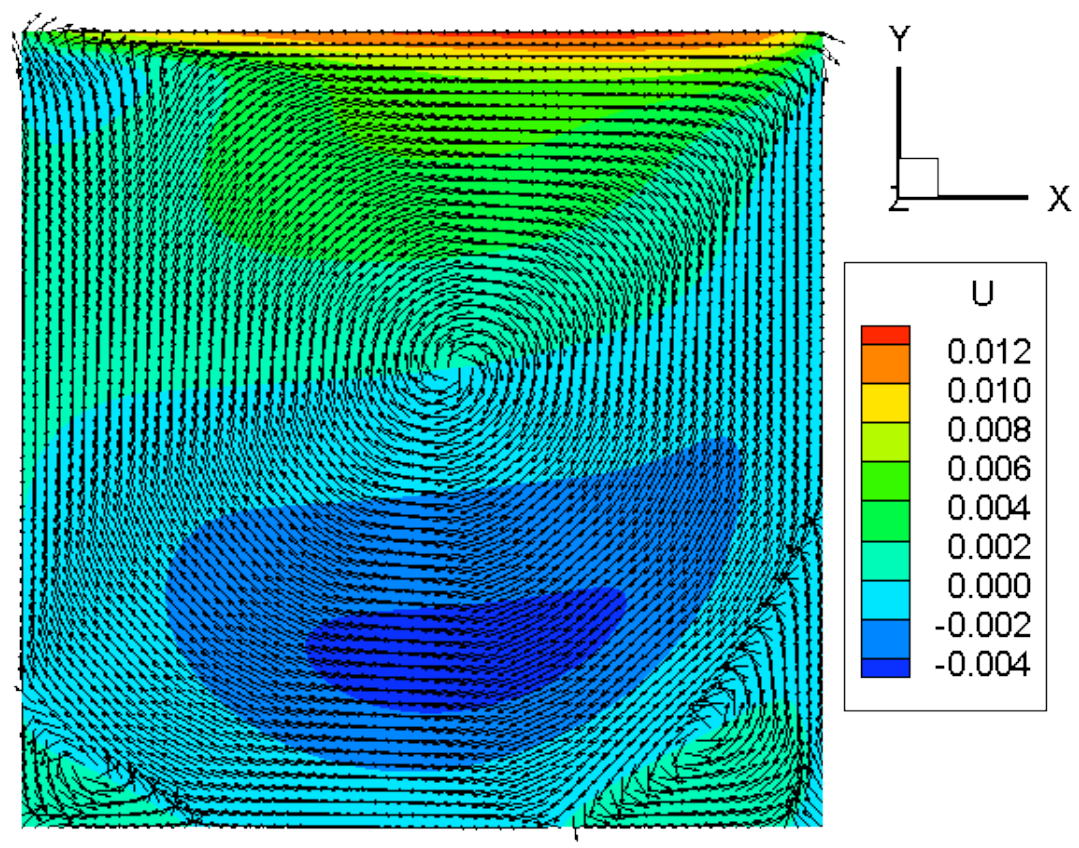

Figura 5.8: Distribuição da componente da velocidade $\left(u_{x}\right)$ superposta aos vetores da velocidade não normalizados para a malha $64 \times 64 \times 4$ volumes.

\subsubsection{Escoamento laminar em dutos retangulares}

De acordo com Maliska (2004), o escoamento laminar entre placas planas, também conhecido por escoamento de Poiseuille, é um problema que permite analisar diversas características da solução, como simetria do escoamento, condições de contorno, etc.

Para este caso, um domínio computacional com $5 \times 1 \times 0,1 \mathrm{~m}^{3}$ foi utilizado. Dada a natureza bi-dimensional deste tipo de problema, nenhuma generalidade foi perdida com as dimensões escolhidas. Duas diferentes malhas com direfentes refinos foram utilizadas: 160x32x4, 320x64x4 volumes. A condição inicial foi definida como nula para as variáveis deste escoamento e foi conduzida uma análise transiente deste problema.

A condição de contorno do tipo parede foi aplicada para as faces normais ao eixo Y. Na face normal e no sentido negativo de $\mathrm{X}$, foi aplicada a condição de entrada, com velocidade não nula apenas para a componente $\left(u_{x}\right)$. Na face oposta, foi considerada condição de saída. As faces normais ao eixo Z foram consideradas com condição de contorno do tipo Neumann com valor nulo para a velocidade e escalares, 
excetuando-se a pressão, para a qual foi definida condição de Dirichlet nula. A figura 5.9 apresenta o domínio computacional utilizado.

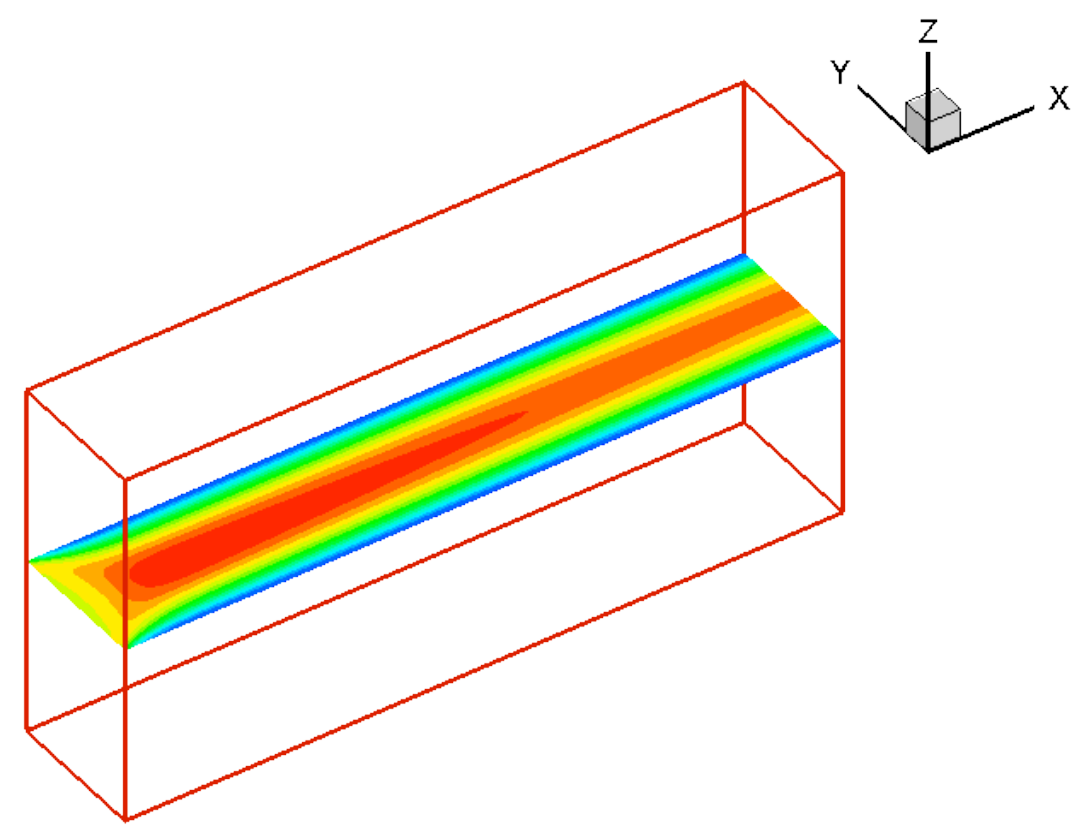

Figura 5.9: Domínio computacional utilizado na validação do código numérico pelo escoamento laminar entre placas planas, no sistema coordenado de eixos cartesianos. (A dimensão do domínio no eixo Z foi escalada para melhor representação.)

Nos ensaios realizados, foi utilizado número de Reynolds igual a 7. A solução analítica para o escoamento na saída do domínio pode ser encontrada, segundo Maliska (2004), pela equação (5.18).

$$
u_{x}=\frac{3}{2} u_{x_{0}}\left(1-\left(\frac{y}{h}\right)^{2}\right)
$$

A figura 5.10 apresenta a comparação dos perfis de velocidade axial na saída do domínio. A distribuição de velocidades axial para as diferentes malhas pode ser observado pela figura 5.11. 


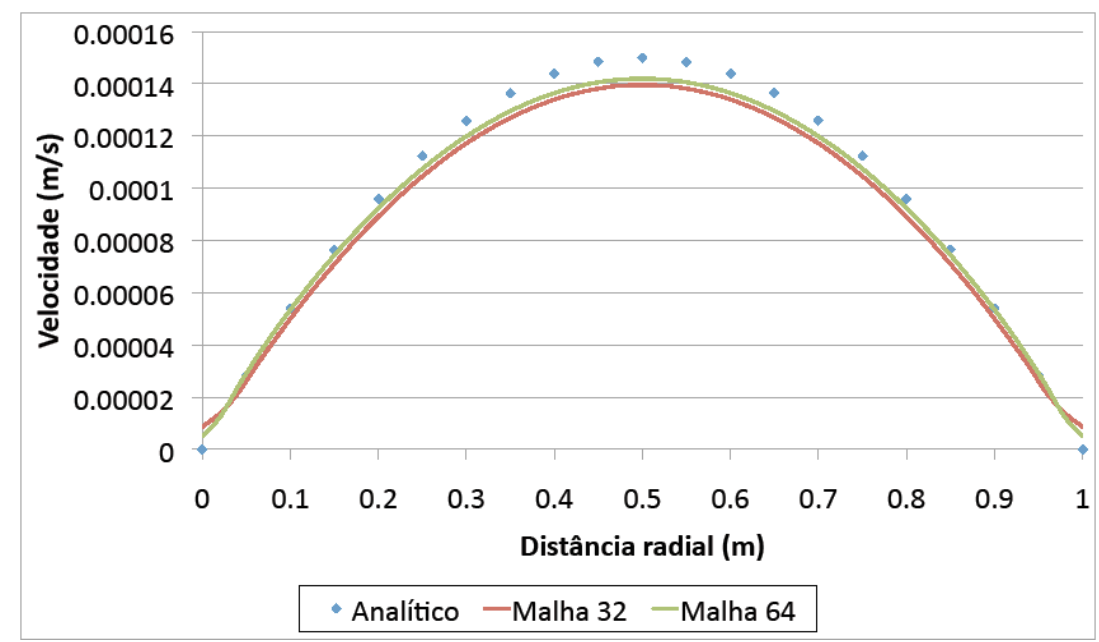

Figura 5.10: Comparação entre os perfis de velocidade axial na saída do domínio computacional.

a)

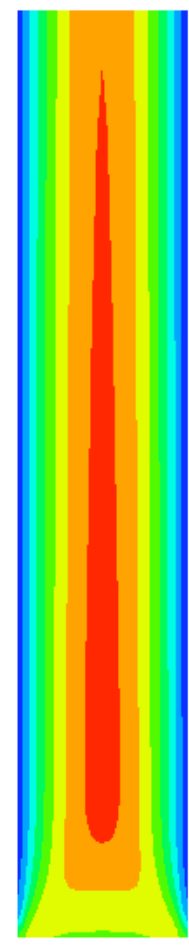

b)
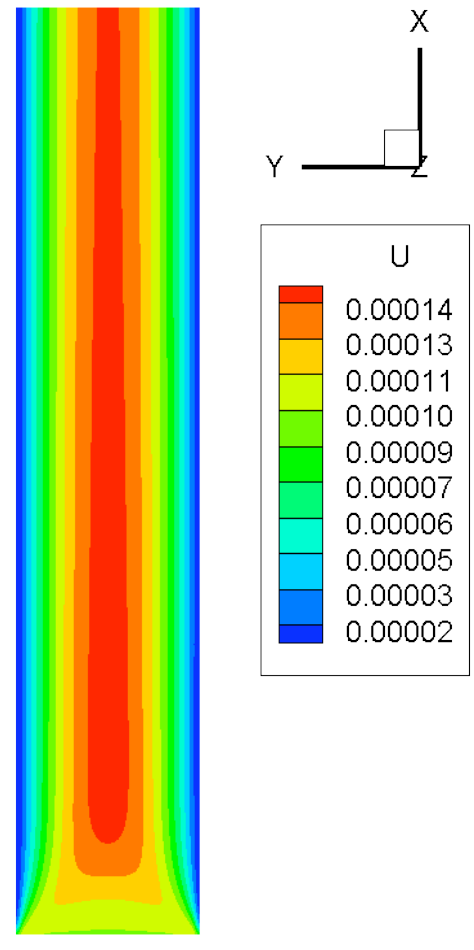

Figura 5.11: Distribuição da velocidade axial para as malhas com diferentes refinos; (a) 160x32x4 volumes e (b) 320x64x4 volumes.

\subsubsection{Escoamento de jatos laminares}

Escoamentos de jatos laminares são utilizados para validação de algorítmos numéricos por possuírem solução analítica na linha de centro do escoamento físico. 
Segundo Turns (2000), a velocidade axial na linha de centro é dada pela equação (5.19). Esta solução possui a restrição de ser válida apenas na região a jusante de 10 diâmetros do jato, ou seja, nesta análise, essa equação prediz com boa precisão os resultados para a velocidade axial do jato na linha de centro a partir de 0,1 m.

$$
u_{z_{c l}}=\frac{3}{32} \operatorname{Re}\left(\frac{D}{z}\right) u_{z 0}
$$

O domínio computacional utilizado foi baseado nas dimensões $0,3 \times 0,3 \times 0,65 \mathrm{~m}^{3}$, e apresentado pela figura 5.12. O diâmetro de saída do jato foi definido em 0,0072m. O número de Reynolds utilizado foi de 50,4. Como condição incial, foi definido campo inicial nulo para todas as variáveis, e conduzida uma análise transiente do escoamento. Condições do tipo parede foram impostas às faces tangentes ao eixo Z. A condição de saída foi utilizada na face normal e sentido positivo de Z. Na face normal e sentido negativo de $\mathrm{Z}$ foi definida a condição de entrada para o jato com secção quadrada do tipo "top-hat" e uma velocidade de "co-flow", região adjacente ao jato, de $2 \%$ da velocidade de saída do jato.

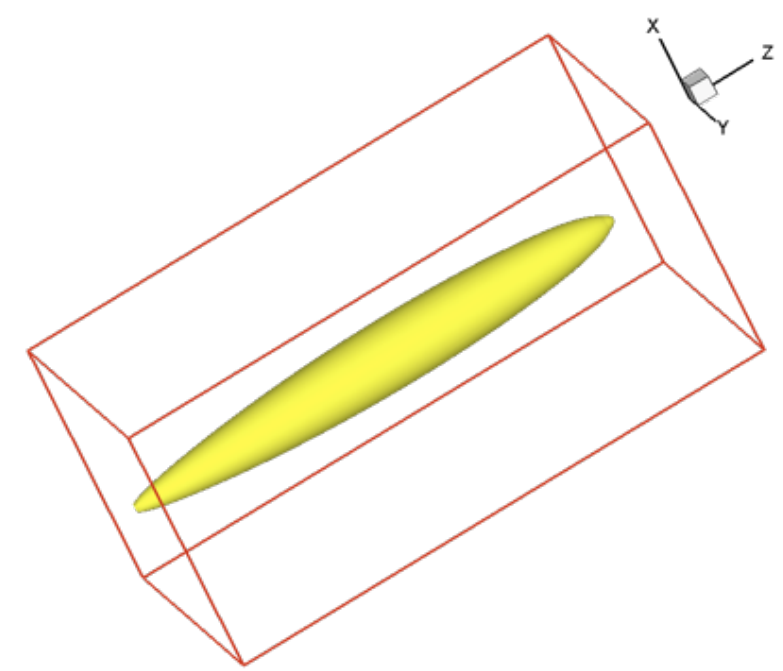

Figura 5.12: Domínio computacional utilizado na validação do código numérico pelo escoamento de um jato laminar, no sistema coordenado de eixos cartesianos.

A figura 5.13 apresenta uma comparação entre o código numérico implementado neste trabalho (LECS), o código comercial Fluent da Fluent Inc. e a solução 
analítica proposta por Turns (2000), para a velocidade axial na linha de centro do jato. A distribuição da velocidade axial no plano médio do domínio computacional é apresentada na figura 5.14.

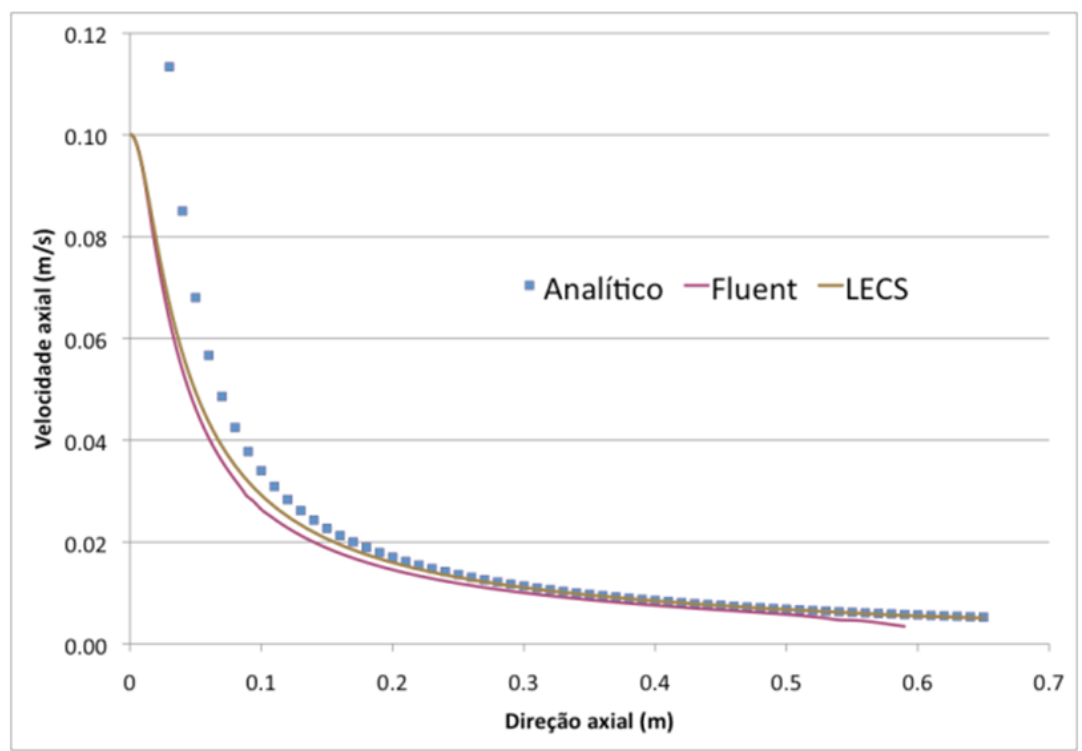

Figura 5.13: Comparação entre os resultados numéricos e analítico para a velocidade axial na linha de centro do jato. 

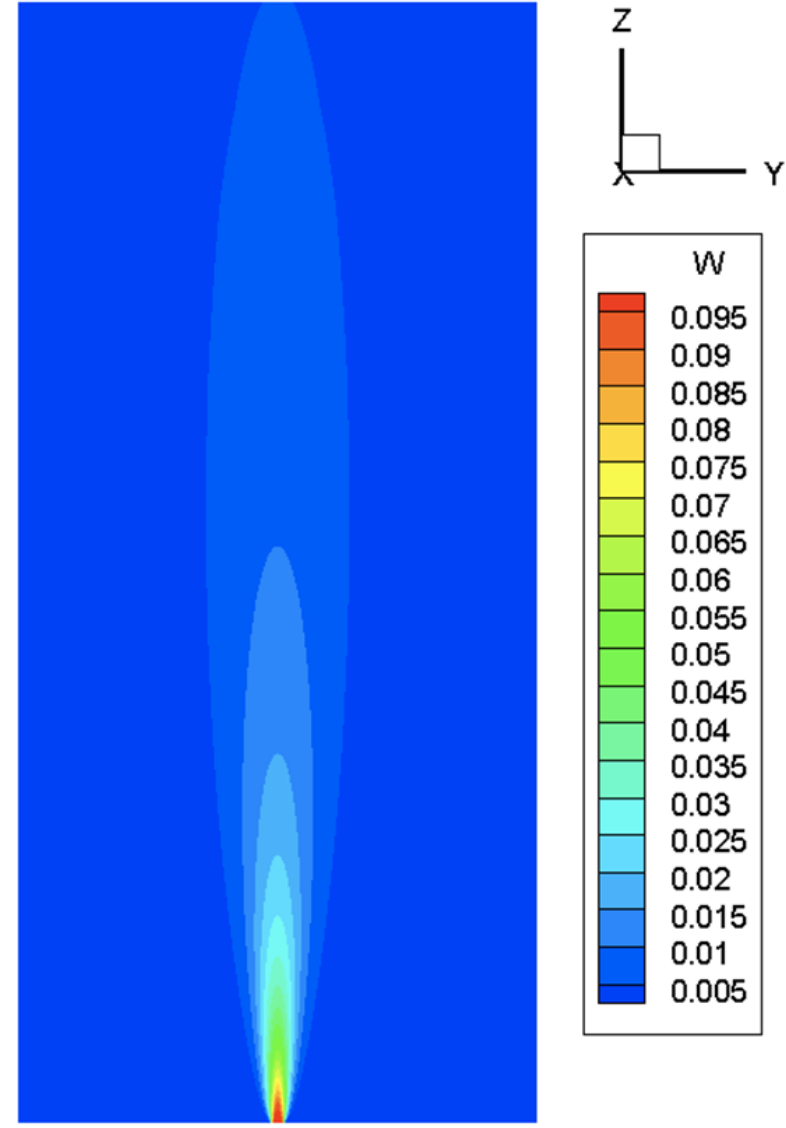

Figura 5.14: Distribuição da velocidade axial no plano médio do domínio computacional. 
Capítulo 6

Análise do escoamento de um jato circular turbulento 
Neste trabalho, para o estudo do escoamento de um jato turbulento, foi utilizada a chama D investigada pelo laboratório SANDIA nos EUA. Inicialmente, estudouse esse escoamento de forma isotérmica para se verificar a implementação do modelo de turbulência submalha.

Após a verificação isotérmica, o modelo "flamesheet" foi utilizado para incluir os efeitos devido a combustão no escoamento deste jato turbulento.

Para a solução numérica dos jato isotérmico, foi empregada uma máquina Apple Mac Pro com dois processadores Xeon de 4 núcleos reais rodando a $2,8 \mathrm{GHz}$ com memória RAM disponível de 6GB. O tempo de simulação deste problema nesta máquina foi de, aproximadamente, 144 horas.

Para o caso do jato reativo, foi utilizada uma máquina $\mathrm{SGI}^{\circledR}$ com dois processadores Xeon de 4 núcleos reais e 4 virtuais, totalizando 16 núcleos rodando a $2,4 \mathrm{GHz}$ com mémoria RAM disponível de 24GB. O tempo de simulação deste caso foi de, aproximadamente, 108 horas.

\subsection{Estudo de uma chama de difusão turbulenta}

O escoamento estudado é de um jato livre que se desenvolve em ambiente com ar parado. O arranjo geométrico para esse escoamento foi baseado nos trabalhos de Masri et al. (1996) e Barlow e Frank (1998), em que o bocal de saída do combustível foi definido em 0,0072mm de diâmetro, acoplado a um dispositivo concêntrico, o qual gera um sub-escoamento chamado de "co-flow", com diâmetro externo de 18,2mm.

O número de Reynolds adotado foi 22.400, caracterizando a chama D do workshop TNF do laboratório SANDIA. Essa chama é baseada na pré-mistura parcial de $0,25 \%$ de metano e $0,75 \%$ de ar. O "co-flow" foi utilizado para reduzir a formação de fuligem, melhorando a acurácia na medida das concentrações das espécies. Essa pré-mistura parcial não descaracteriza essa chama de difusão, permitindo alcançar elevados números de Reynolds. De acordo com Barlow e Frank (1998), essa chama não apresenta extinção local, permitindo seu uso para a validação de modelos numéricos simplificados. A figura 6.1 apresenta a chama estudada na região próxima ao bocal de 
saída do combustível. Nesta figura, as sub-chamas próximas ao bocal são chamadas de chamas piloto e se encontram na região do "co-flow".

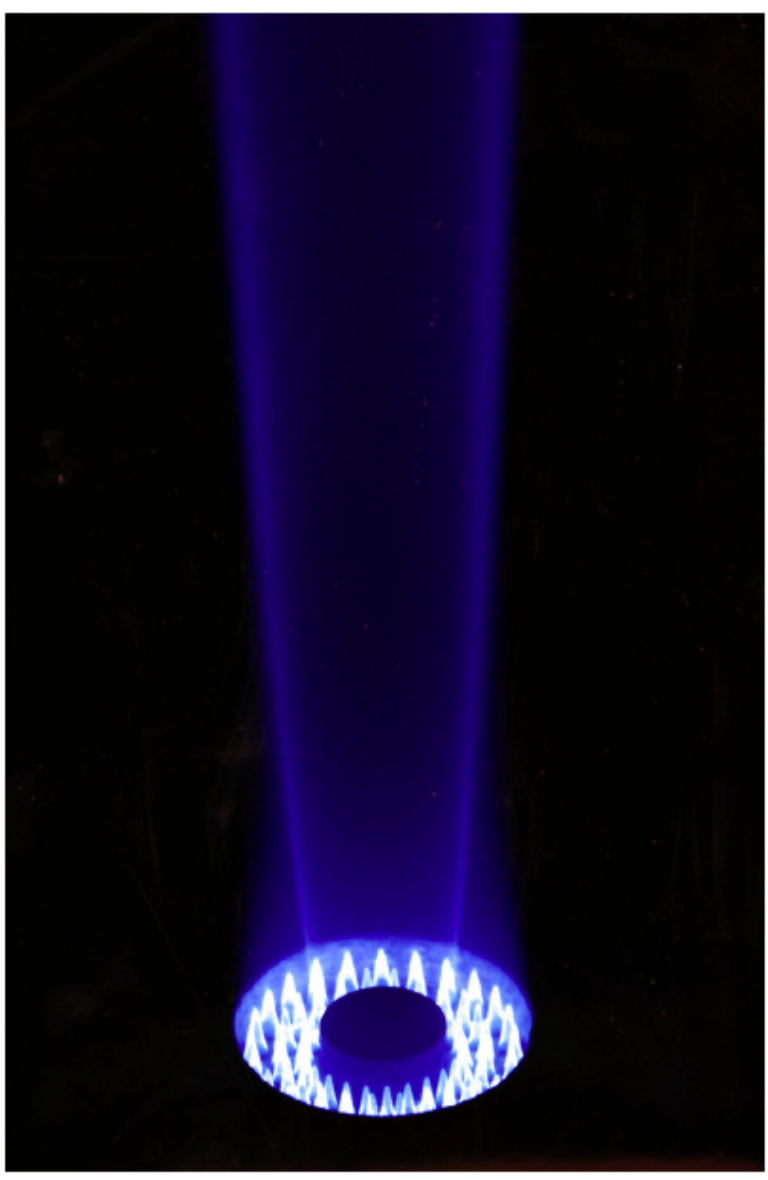

Figura 6.1: Chama D utilizada como padrão para validação de modelos de combustão. Apresentação da chama principal e das chamas pilotos, localizadas na região de "coflow". Fonte: site do Laboratório SANDIA

As medições do campo de velocidades foram obtidas pelo método "laserDoppler anemometry" (LDA), segundo Barlow e Frank (2007).

\subsection{Experimento numérico do jato isotérmico}

Para o jato turbulento isotérmico, foi empregado o método Adams-BashforthMoulton como acoplamento pressão/velocidade e utilizado o modelo submalha de Smagorinsky. A constante de Smagorinsky foi definida em 0,1 e o escoamento foi analisado 
em regime transiente, com condições iniciais nulas para todas as variáveis analisadas. A velocidade axial na entrada do domínio computacional é definida pelo gráfico 6.2. Neste mesmo gráfico, verifica-se, inclusive, a magnitude da perturbação nesta componente da velocidade.

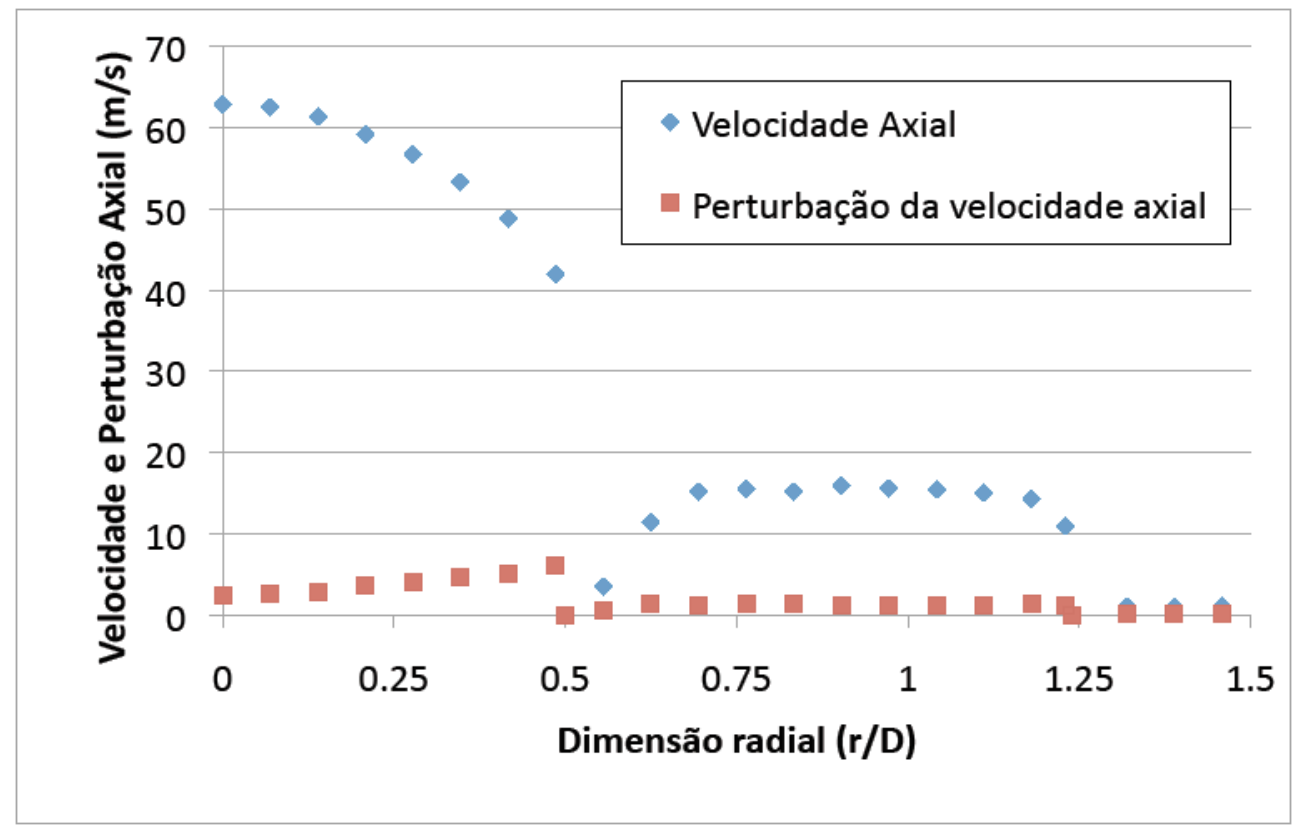

Figura 6.2: Definição da componente axial da velocidade, e sua perturbação, na entrada do domínio computacional. Fonte: dados do site do Laboratório SANDIA

Pela figura 6.2, é possível determinar a região do escoamento principal da chama estudada e de seu "co-flow".

O domínio computacional utilizado possui as dimensões de $0,3 \times 0,3 \times 0,7 m^{3}$ e é apresentado pela figura 6.3. A figura 6.4 apresenta a malha empregada na discretização deste domínio, a qual foi composta por 1.795.986 volumes, os quais foram uniformemente espaçados na direção $\mathrm{Z}$ até a posição $\left(\frac{z}{D}\right)$ igual a 48 , correspondente a metade do comprimento na direção Z do domínio. Na outra metade, definiu-se uma taxa de crescimento de $10 \%$ para o tamanho dos volumes nessa direção.

Ainda na figura 6.4, um refino, nas direções $\mathrm{X}$ e $\mathrm{Y}$, foi aplicado na região do jato, de forma que o espaçamento dos volumes foi definido por uma função hiperbólica, com espaçamento de $0.03 \mathrm{~m}$ para os volumes das extremidades. Assim, uma malha relativamente homogênea na região de saída do jato foi obtida com espaçamento de 


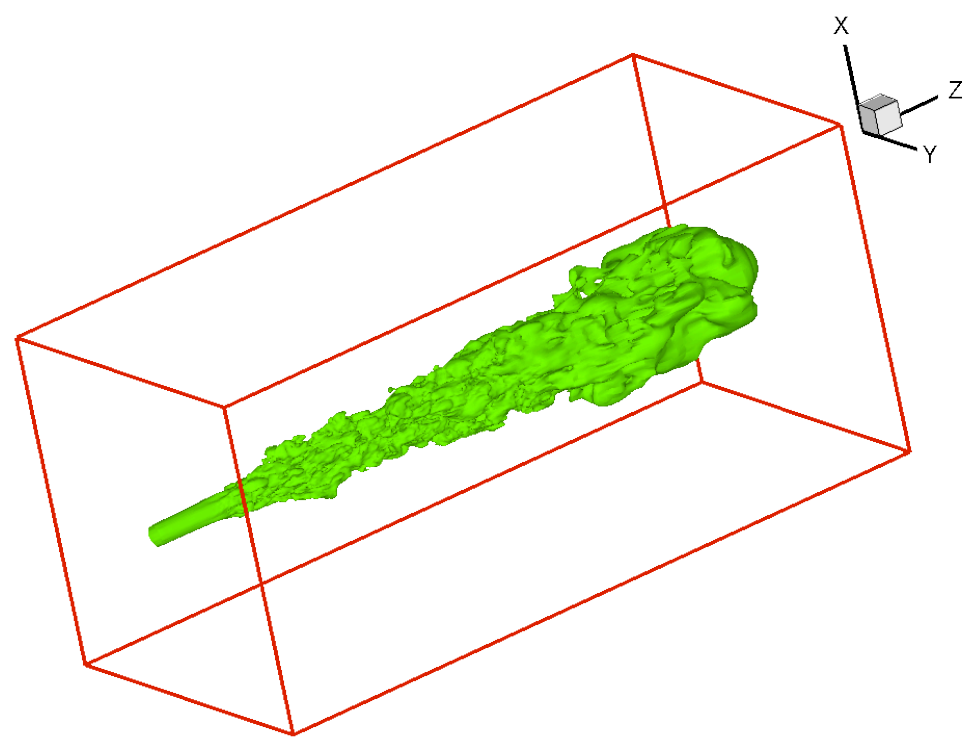

Figura 6.3: Domínio utilizado para a solução do escoamento do jato turbulento.

a)

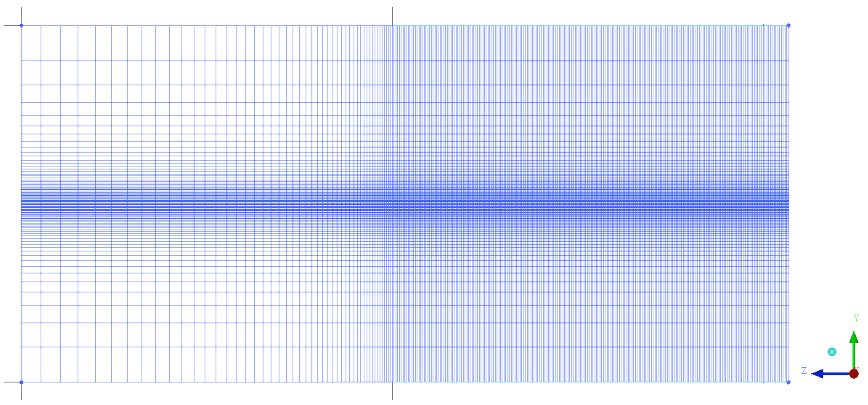

b)

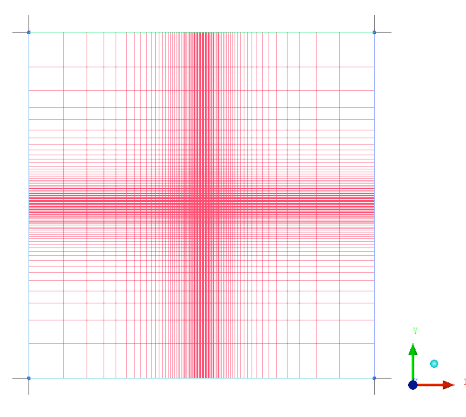

Figura 6.4: Malha utilizada na discretização do domínio computacional. a) vista superior, b) vista frontal.

$0,001 \times 0,001 \times 0,001 m^{3}$.

A condição de contorno do tipo saída foi definida nas laterais do domínio, isto é, nas faces normais às direções X e Y. Devido ao tamanho do domínio escolhido, de acordo com Mustata et al. (2005), essa condição não influencia, de forma significativa, o desenvolvimento do jato turbulento. A condição de saída do domínio, face normal no sentido positivo do eixo Z, foi definida como condição de saída, aplicando-se a condição de Neumann com fluxo nulo para as velocidades e Dirichlet com valor nulo para a pressão. A face normal no sentido negativo de Z, foi definida com condição de entrada com os valores nulos para as velocidades na direção X e Y e condição de Neumann com fluxo nulo para a pressão. Nessa região, a velocidade e suas respectivas perturbações 
na direção Z, ou axial, foram definidas de acordo com o perfil apresentado pela figura 6.2 .

\subsubsection{Resultados}

Os resultados analisados para o escoamento do jato turbulento isotérmico foram obtidos após ser alcançado o regime estatisticamente permanente, em que o jato se encontra com escoamento totalmente desenvolvido e com propriedades médias temporais estatisticamente constantes.

A figura 6.5 apresenta a distribuição da velocidade axial filtrada e média temporal. A figura 6.6 apresenta os vetores normalizados da velocidade do escoamento na região próxima a saída do jato e na região do jato turbulento totalmente desenvolvido. Em ambas regiões, é possível identificar estruturas turbulentas com diferentes comprimentos de onda espacial.

A figura 6.7 apresenta a distribuição da viscosidade efetiva no plano médio do domínio analisado. Nesta figura, é possível verificar a alta influência das taxas de deformação do escoamento na região próxima à saída do jato, devido ao aumento da viscosidade turbulenta, dado que a viscosidade molecular é constante nos casos analisados. A figura 6.8 apresenta a distribuição da viscosidade efetiva na região próxima

ao bocal do jato. É nessa região de altos gradientes que ocorre a transição turbulenta do escoamento.

As figuras 6.9 e 6.10 apresentam a distribuição da velocidade axial média na linha de centro do domínio computacional e nos planos $(x / D)$ iguais a $5,10,20,30$ e 50.

\subsubsection{Cálculo da cascata de energia}

A cascata de energia, apresentada pela figura 2.6, pode ser baseada nas estatísticas temporais ou espaciais dos campos de velocidade. Neste trabalho foram utilizadas as estatísticas temporais para o cálculo do espectro de energia. Essas estatísticas 

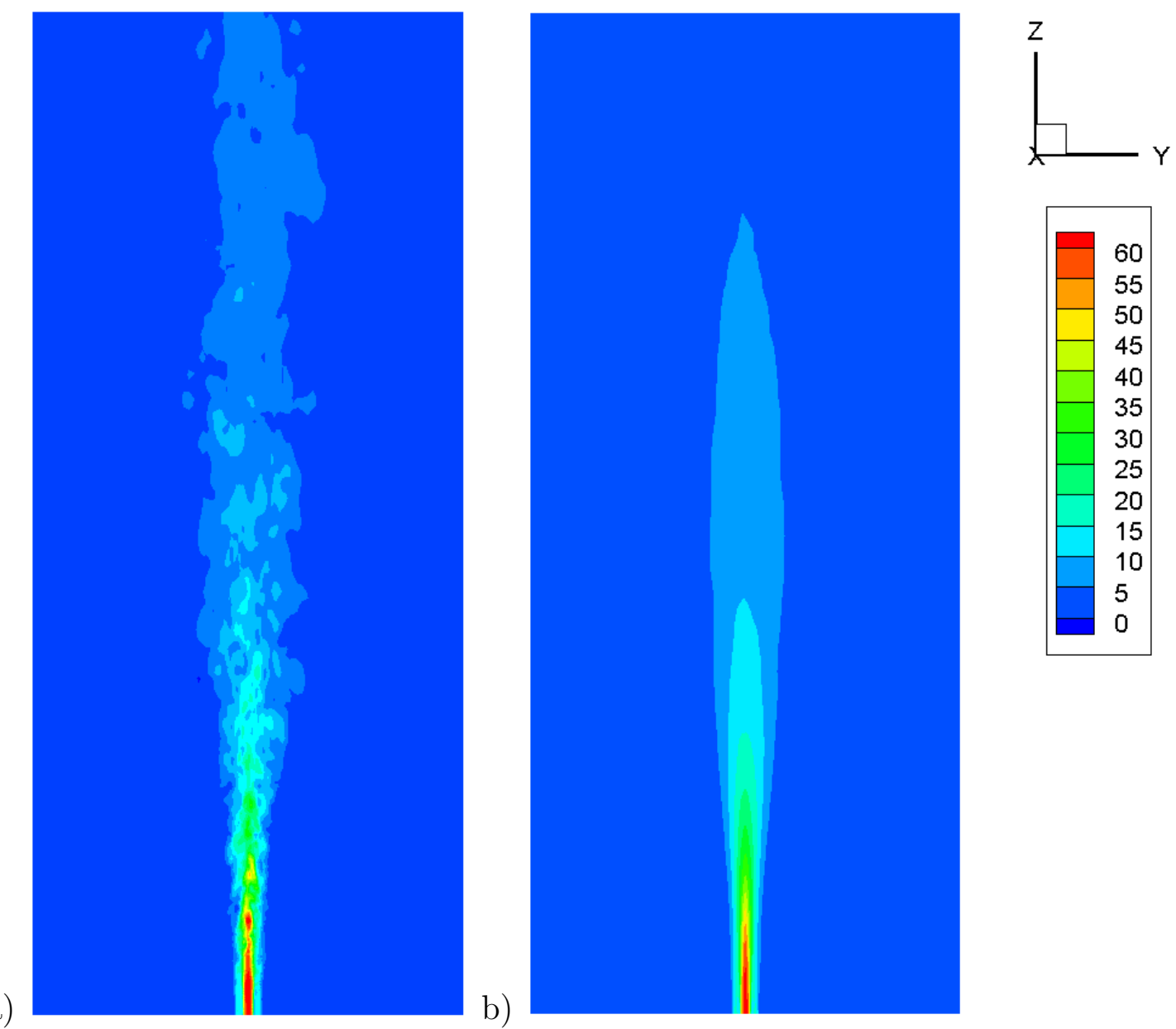

Figura 6.5: Distribuição da velocidade axial filtrada no plano médio do domínio computacional: a) campo da velocidade filtrada, b) campo da velocidade média temporal. foram obtidas em determinados pontos do domínio computacional, os quais são apresentados na figura 6.11 e correspondem às coordenadas $(0,15 ; 0,15 ; 0,10),(0,15 ; 0,15 ; 0,30)$ e $(0,15 ; 0,15 ; 0,50)$, respectivamente para os pontos $P_{1}, P_{2}$ e $P_{3}$.

O cálculo dos espectros de energia é apresentado por Pope (2000) em que os resultados para os pontos $P_{1}, P_{2}$ e $P_{3}$ são apresentados pelas figuras $6.12,6.13$ e 6.14, respectivamente. Estes espectros de energia cinética turbulenta foram calculados segundo um algorítmo desenvolvido por Volpi (2009). 
a)

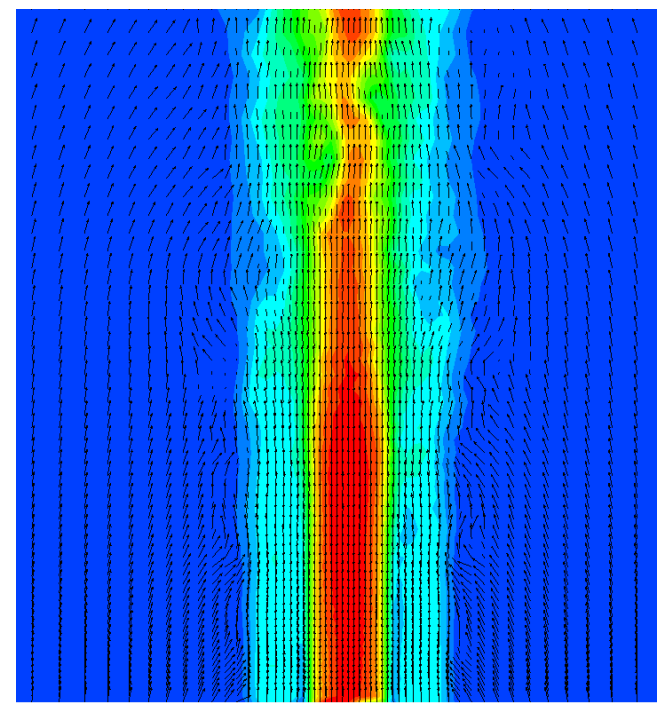

b)

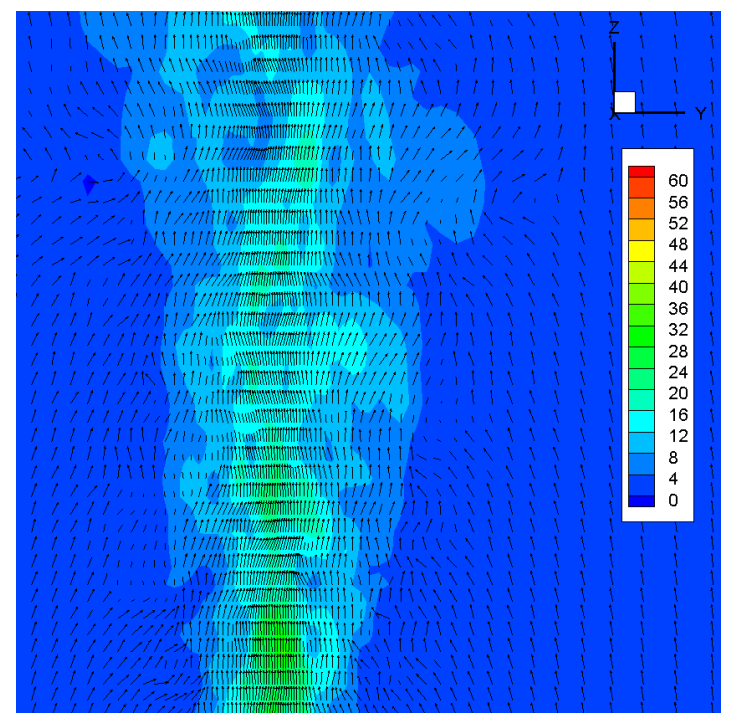

Figura 6.6: Detalhes do campo de velocidades axial: a) próximo ao bocal do jato, b) numa região de esocamento plenamente desenvolvido. Vetores com mesma distribuição de tamanho. 


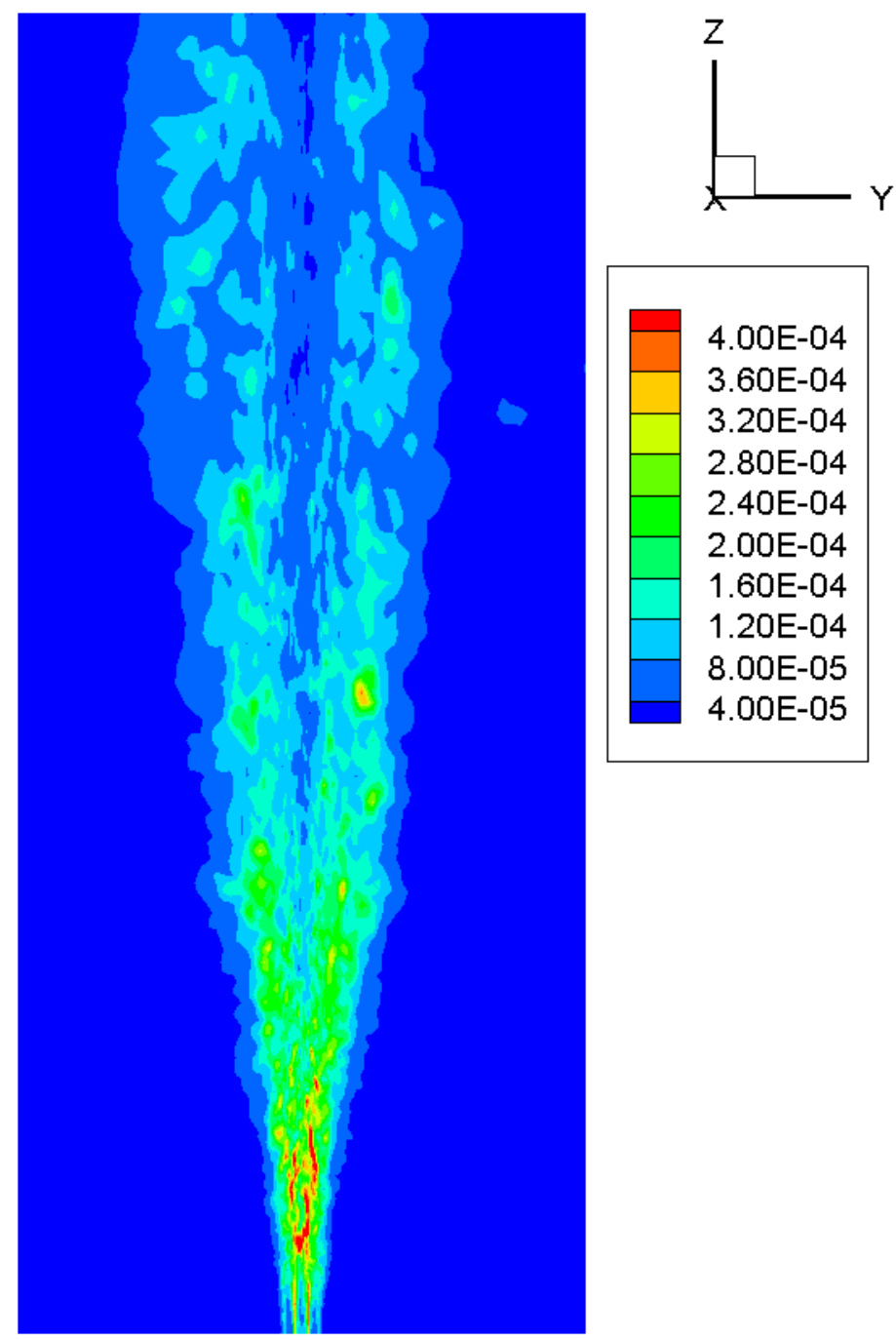

Figura 6.7: Distribuição da viscosidade efetiva (molecular + turbulenta) no plano médio do domínio computacional. 


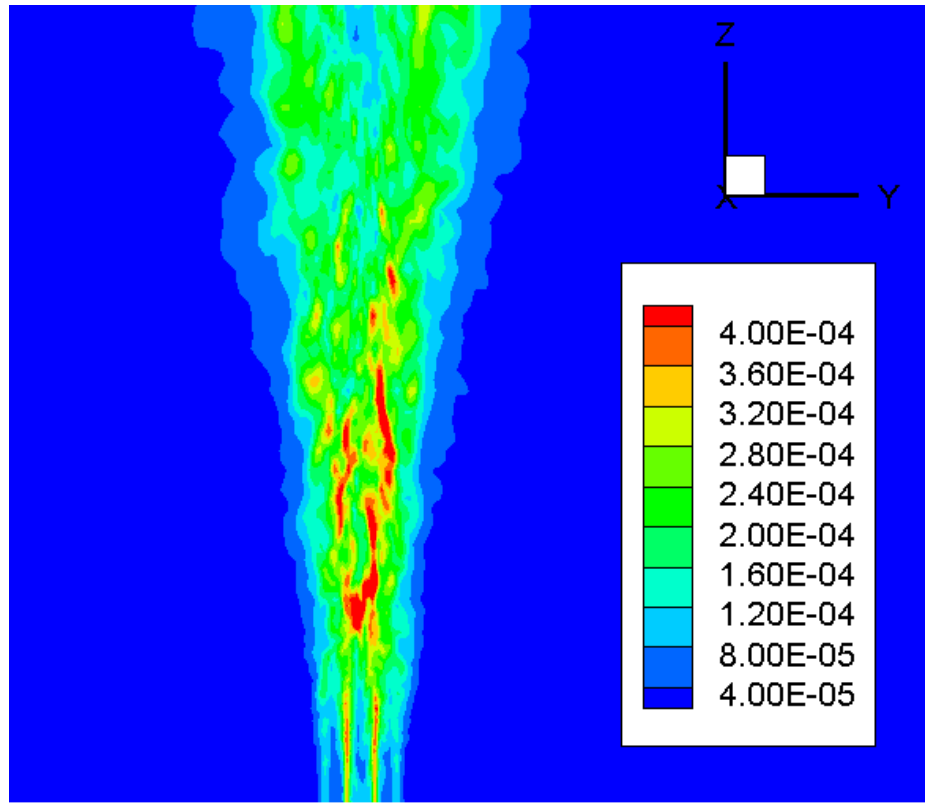

Figura 6.8: Detalhe da distribuição da viscosidade efetiva no plano médio do domínio computacional na região próxima ao bocal de saída do jato principal.

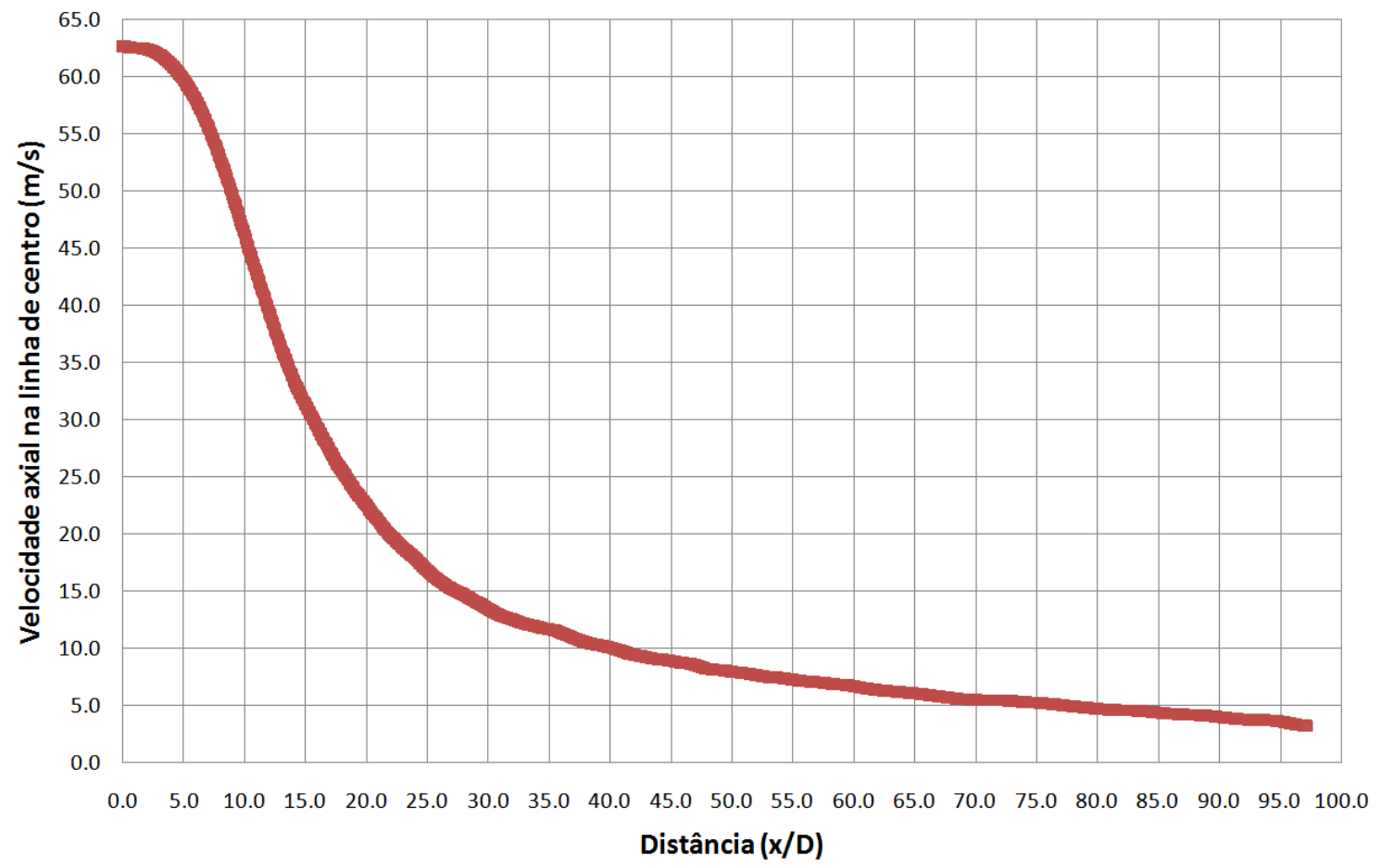

Figura 6.9: Perfil da velocidade axial média na linha de centro do domínio estudado. 


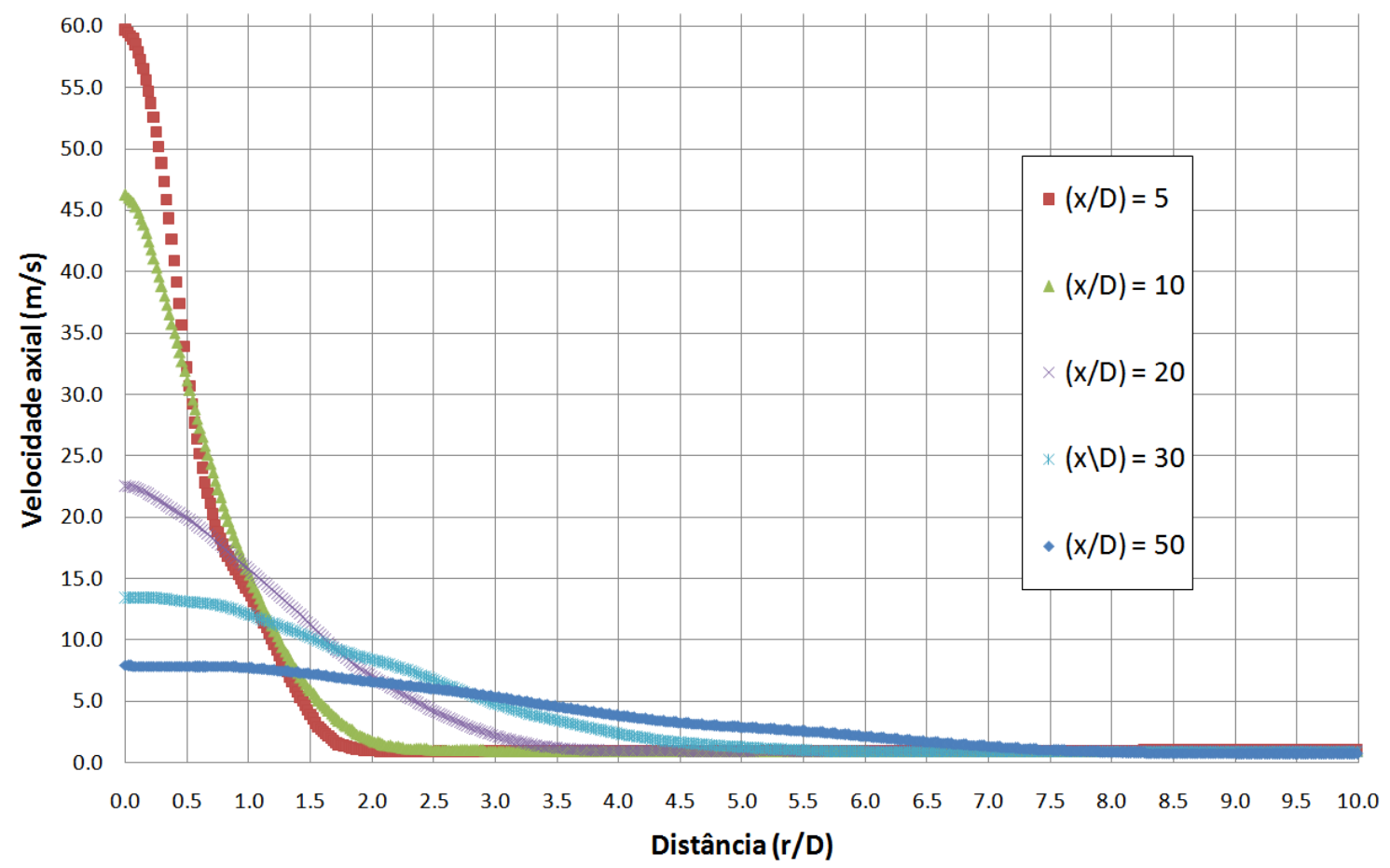

Figura 6.10: Perfis da velocidade axial média ao longo da direção $\mathrm{X}$, nos planos $(x / D)$ iguais a $5,10,20,30$ e 50 .

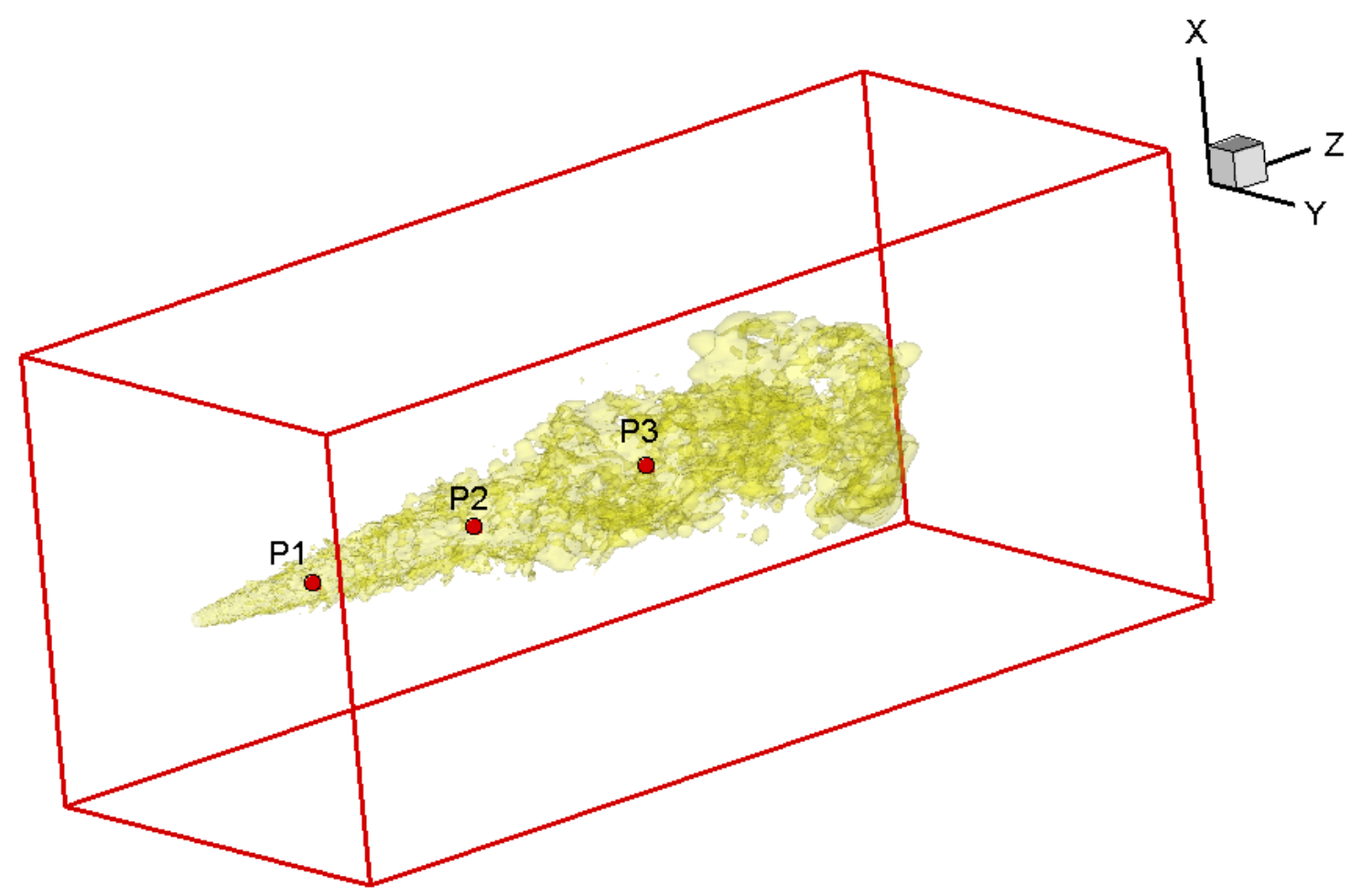

Figura 6.11: Figura ilustrativa com os pontos $P_{1}, P_{2}$ e $P_{3}$ selecionados para a obtenção das estatísticas no cálculo do espectro de energia cinética turbulenta. 


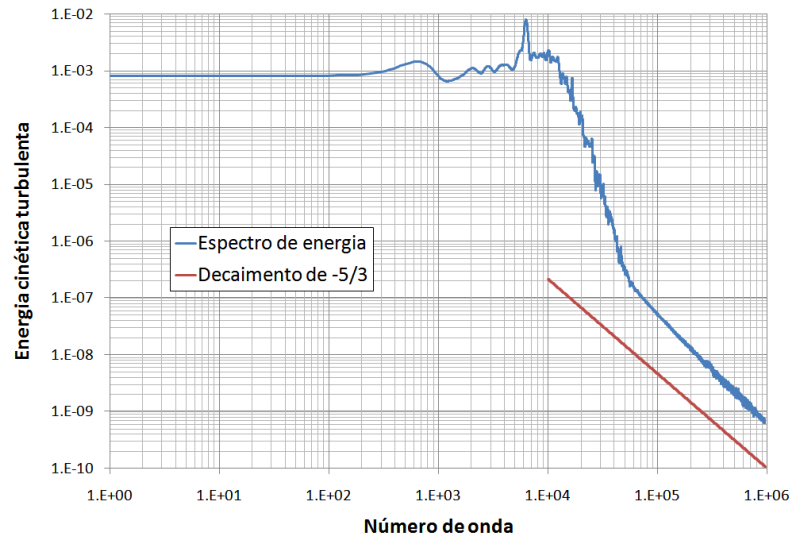

Figura 6.12: Espectro de energia calculado para o ponto $P_{1}$.

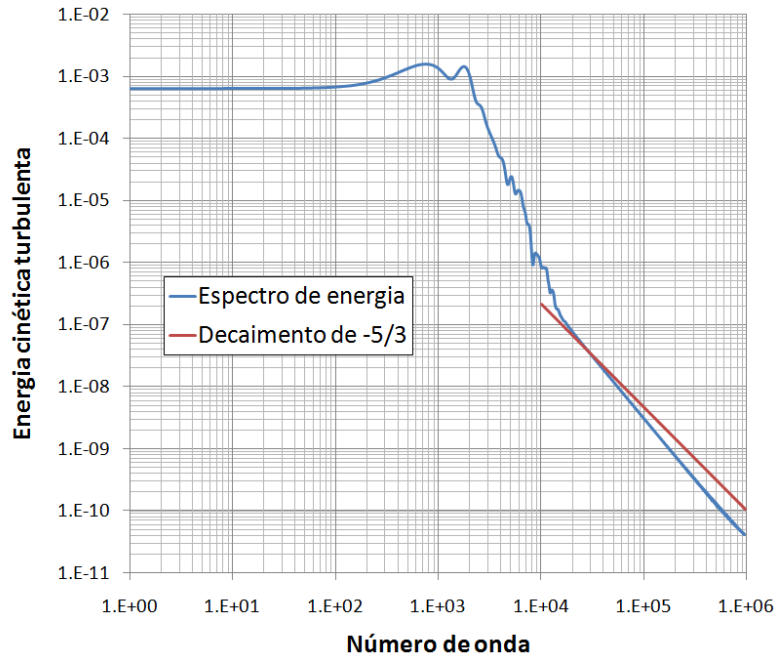

Figura 6.13: Espectro de energia calculado para o ponto $P_{2}$.

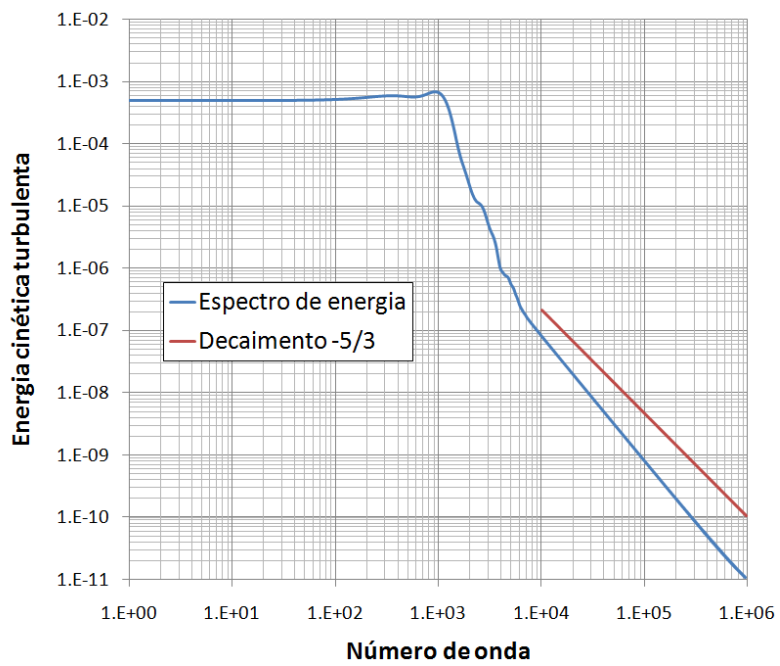

Figura 6.14: Espectro de energia calculado para o ponto $P_{3}$. 


\subsection{Experimento numérico do jato reativo}

Assim como para o jato turbulento isotérmico, foi empregado o método AdamsBashforth-Moulton para o acoplamento pressão/velocidade e utilizado o modelo submalha de Smagorinsky, com constante de Smagorinsky definida em 0,1 e o escoamento foi analisado em regime transiente, com condições iniciais nulas para todas as variáveis analisadas. Para o caso do jato turbulento reativo, os efeitos da combustão sobre a variação da densidade do fluido foram obtidos pela aplicação do modelo "flamesheet", baseado no transporte da fração de mistura.

Para o cálculo do jato turbulento reativo, foram aplicados o mesmo domínio computacional e perfil de velocidades na entrada, utilizados na solução do jato turbulento isotérmico, permitindo direta comparação dos resultados, independente da malha e das condições de contorno empregadas. A única excessão é a definição da condição de contorno de entrada da fração de mistura, a qual, para o escoamento reativo, foi definida como condição de Dirichlet igual a unidade para o bocal do jato principal e nula para o restante da face de entrada. Em todas as outras faces do domínio, foi definida condição de Neumann nulo para esta variável.

\subsubsection{Resultados}

Os resultados analisados para o escoamento do jato turbulento reativo foram obtidos após ser alcançado o regime estatisticamente permanente, em que o jato se encontra com escoamento totalmente desenvolvido.

A figura 6.15 apresenta a distribuição da velocidade axial filtrada e média temporal. A figura 6.16 apresenta os vetores normalizados da velocidade do escoamento na região próxima a saída do jato e na região do jato turbulento totalmente desenvolvido. Igualmente ao jato isotérmico, é possível identificar estruturas turbulentas com diferentes comprimentos de onda espacial.

As figuras 6.17 e 6.18 apresentam, respectivamente, a distribuição da temperatura e da densidade no plano médio do domínio computacional. Já a figura 6.19 apresenta a distribuição da viscosidade turbulenta neste mesmo plano médio. 

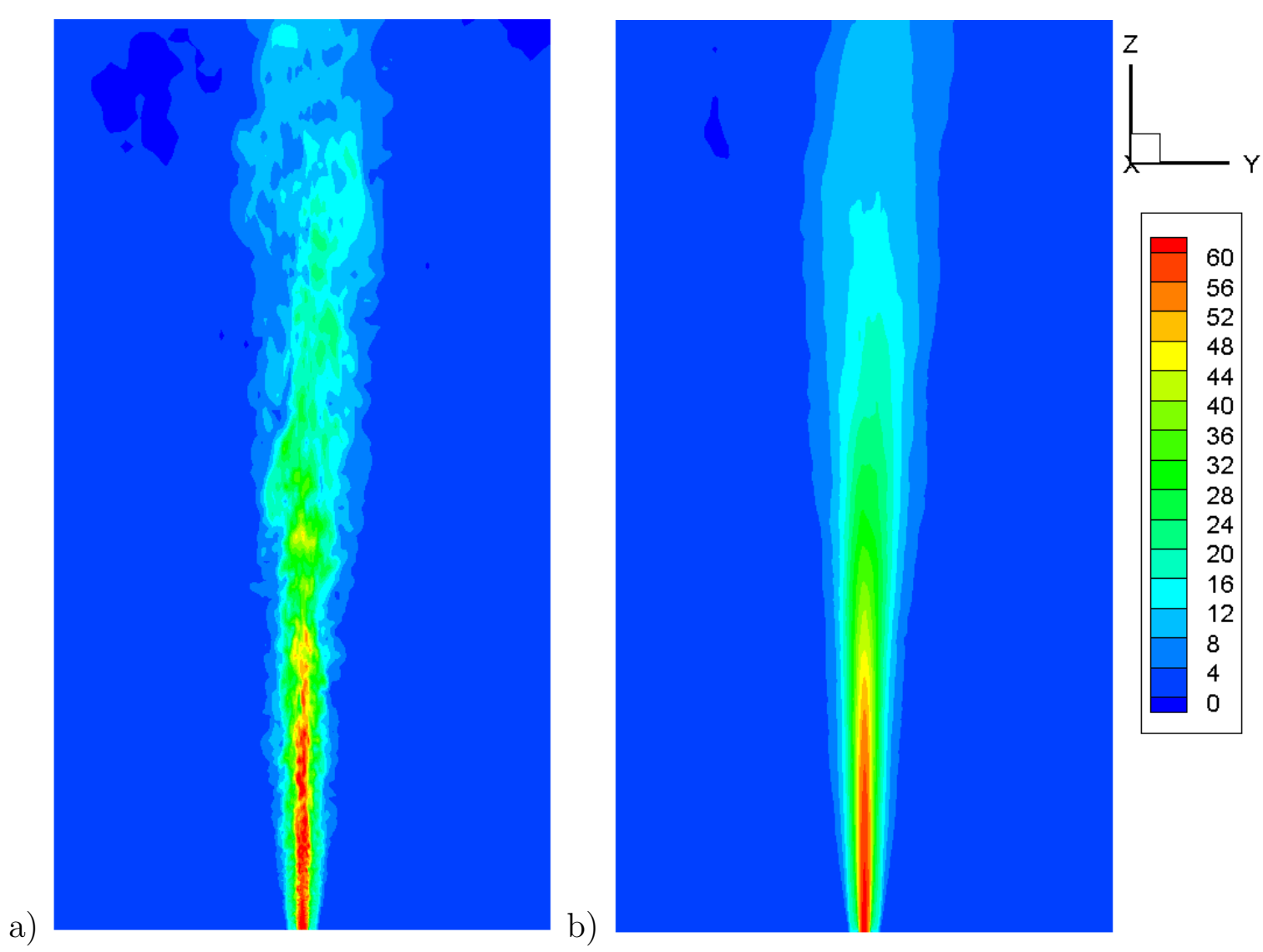

Figura 6.15: Distribuição da velocidade axial filtrada no plano médio do domínio computacional para o jato reativo: a) campo da velocidade filtrada, b) campo da velocidade média temporal.

A figura 6.20 apresenta a comparação entre a velocidade axial média na linha de centro calculada neste trabalho e o experimental obtido por Masri et al. (1996) para o workshop TNF do laboratório SANDIA. Os perfis da temperatura filtrada e da densidade filtrada na linha de centro do domínio computacional são apresentados pelas figuras 6.21 e 6.22 , respectivamente.

As figuras 6.23, 6.24 e 6.25 apresentam o perfil da velocidade axial média, da temperatura filtrada e da densidade filtrada nos planos $(x / D)$ iguais a $5,10,20,30$ e 50 , respectivamente.

As distribuições da fração de mistura filtrada e média temporal no plano médio do domínio computacional são apresentadas pela figura 6.26. A figura 6.27 apresenta o perfil da fração de mistura média nos planos $(x / D)$ iguais a 5, 10, 20, 30 e 50, 

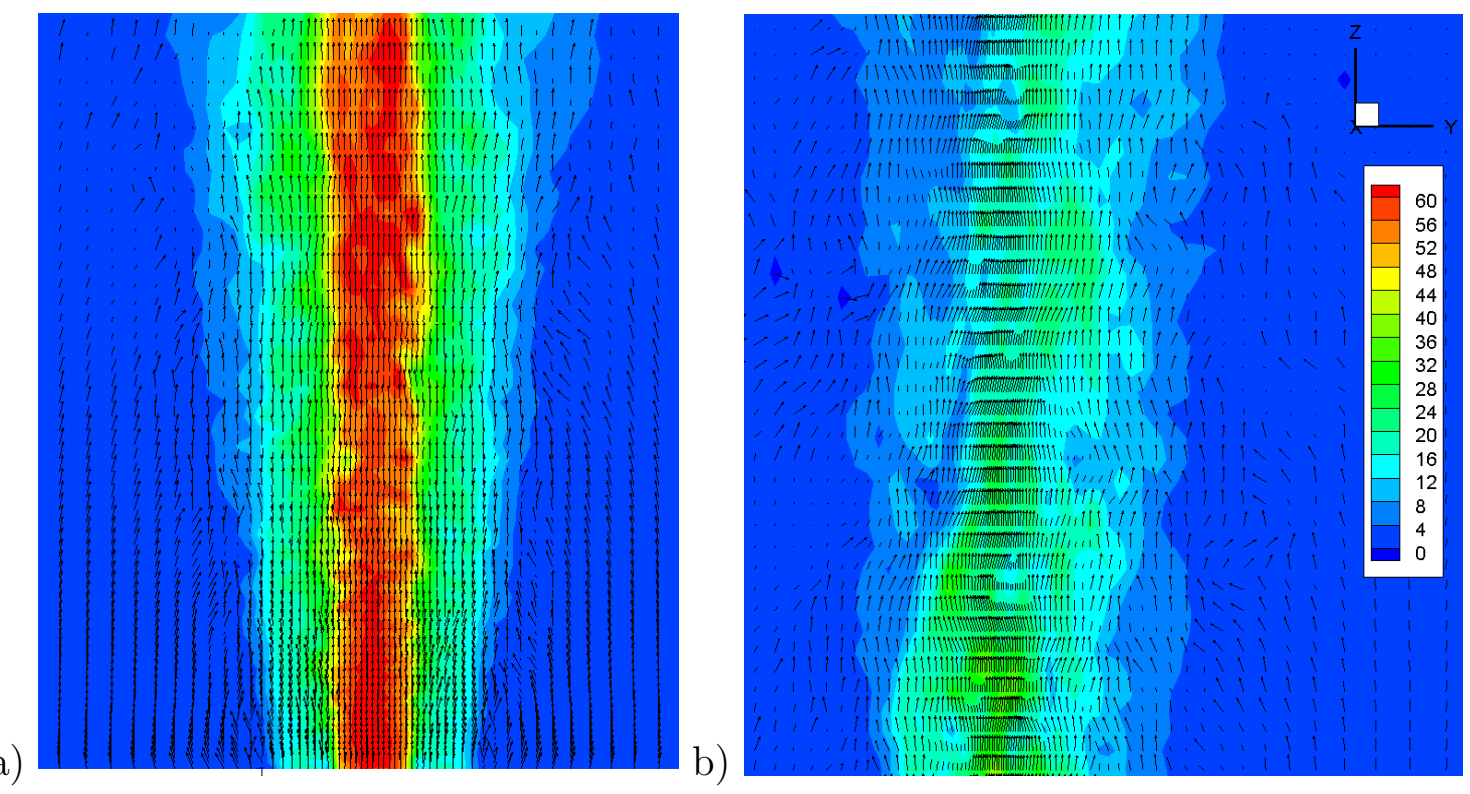

Figura 6.16: Detalhes do campo de velocidades axial do jato reativo: a) próximo ao bocal do jato, b) numa região de esocamento plenamente desenvolvido. Vetores com mesma distribuição de tamanho.

respectivamente. 


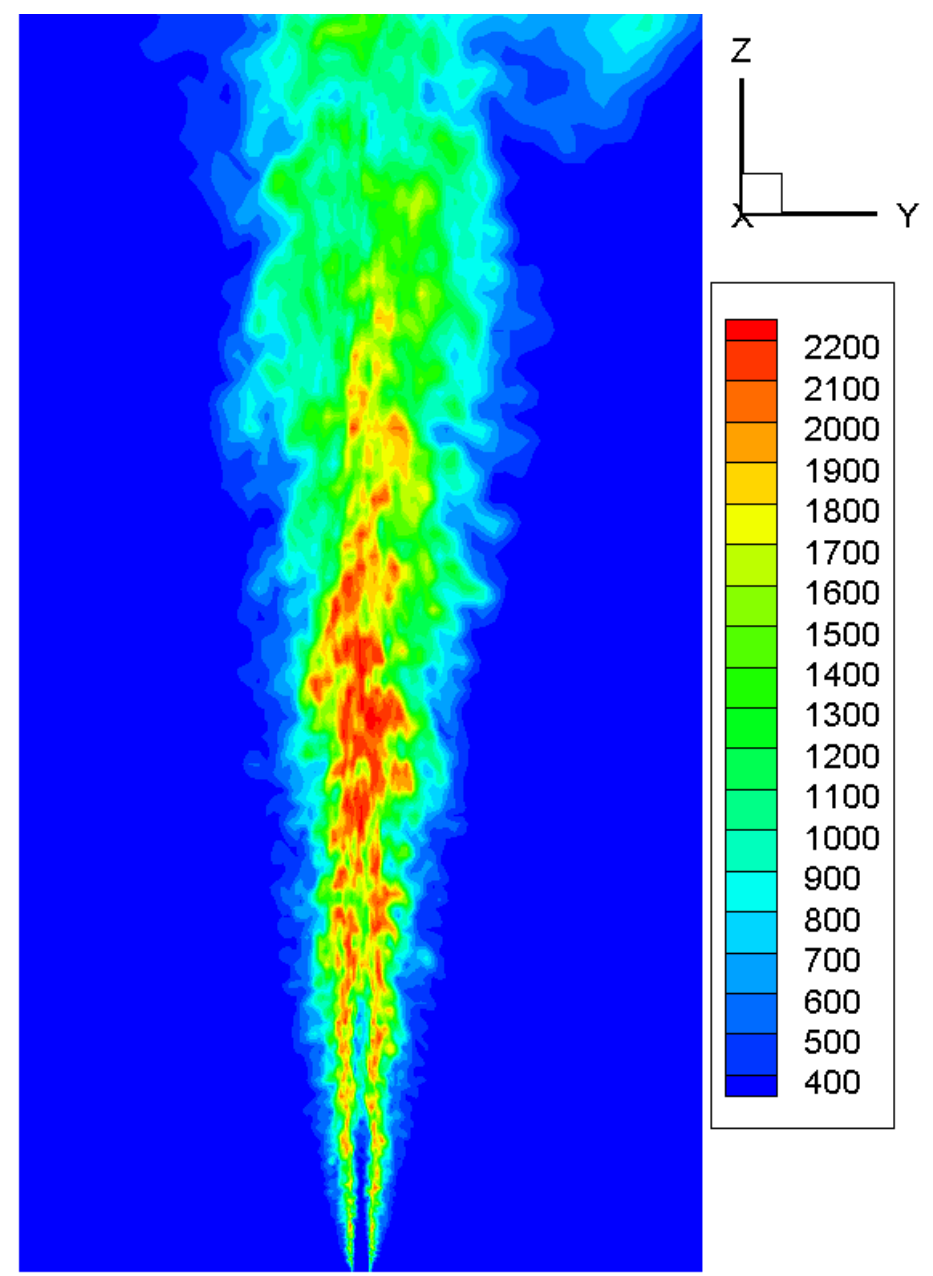

Figura 6.17: Distribuição da temperatura da mistura no plano médio do domínio computacional. 


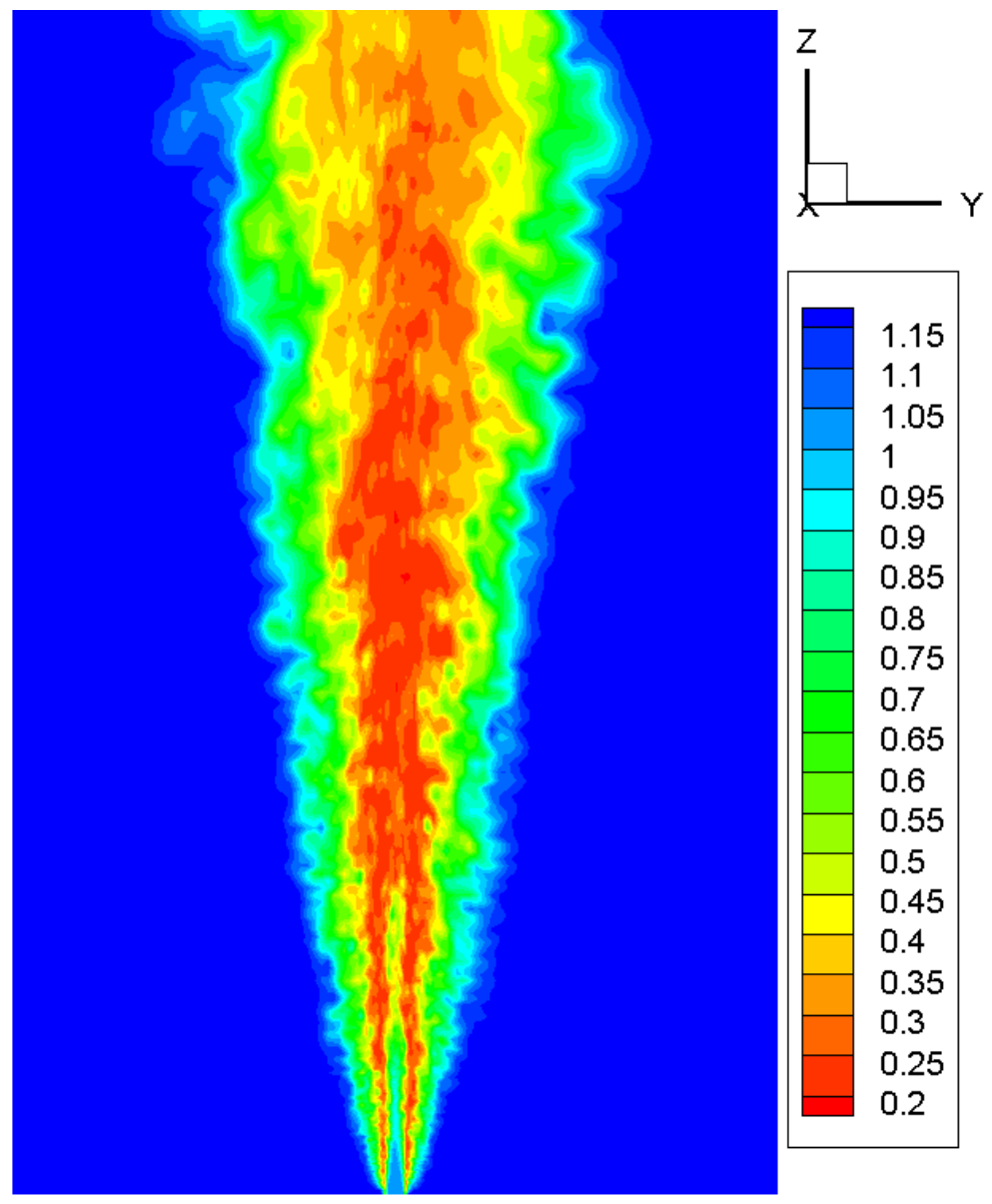

Figura 6.18: Distribuição da densidade da mistura no plano médio do domínio computacional. 

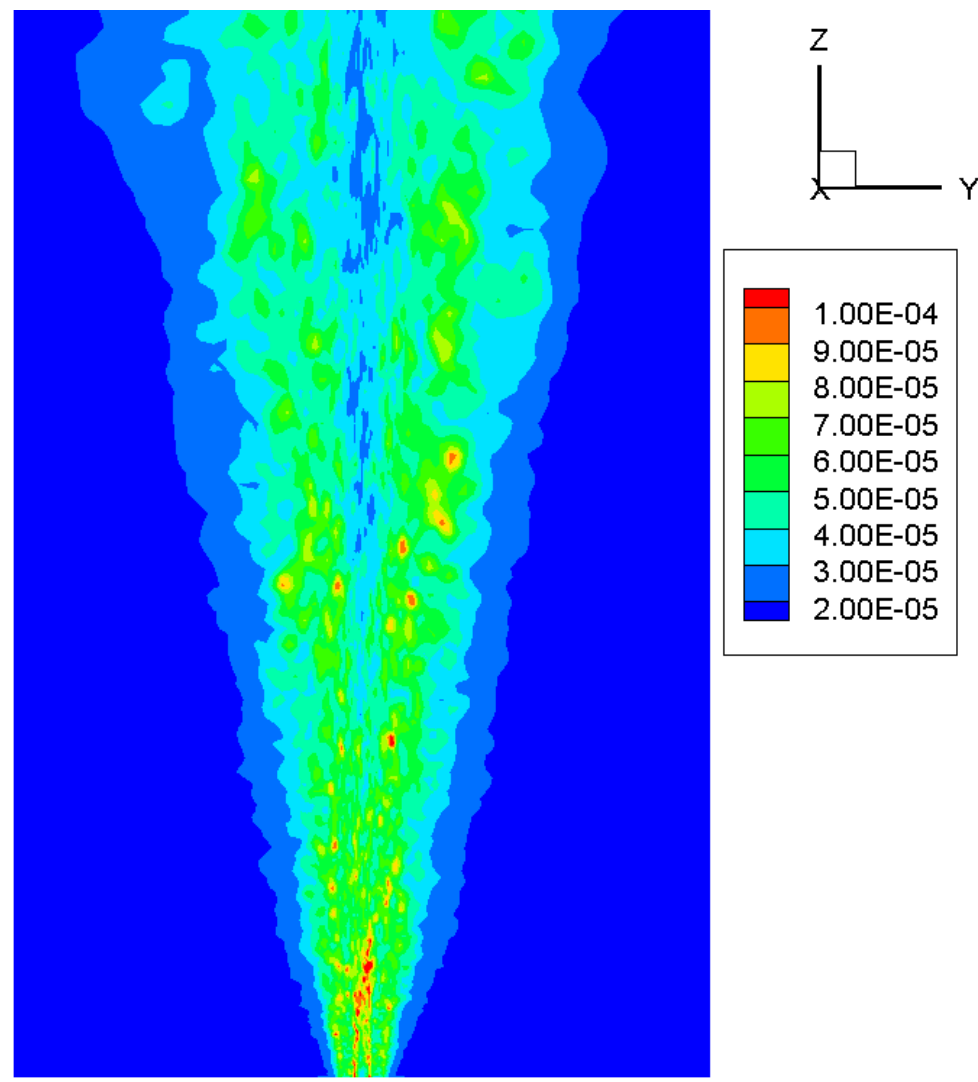

Figura 6.19: Distribuição da viscosidade efetiva (molecular + turbulenta) no plano médio do domínio computacional para o jato reativo.

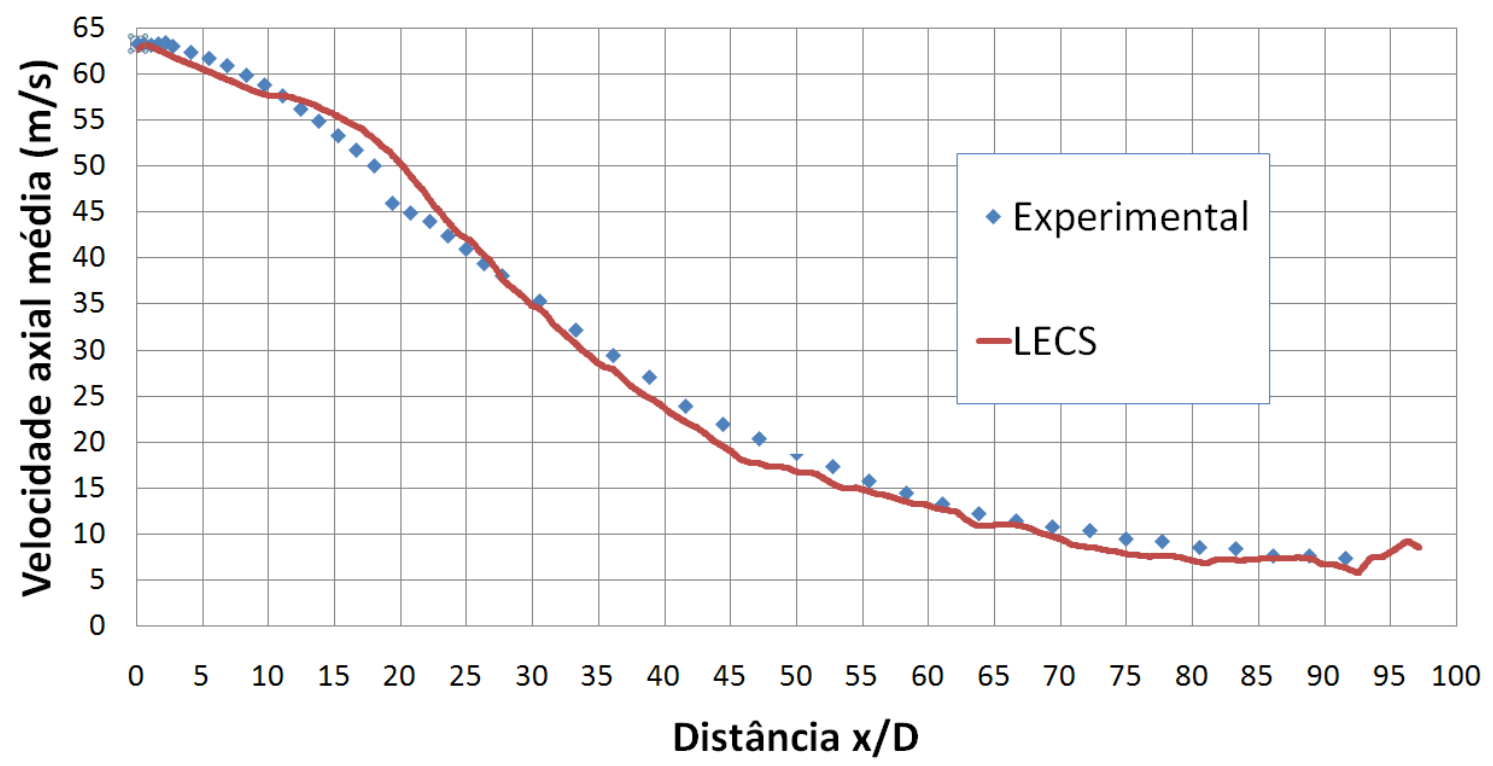

Figura 6.20: Comparação entre a velocidade axial média calculada pelo algorítmo implementado e a obtida experimentalmente por Masri et al. (1996). 


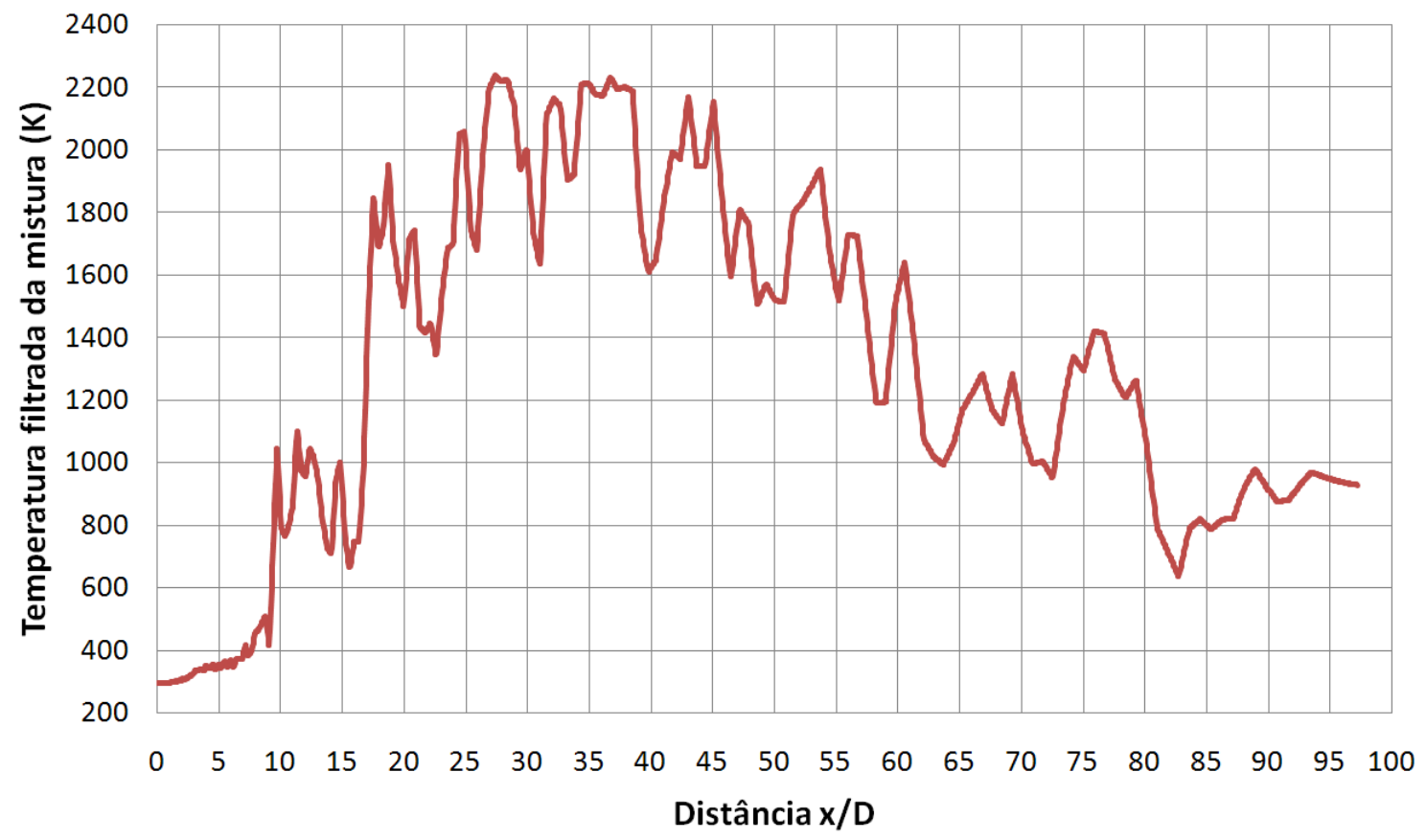

Figura 6.21: Perfil da temperatura filtrada na linha de centro do domínio estudado.

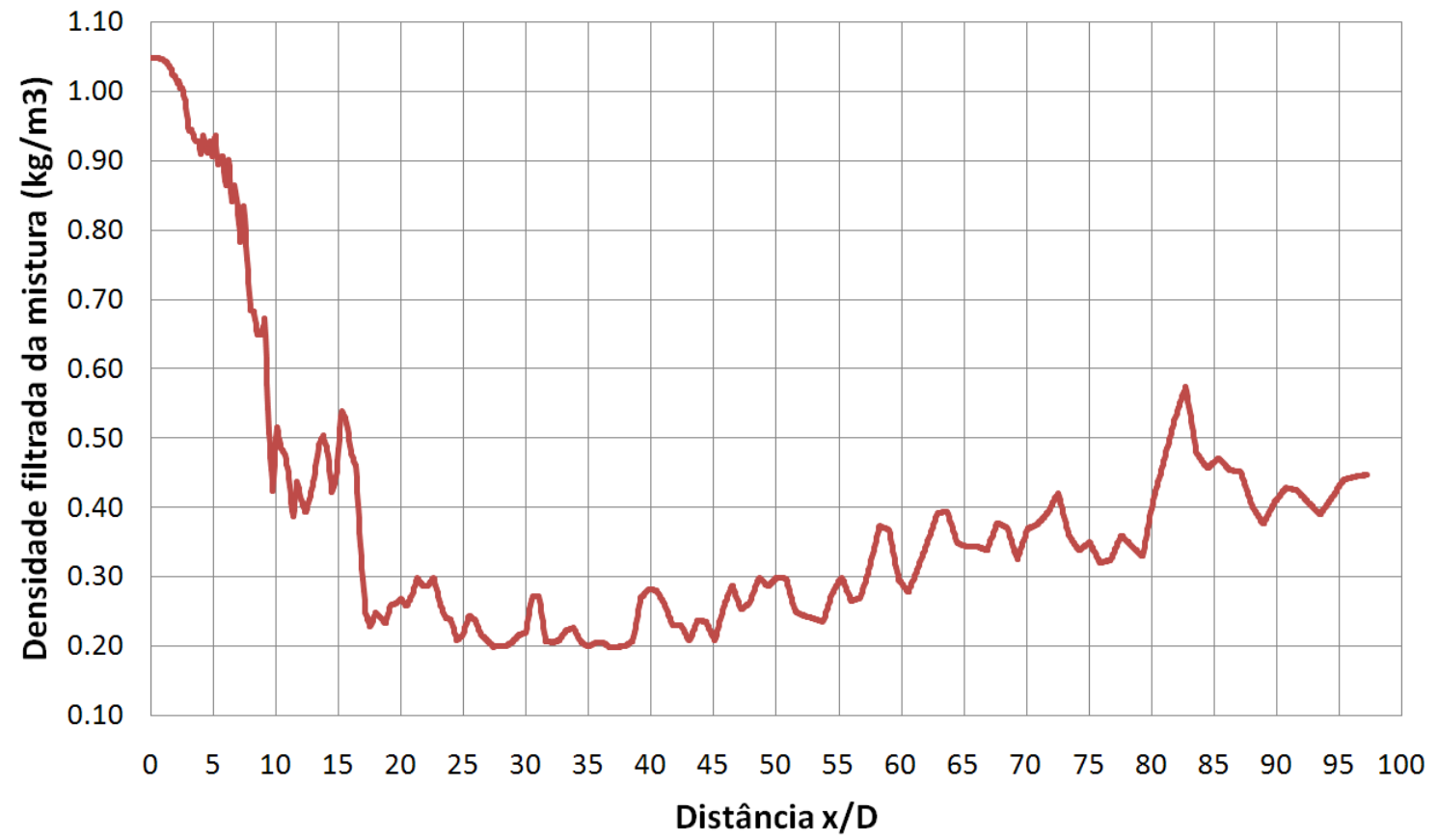

Figura 6.22: Perfil da densidade filtrada na linha de centro do domínio estudado. 


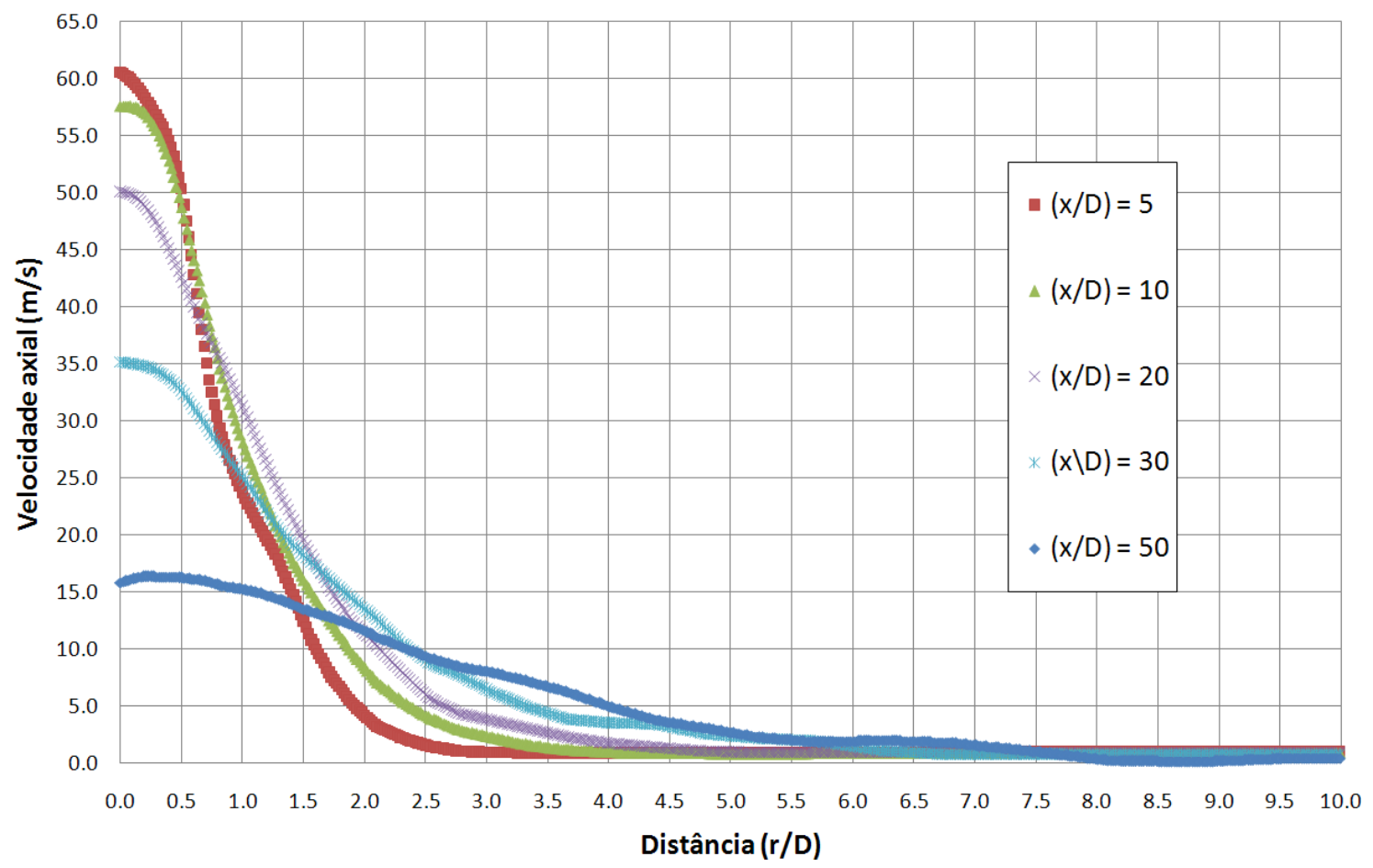

Figura 6.23: Perfis da velocidade axial média ao longo da direção $\mathrm{X}$, nos planos $(x / D)$ iguais a $5,10,20,30$ e 50 .

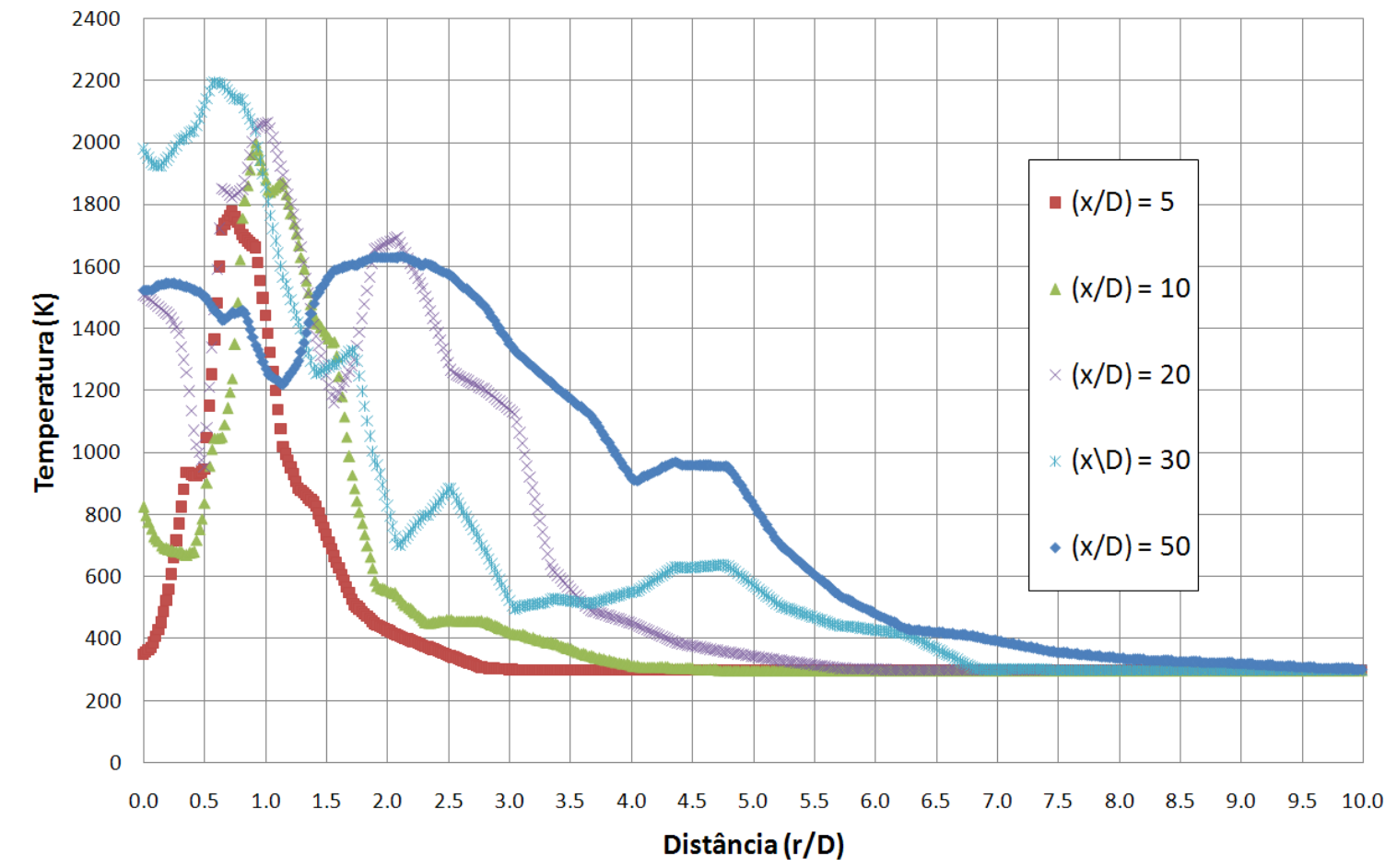

Figura 6.24: Perfis da temperatura filtrada ao longo da direção $\mathrm{X}$, nos planos $(x / D)$ iguais a $5,10,20,30$ e 50. 


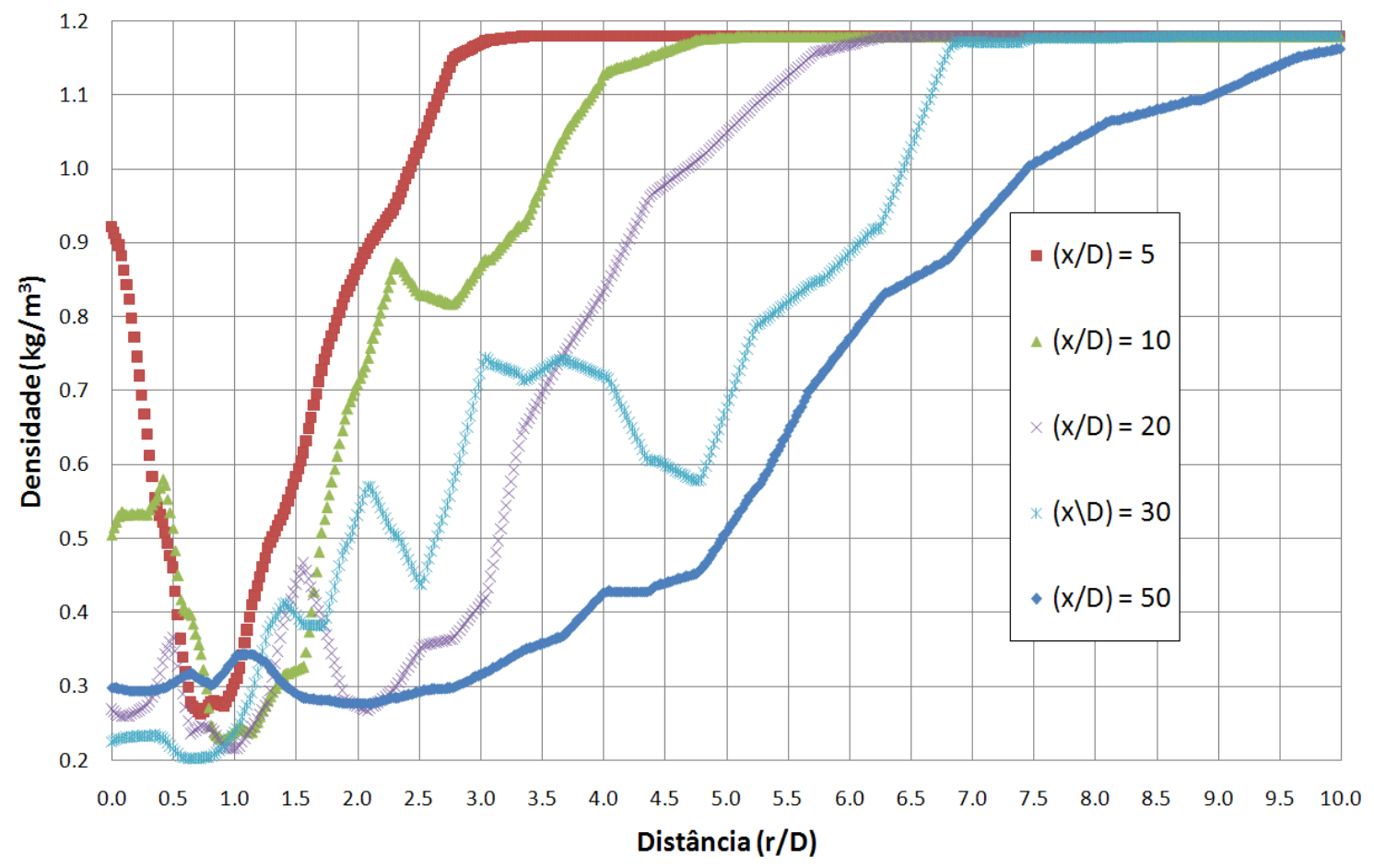

Figura 6.25: Perfis da densidade filtrada ao longo da direção $\mathrm{X}$, nos planos $(x / D)$ iguais a $5,10,20,30$ e 50 .

a)

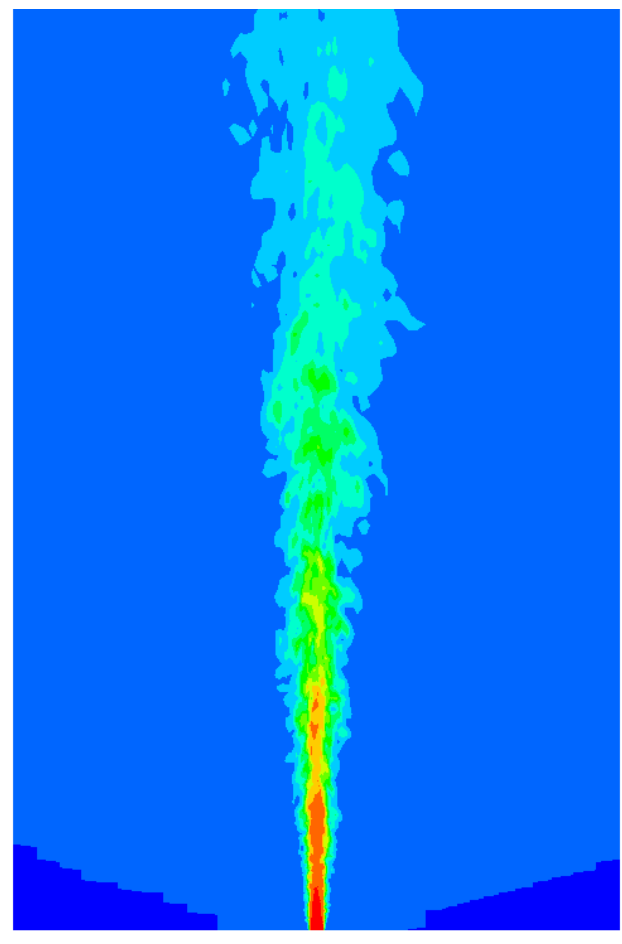

b)

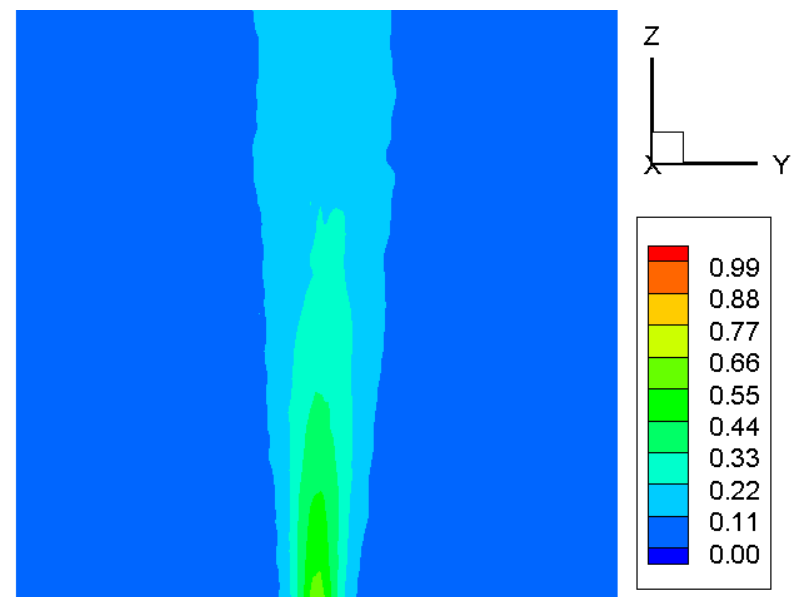

Figura 6.26: Distribuição da fração de mistura no plano médio do domínio computacional: a) fração de mistura filtrada, b) fração de mistura média. 


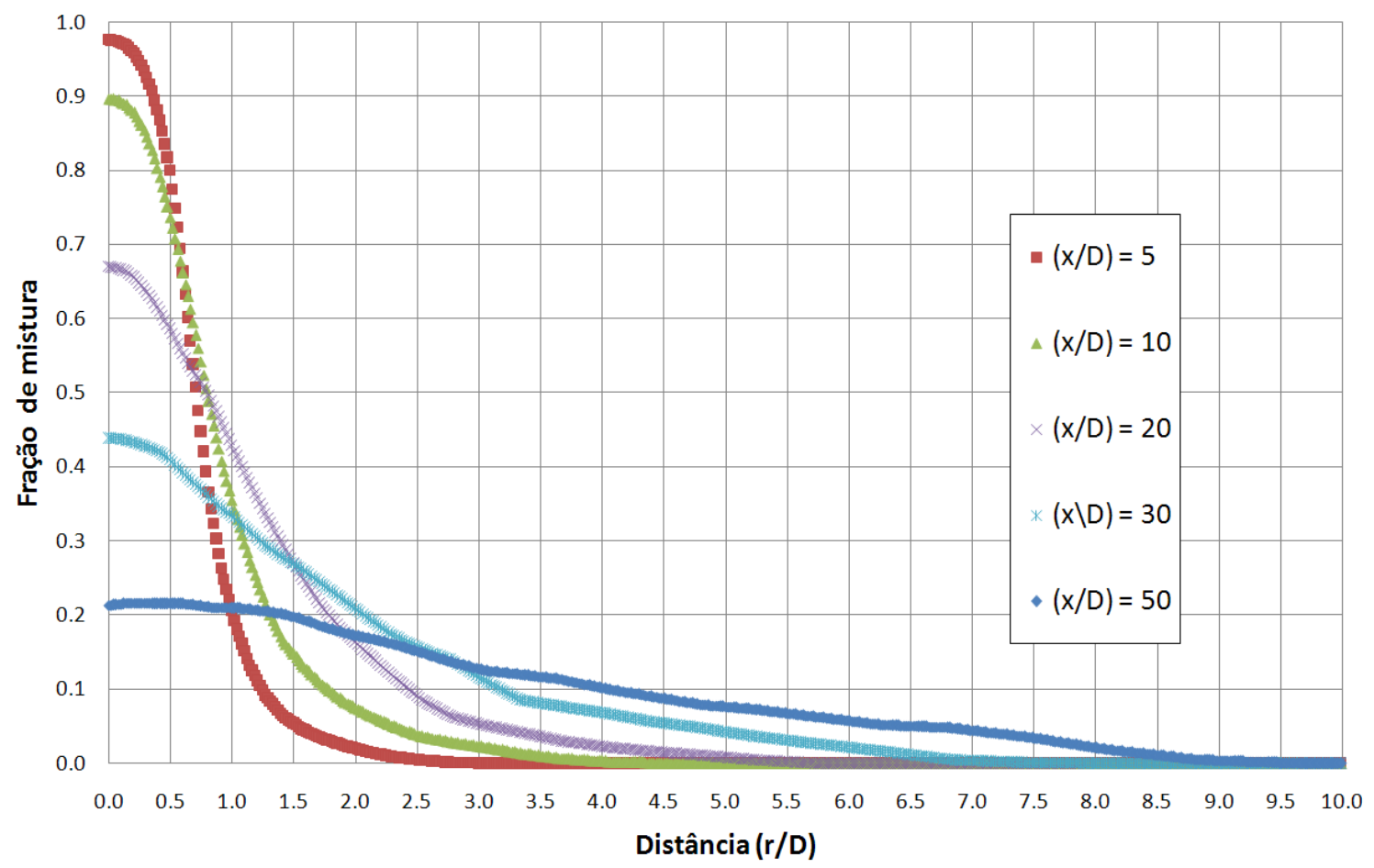

Figura 6.27: Perfis da fração de mistura média ao longo da direção X, nos planos $(x / D)$ iguais a $5,10,20,30$ e 50. 


\subsubsection{Cálculo da cascata de energia}

O cálculo do espectro de energia para o jato turbulento reativo foi realizado para os mesmos pontos do escoamento do jato isotérmico, isto é, nos pontos $P_{1}, P_{2}$ e $P_{3}$, da figura 6.11. As figuras 6.28, 6.29 e 6.30, apresentam os espectros de energia para os pontos $P_{1}, P_{2}$ e $P_{3}$, respectivamente. Novamente, estes espectros de energia cinética turbulenta foram calculados segundo um algorítmo desenvolvido por Volpi (2009).

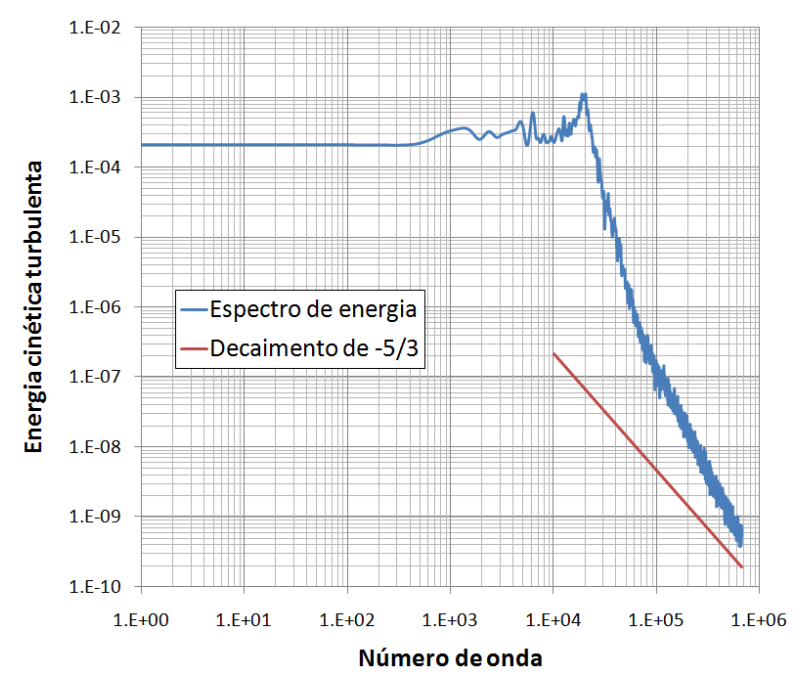

Figura 6.28: Espectro de energia calculado para o ponto $P_{1}$.

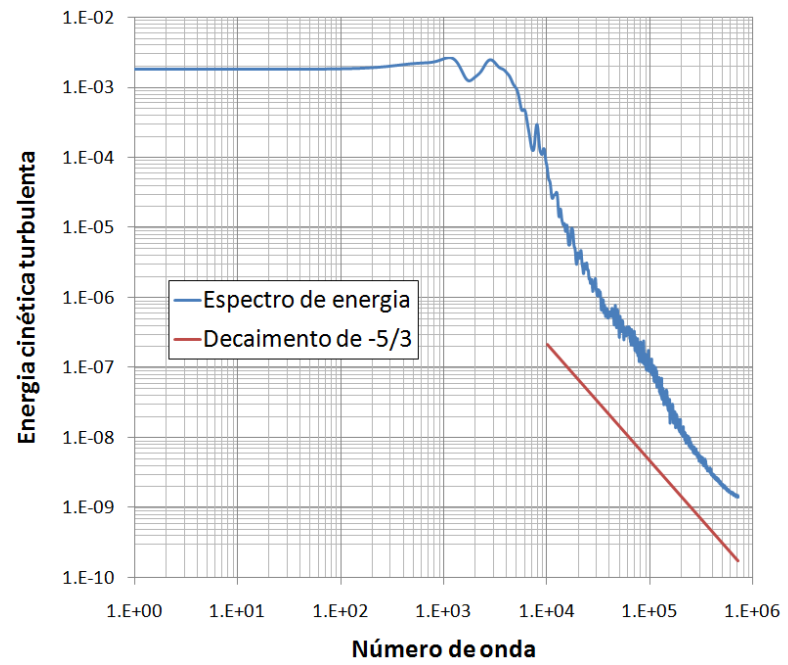

Figura 6.29: Espectro de energia calculado para o ponto $P_{2}$. 


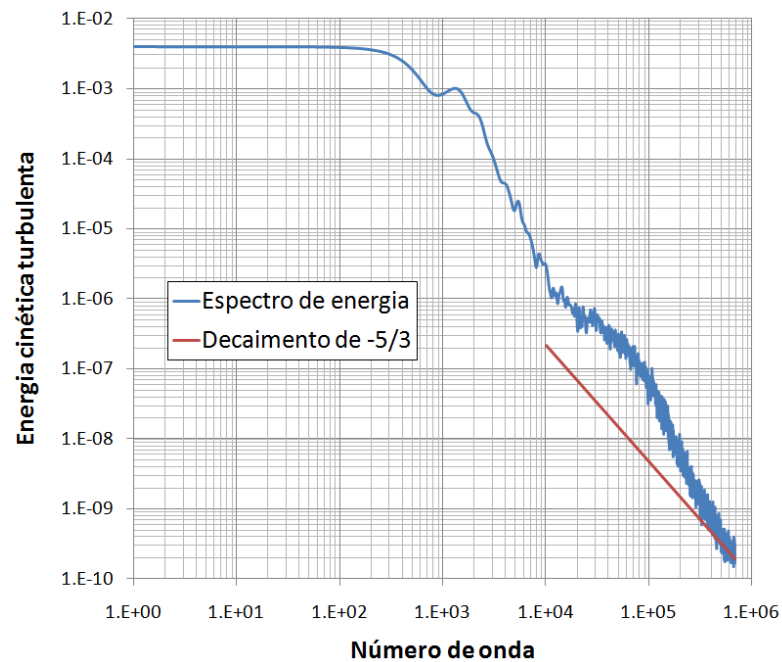

Figura 6.30: Espectro de energia calculado para o ponto $P_{3}$. 


\subsection{Análise do decaimento da velocidade axial na linha de centro}

De acordo com Hussein et al. (1994), para se caracterizar jatos turbulentos isotérmicos, o decaimento da velocidade axial na linha de centro ocorre de acordo com a equação (6.1). Nesta equação, $\left(B_{u}\right)$ e $\left(x_{0}\right)$ valem 5,8 e 4,0, respectivamente. A figura 6.31 apresenta a comparação entre o decaimento da velociade axial na linha de centro para os jatos turbulentos isotérmico e reativo calculados pelo código implementado neste trabalho e o decaimento segundo determinado por Hussein et al. (1994).

$$
\frac{U_{0}}{U_{c l}}=\frac{1}{B_{u}}\left(\frac{x}{D}-\frac{x_{0}}{D}\right)
$$

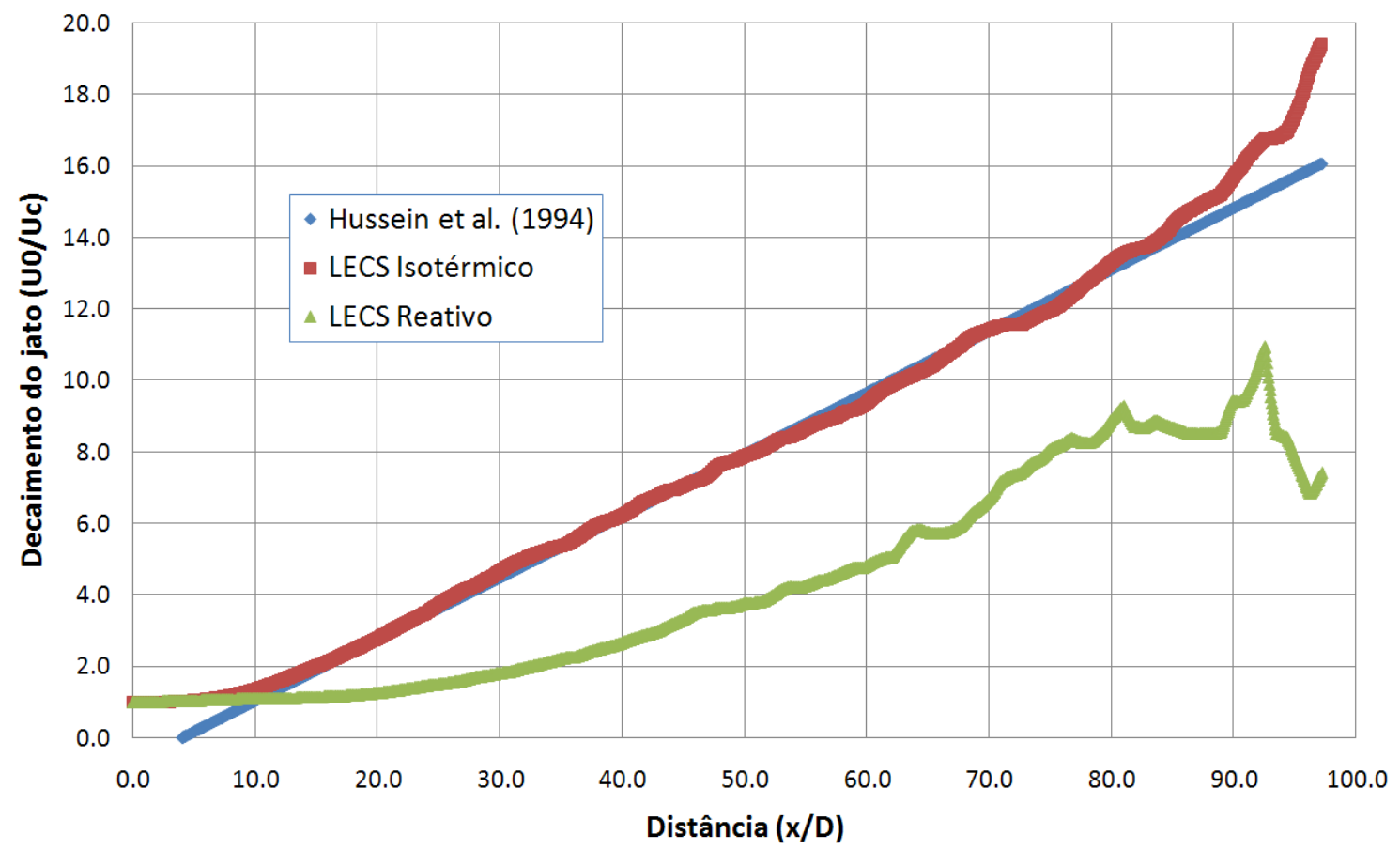

Figura 6.31: Comparação do decaimento da velocidade na linha de centro dos jatos turbulentos isotérmico e reativo com o proposto por Hussein et al. (1994). 
Capítulo 7

Conclusões 
Neste trabalho foram implementados modelos matemáticos para a solução das equações que descrevem o escoamento de um jato turbulento reativo, buscando melhorar a compreenção dos efeitos da combustão e turbulência sobre a solução numérica de chamas de difusão. Para tanto, foi desenvolvido e implementado um algorítmo numérico chamado "Large Eddy Combustion Simulator" ou LECS.

Com o uso das soluções manufaturadas para a verificação do código implementado, foi possível garantir o decaimento de $2^{a}$ ordem para o erro em todas as equações resolvidas, tanto para a discretização espacial quanto para a temporal.

A validação pelos métodos de engenharia, garantiu que os modelos matemáticos foram corretamente implementados, de modo a se obter resultados físicos nestes escoamentos e com boas correlações quando comparados aos resultados consagrados na literatura.

Nos escoamentos dos jatos turbulentos isotérmico e reativo, foram possíveis de se identificar diversas escalas do movimento turbulento sendo transportadas pelo escoamento. Logo, verifica-se que a metodologia LES foi implementada adequadamente.

A comparação entre a velocidade axial média na linha de centro do domínio computacional e os dados experimentais obtidos por Masri et al. (1996) apresentou boa correlação, o que valida os modelos de turbulência e combustão utilizados.

O espectro de energia, calculado nos pontos $P_{1}$ do escoamento isotérmico e $P_{2}$ do escoamento reativo, apresentam claramente a região de transporte inercial de energia, indicando que o incremento de tempo utilizado nas integrações numéricas foi suficiente para a solução das grandes escalas turbulentas destes escoamentos, validando, assim, o uso do modelo submalha de Smagorinsky para estes casos.

Os pontos $P_{2}$ e $P_{3}$ do escoamento isotérmico e $P_{1}$ e $P_{3}$ do escoamento reativo, apresentaram a tendência de formação da região de transporte inercial de energia. Para os pontos $P_{3}$ de ambos os escoamentos e o ponto $P_{2}$ do escoamento isotérmico, a região de transporte inercial não foi completamente desenvolvida devido ao tempo de simulação utilizado ser restrito, ou seja, apesar do escoamento médio se apresentar em regime estatisticamente permanente, o escoamento não se apresentava completamente desenvolvido nestes pontos. 
Para o ponto $P_{1}$ do escoamento reativo, devido a grande influência dos efeitos de combustão nesta região, o escoamento apresenta grandes gradientes de densidade, o que implica em variações no campo de velocidades. Esta região do escoamento pode não garantir as hipóteses adotadas, porém sua influência é localizada e não afetou o escoamento global.

Na comparação do decaimento da velocidade axial dos jatos turbulentos reativo e isotérmico com o decaimento proposto por Hussein et al. (1994), foi verificada boa correlação apenas para o jato isotérmico, pois quando se considerou os efeitos do processo de combustão sobre o escoamento deste jato, a curva de decaimento sofreu mudanças significativas.

Para o jato reativo, nota-se um decaimento, da velocidade axial na linha de centro, inferior ao jato isotérmico, devido aos gradientes de densidade gerados pelo modelo de combustão. Esse comportamento é esperado, pois, segundo Rauwoens et al. (2009), um gradiente negativo da densidade implica, geralmente, em uma aceleração do fluido, diminuindo seu decaimento. É possível verificar, também, que a magnitude da viscosidade efetiva em determinadas regiões para o escoamento reativo é inferior a do escoamento isotérmico, indicando um menor consumo de energia devido a dissipação turbulenta.

Por fim, apesar da aplicação do modelo simplificado para a inclusão dos efeitos de combustão na análise da chama $\mathrm{D}$, foco deste trabalho, foram alcançados bons resultados para os campos de velocidades e de fração de mistura, quando comparados com os dados experimentais. 
Capítulo 8

\section{Bibliografia}


Araújo, H.F.S., (2006) Modelagem de uma chama de difusão utilizando-se a técnica de simulação de grandes estruturas turbulentas, Dissertação apresentada à Escola Politécnica da Universidade de São Paulo.

Armênio, V. e Sarkar, S., (2002) An Investigation of Stably Stratified Turbulent Channel Flow Using Large-Eddy Simulation, Journal of Fluid Mechanics, 459, 1-42.

Barlow, R. S., and Frank, J. H., (1998) Proc. Comb. Inst. 27:1087 .

Barlow, R. S., and Frank, J. H., (2007) Piloted CH4/Air Flames C, D, E, and F, documentação descritiva, SANDIA National Laboratories, Release 2.1.

Bilger, R.W. (1980) Turbulent Flows with Non-premixed Reactants, in P.A Libby e F.A Williams (eds) Turbulent Reacting Flows, Topics in Applied Physics, Springer-Verlag, Berlim, Alemanha.

Boersma, B.J., Brethouwer, G., Nieuwstadt, F.T.M. (1998) A numerical investigation on the effect of the inflow conditions on the self-similar region of a round jet, Physics of Fluids, 10, 4

Branley, N. e Jones, W.P. (2001) Large Eddy Simulation of a Turbulent Non-Premixed Flame, Combustion and Flame, 127, 1914-1934.

Butcher, J.C., (2003) Numerical methods for ordinary differential equations, Ed. J. Wiley, EUA.

Choi, H. e Moin, P., (1993) Effects of the Computational Time Step on Numerical Solutions of Turbulent Flow, Journal of Computation Physics, 113, 1-4.

Cook, A.W., Riley, J.J. e Kosály, G., (1997) A Laminar Flamelet Approach to Subgrid-Scale Chemistry in Turbulent Flows. Combustion and Flame, 109, 332-341.

Courant, R., Friedrichs, K. e Lewy, H. (1967) On the partial difference equations of mathematical physics. IBM journal, traduzido do texto original de 1928.

Dimotakis, P.E., Lye, R.C. e Papantoniou, D.Z. (1981) Proc. XV Int. Syp. Fluid Dyn., Jachranka, Poland. 
Volpi, E. V. (2009) Comunicação interna para desenvolvimento de um algorítmo de cálculo de espectros de energia cinética turublenta segundo o apresentado por Pope (2000).

Evans, M., Hastings, N. e Peacock, B. (2000) Statistical Distributions, tercira edição, editora John Wiley \& Sons, Nova York, EUA.

Ferziger, J.H. e Peric, M. (2002) Computational Methods for Fluid Dynamics, Ed. Springer-Verlag, New York, EUA.

Germano, M., Piomelli, U., Moin, P. e Cabot, W.H., (1991) A Dynamic Subgrid-Scale Eddy Viscosity Model, Physics of Fluids A, vol 3, 1760-1765.

Ghia, U., Ghia, K.N., Shin, C.T., (1982) High-Re solutions for incomplessible flow using the Navier-Stokes equations and the Multigrid method, Journal of Computational Physics, 48, 387-411.

Griffiths, J.F., Barnard, J.A., (1995) Flame and combustion, Ed. Blackie Academic and Professional, Grã-Bretanha.

Hairer, E., Nørsett, S.P., Wanner, G. (1993) Solving ordinary differential equations I: Nonstiff problems (2nd ed.), Ed. Springer Verlag, Berlim, Alemanha.

Harten, A., (1983) High resolution schemes for hyperbolic conservation laws. Journal of Computational Physics, 49, 357-393.

He, G.W., Wang, M. e Lele, S. K., (2002) Evaluation of Subgrid-Scale models in Terms of Time Correlations, Center for Turbulence Research.

Hoffmann, K.A. e Chiang, S.T. (2000) Computational Fluid Dynamics, $3^{\circ}$ volume, $4^{\circ}$ edição, Engineering Education System, Wichita, EUA.

Hussein, H.J., Capp, S.P., George, W.K., (1994) Velocity measurements in a high-Reynolds-number, momentum-conserving, axisymmetric, turbulent jet, Journal of Fluid Mechanics, 258, 31-75.

Ilyushin, B.B. e Krasinsky, D.V., (2006) Large eddy simulation of dynamics of the turbulent round jet with imposed inlet fluctuations, Selected Papers of Inter. Conf. "Fluxes and Structures in Fluid 2005", Yu.D.Chashechkin, and V.G.Baydulov Edt., Moscow. 
Kaufmann, A., Nicoud, F. e Poinsot, T., (2002) Flow Forcing Techniques for Numerical Simulation of Combustion Instabilities, Combustion and Flame, $131,371-385$.

Kempf, A., Lindstedt, R.P. e Janicka, J. (2005) Large Eddy Simulation of a Bluff-Body Stabilized Non-Premixed Flame, Combustion and Flame, 144, 170-189.

Kim, J., Moin, P. (1985) Application of a Fractional-Step Method to Incompressible Navier-Stokes Equations, Journal of Computational Physics, 59, 308-323.

Lilly, D.K., (1991) A Proposed Modification to the Germano Subgrid -Scale Closure Method, Physics of Fluids A, vol 4, 633-635.

Lund, T.S., (2003) The Use of Explicit Filters in Large Eddy Simulation, Journal of Computers \& Mathematics with Applications, vol 46, issue 4, 603-616.

Magnussen, B.F., Hjertager, H., (1976) On Mathematical Modeling of Turbulent Combustion with Special Emphasis on Soot Formation and Combustion, 16th Symp. (Int.) on Combustion, The Combustion Institute, Pittsburgh, 719-729.

Magel, H.C., Schnell, U. and Hein, K.R.G., (1996) Simulation of Detailed Chemistry in a Turbulent Combustor Flow, 26th Symp. (Int.) on Combustion, The Combustion Institute, Pittsburgh, 67-74.

Maliska, C.R., (2004) Transferência de calor e mecânica dos fluidos computacional, segunda edição, Ed. LTC S.A., Rio de Janeiro, Brasil.

Maré, F., Jones, W.P. e Menzies, K.R., (2004) Large Eddy Simulation of a Model Gas Turbine Combustor, Combustion and Flame, 137, 278-294.

Masri, A. R., Dibble, R. W., and Barlow, R. S., (1996) Prog. Energy Combust. Sci. 22:307-362

Moeng, C.H., (1984) A Large-Eddy Simulation Model for the Study of Planetary Boundary-Layer turbulence. Journal of Atmospheric Sciences, 41, 20522062 .

Munson, B.R., Young, D.F., Okiishi, T.H., (2003) Fundamentos da mecânica dos fluidos, traduzido por E. J. Zerbini, Ed. Edgard Blücher, São Paulo, Brasil. 
Mustata, R., Valiño, L., Jiménez, C., Jones, W.P., Bondi, S., (2005) A Probability Density Function Eulerian Monte Carlo Field Method for Large Eddy Simulations: Application to a Turbulent Piloted Methane/Air Diffusion Flame (Sandia D), Combustion and Flame, 145, 88-104.

Pfuderer, D.G., Neuber, A.A., Früchtel, G., Hassel, E.P. e Janicka, J. (1996) Turbulence Modulation in Jet Diffusion Flames: Modeling and Experiments, Combustion and Flame, 106, 301-317.

Pitsch, H., Steiner, H. (2000) Large-eddy simulation of a turbulent piloted methane-air diffusion flame (Sandia flame D), Physics of Fluids, 12, 10.

Pope, S.B. (2000) Turbulent Flows. Cambridge University Press, Cambridge, New York, EUA.

Rauwoens, P., Vierendeels, J., Dick, E., Merci, B. (2009) A conservative pressure-correction scheme for transient simulations of reacting flows, Journal of Computational and Applied Mathematics, article in press.

Roache, P.J. (2002) Code verification by the method of manufactured solutions, Transactions of the ASME, 124, 4-10.

Roy, C.J., Nelson, C.C., Smith, T.M., Ober, C.C. (2004) Verification of Euler/Navier-Stokes codes using the method of manufactured solutions. International Journal for Numerical Methods in Fluids, 44, 599-620.

SANDIA, Laboratório nos Estados Unidos da América. (2009) International Workshop on measurement and computation of turbulent nonpremixed flames. http://www.sandia.gov/TNF

Smagorinsky, J., (1963) General Circulation Experiments with the Primitive Equations. Monthly Weather Review, 91, 99-164.

Solokov, I.V., Powell, K.G., Gombosi, T.I. e Roussev, I.I., (2006) A TVD Principle and Conservative TVD Schemes for Adaptive Cartesian Grids, Journal of Computational Physics, 220, 1-5.

Tennekes, H., Lumley, J.L., (1972) A First Course in Turbulence, MIT Press, Massachusetts, EUA. 
Turns, S.R. (2000) Introduction to combustion: concepts and application. Segunda edição, WCB/McGraw-Hill, Boston, EUA.

Versteeg, H.K., Malalasekera, W., (2007) An introduction to computational fluid dynamics: The finite volume method, Addison Wesley Longman Ltd., Reino Unido. 


\section{Apêndice A}

\section{Método dos volumes finitos}

O método dos volumes finitos consiste na discretização da geometria estudada em células menores de forma a realizar a integração das equações de Navier-Stokes em cada célula e, assim, obter um sistema algébrico de equações discretas no espaço e no tempo.

As quantidades que governam o escoamento podem ser modeladas por uma equação de transporte genérica, dada pela equação A.1. Cada célula é tomada como um volume de controle de modo a satisfazer a conservação das quantidades vetoriais e escalares.

$$
\frac{\partial}{\partial t}(\rho \phi)+\nabla(\rho \boldsymbol{u} \phi)=\nabla(\Gamma \nabla \phi)+S_{\phi}
$$

O conjunto de volumes que representa a geometria original é chamado de domínio computacional ou malha numérica. Usualmente, para geometrias simples, utilizam-se volumes de tamanhos homogêneos e ordenados no espaço, como apresenta a figura A.1. Essas malhas são conhecidas por malhas estruturadas. Outros tipos de malhas podem ser criados de forma a manter algumas propriedades das malhas estruturadas, como, por exemplo, malhas refinadas representadas pela figura A.2. Tais malhas são utilizadas em casos específicos para a melhorar a precisão dos cálculos. Cada volume é definido como um paralelepípedo ortogonal como apresentado pela figura A.3.

De acordo com Maliska (2004), para facilidade de implementação em geometrias complexas e genéricas, todas as variáveis calculadas são armazenadas no centro 


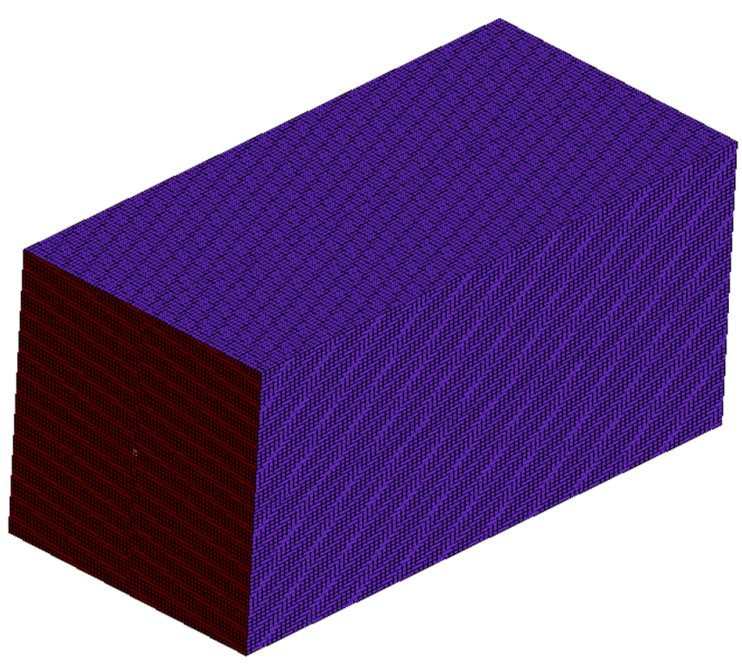

Figura A.1: Exemplo de discretização espacial de um volume em um domínio computacional por células igualmente espaçadas.

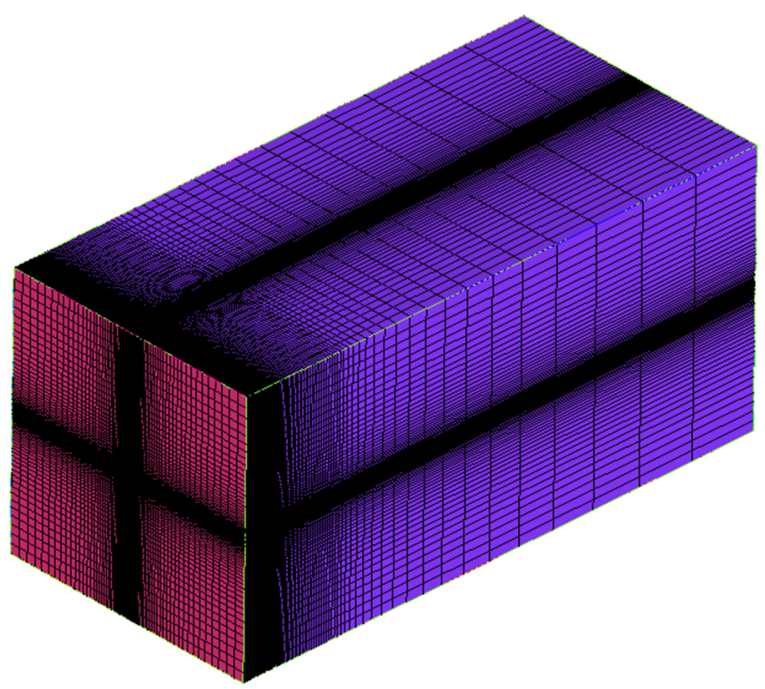

Figura A.2: Exemplo de discretização espacial de um volume em um domínio computacional por meio de células com espaçamento refinado no centro do domínio.

de cada volume. Este método é conhecido por malha colocada. Quando o domínio estudado é extremamente simples, utilizam-se malhas deslocadas, pois estas melhoram a precisão no cálculo das variáveis analisadas. Nas malhas deslocadas, apenas a pressão e propriedades escalares são armazenada no centro dos volumes e as velocidades, armazenadas nas faces.

A equação A.2 é uma reformulação da equação de transporte para uma propriedade qualquer no escoamento. Integrando-se essa equação da equação sobre as 


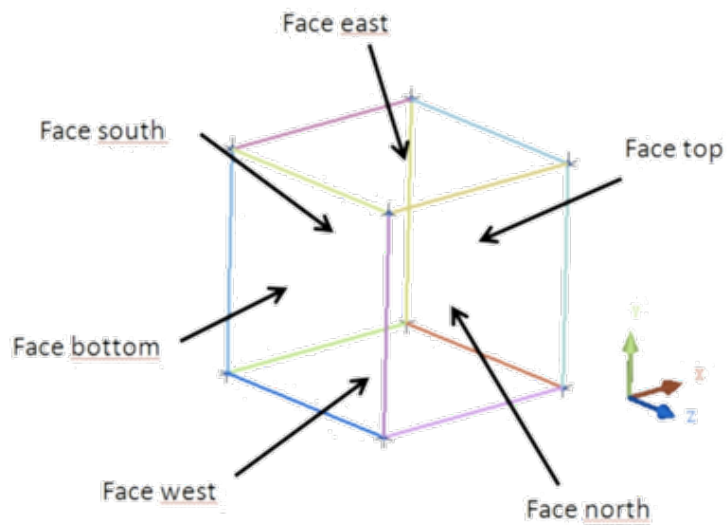

Figura A.3: Volume genérico utilizado para a discretização espacial do domínio computacional; nomeclatura das faces a ser utilizada nas equações discretizadas.

coordenadas espaciais e temporal, obtem-se a equação A.3.

$$
\begin{gathered}
\frac{\partial}{\partial t}(\rho \phi)+\frac{\partial}{\partial x_{i}}\left(\rho u_{i} \phi\right)=\frac{\partial}{\partial x_{i}}\left(\Gamma\left(\frac{\partial \phi}{\partial x_{j}}\right)\right)+S_{\phi} \\
\int_{t} \int_{V}\left(\frac{\partial}{\partial t}(\rho \phi)\right) d t d V+\int_{t} \int_{V}\left(\frac{\partial}{\partial x_{i}}\left(\rho u_{i} \phi\right)\right) d t d V= \\
\int_{t} \int_{V}\left(\frac{\partial}{\partial x_{i}}\left(\Gamma\left(\frac{\partial \phi}{\partial x_{j}}\right)\right)\right) d t d V+\int_{t} \int_{V}\left(S_{\phi}\right) d t d V
\end{gathered}
$$

Aplicando-se o teorema de Gauss, equação A.4, na equação A.3, obtém-se a equação A.5.

$$
\begin{aligned}
& \int_{V}\left(\frac{\partial}{\partial x_{i}} \alpha\right) d V=\int_{A}(\vec{n} \alpha) d A \\
& \rho \phi V+\Delta t \int_{A} \vec{n}\left(\rho u_{i} \phi\right) d A=\Delta t \int_{A} \vec{n}\left(\Gamma\left(\frac{\partial \phi}{\partial x_{j}}\right)\right) d A+S_{\phi} \Delta t V
\end{aligned}
$$

Ao se fazer $\Delta t \neq 0$ e utilizando a nomeclatura das faces definida na figura A.3, encontra-se a equação A.6.

$$
\begin{gathered}
\frac{\rho \phi V}{\Delta t}+(\rho u A \phi)_{b}^{t}+(\rho v A \phi)_{w}^{e}+(\rho w A \phi)_{s}^{n}= \\
\left(\Gamma \frac{\partial \phi}{\partial x}\right)_{b}^{t}+\left(\Gamma \frac{\partial \phi}{\partial y}\right)_{w}^{e}+\left(\Gamma \frac{\partial \phi}{\partial z}\right)_{s}^{n}+S_{\phi} V
\end{gathered}
$$


O método das diferenças centrais para os termos $\phi$ nas faces, equação A.7, e suas derivadas, equação A.9, foram utilizados na discretização das equações algébricas. Definindo o termo advectivo pela equação A.9 e difusivo, pela equação A.10, encontrase a equação A.11, base do método dos volumes finitos.

$$
\begin{aligned}
& \phi_{t}=\frac{\phi_{T}+\phi_{P}}{2} \\
& \left(\frac{\partial \phi}{\partial x}\right)_{t}=\frac{\phi_{T}-\phi_{P}}{\Delta_{T P}} \\
& \left(\frac{\partial \phi}{\partial x}\right)_{b}=\frac{\phi_{P}-\phi_{B}}{\Delta_{P B}} \\
& F_{i}=\frac{(\rho u A)_{i}}{2} \\
& D_{i}=\left(\frac{\Gamma A}{\Delta x_{i}}\right)_{i}
\end{aligned}
$$

$$
\begin{array}{r}
\frac{\rho \phi V}{\Delta t}+\phi_{P}\left(F_{b}-F_{t}+F_{w}-F_{e}+F_{s}-F_{n}\right)+ \\
\phi_{P}\left(D_{b}+D_{t}+D_{w}+D_{e}+D_{s}+D_{n}\right) \\
=-\left(\phi_{T} F_{t}-\phi_{B} F_{b}+\phi_{E} F_{e}-\phi_{W} F_{w}+\phi_{N} F_{n}-\phi_{S} F_{s}\right)+ \\
\phi_{P} D_{b}+\phi_{T} D_{t}+\phi_{W} D_{w}+\phi_{E} D_{e}+\phi_{S} D_{s}+\phi_{N} D_{n}+ \\
S_{\phi} V
\end{array}
$$

Fazendo $A=\sum_{i}\left(F_{i} \phi_{i}\right)-\phi_{P}\left(F_{b}-F_{t}+F_{w}-F_{e}+F_{s}-F_{n}\right)$ e $D=\sum_{i}\left(D_{i} \phi_{i}\right)-$ $\phi_{P}\left(D_{b}+D_{t}+D_{w}+D_{e}+D_{s}+D_{n}\right)$, obtem-se a equação A.12.

$$
\frac{\rho \phi V}{\Delta t}=(A+D)+S_{\phi} V
$$

Para se recuperar as equações de conservaçã de quantidade de movimento, faz-se $\phi=$ $u, v, w$ e $S_{i}=-\frac{\partial P}{\partial x_{i}}-\rho g_{i}$. 


\section{Apêndice B}

\section{Método dos passos fracionados}

De acordo com Ferziger e Peric (2002), o método dos passos fracionados se baseia na idéia de se dividir a solução da equação de transporte A.2, simplificada na equação B.1 por seus termos temporal, advectivo, difusivo e de pressão, de forma a compor uma seqüência de passos de soluçao mostrados na seqüência de equações B.2 à B.4.

$$
\begin{aligned}
& u_{i}^{n+1}=u_{i}^{n}+\left(A_{i}+D_{i}+P_{i}\right) \Delta t \\
& u_{i}^{*}=u_{i}^{n}+\left(A_{i}\right) \Delta t \\
& u_{i}^{* *}=u_{i}^{*}+\left(D_{i}\right) \Delta t \\
& u_{i}^{n+1}=u_{i}^{* *}+\left(P_{i}\right) \Delta t
\end{aligned}
$$

Essa metodologia garante ainda que outros passos possam ser inseridos de modo a melhorar a estabilidade da solução numérica e da precisão dos resultados, garantindo uma infinidade de possibilidades para a solução do acoplamento entre a pressão e a velocidade. 
O método utilizado neste trabalho é apresentado por Ferziger e Peric (2002), o qual se baseia no originalmente proposto por Choi e Moin (1993). Este método é composto por quatro passos e utiliza a discretização Crank-Nicholson para a evolução temporal.

O procedimento de solução deste método é dividido em quatro etapas, discutidas abaixo.

Etapa 1: inicialmente define-se um campo para o vetor velocidade e pressão. Resolve-se então, neste primeiro passo, o sistema linear em dado pela equação B.5. Nas próximas equações, vale ressaltar que os índices superiores se referem a evolução temporal e os inferiores, à discretização espacial.

$$
\frac{\left(\rho u_{i}\right)^{*}-\left(\rho u_{i}\right)^{n}}{\Delta t}=\frac{1}{2}\left(H\left(u_{i}\right)^{n}+H\left(u_{i}\right)^{*}\right)-\frac{\partial P^{n}}{\partial x_{i}}
$$

Na equação B.5, o operador $H\left(u_{i}\right)$ indica a discretização dos termos advectivo, difusivo e fonte. Não existe restrição para o tipo de discretização espacial a ser utilizada.

Etapa 2: metade do gradiente inicial da pressão é removido da solução, representado pela equação B.6

$$
\frac{\left(\rho u_{i}\right)^{* *}-\left(\rho u_{i}\right)^{*}}{\Delta t}=\frac{1}{2} \frac{\partial P^{n}}{\partial x_{i}}
$$

Para se encontrar a velocidade no final do incremento de tempo, etapa 4, se faz necessário o gradiente da pressão neste instante. Assim, sabendo-se que o campo de velocidades deve respeitar o critério de divergente nulo para garantir a conservação da massa, encontra-se a equação de poisson para a nova pressão, equação B.7.

$$
\frac{\partial}{\partial x_{i}}\left(\frac{\partial P^{n+1}}{\partial x_{i}}\right)=\frac{2}{\Delta t}\left(\frac{\partial\left(\rho u_{i}\right)^{* *}}{\partial x_{i}}\right)
$$


Etapa 3: solução do sistema linear dado pela equação B.7. Com este passo é possível obter o campo de pressoões no final do incremento.

Etapa 4: correção do campo das velocidades pela equação B.8.

$$
\frac{\left(\rho u_{i}\right)^{* *}-\left(\rho u_{i}\right)^{*}}{\Delta t}=-\frac{1}{2} \frac{\partial P^{n+1}}{\partial x_{i}}
$$

Essa seqüência de passos representa a equação B.9, a qual é a equação de conservação da quantidade de movimento discretizada pelo método Crank-Nicholson no tempo.

$$
\frac{\left(\rho u_{i}\right)^{*}-\left(\rho u_{i}\right)^{n}}{\Delta t}=\frac{1}{2}\left(H\left(u_{i}\right)^{n+1}+H\left(u_{i}\right)^{*}\right)-\frac{1}{2}\left(\frac{\partial P^{n}}{\partial x_{i}}+\frac{\partial P^{n+1}}{\partial x_{i}}\right)
$$

Para a discretização temporal da equação B.9 ser correta, o termo $H\left(u_{i}\right)^{*}$ deveria ser substituído por $H\left(u_{i}\right)^{n}$. Entretanto, Ferziger e Peric (2002) indicam que a equação B.9 apresenta decaimento de $2^{a}$ ordem para o erro. Esse decaimento é demosntrado partindo-se das equações B.6 e B.8, encontrando-se a equação B.10. Nesta equação, verifica-se que o erro adimitido apresenta decaimento de $2^{a}$ ordem para a discretização temporal.

$$
\operatorname{Erro}=\left(u_{i}\right)^{n+1}-\left(u_{i}\right)^{*}=-\frac{\Delta t}{2 \rho}\left(\frac{\partial\left(P^{n+1}-P^{n}\right)}{\partial x_{i}}\right) \approx \frac{(\Delta t)^{2}}{2 \rho}\left(\frac{\partial P}{\partial x_{i}}\right)
$$

Verifica-se ainda, de acordo com Ferziger e Peric (2002), que a maior diferença entre este método de acoplamento pressão-velocidade, comparado a métodos iterativos do tipo SIMPLE, está na solução da equação da pressão, a qual é resolvida apenas uma vez a cada incremento de tempo, implicando em menor custo computacional, sendo ideal para escoamento transientes.

Vale ressaltar que se o incremento de tempo for relativamente grande, erros são acumulados devido a separação da solução dos sistemas em diversos passos, o que é rapidamente corrigido com a diminuição do incremento de tempo ou a iteração de todo o processo de solução dentro de uma mesmo incremento de tempo. 


\section{Apêndice C}

\section{Método de Germano e Lilly para a viscosidade turbulenta}

Os modelos dinâmicos propõem uma melhora sobre o modelo proposto por Smagorinsky (1963), de modo a definir a constante de Smagorinsky com base na dinâmica das estruturas turbulentas no escoamento.

Germano et al. (1991) propôs que um filtro de teste, maior que o filtro inicialmente adotado para modelagem dos efeitos submalha, fosse utilizado de modo a desenvolver a equação C.1, a qual representa as tensões modeladas com a aplicação deste filtro teste. Para compatibilidade, desenvolveu-se a equação C.2 junto com o modelo proposto por Smagorinsky (1963).

$$
\begin{aligned}
& \hat{\tau}_{i j}^{+}=2 C \hat{\Delta}^{2}|\widehat{\bar{S}}| \widehat{\overline{S_{i j}}} \\
& \tau_{i j}{ }^{+}=2 C \Delta^{2}|\bar{S}| \overline{S_{i j}}
\end{aligned}
$$

Depois de realizada algumas orperações algébricas, chega-se a uma estimativa para o cálculo da constante $C$, dada pela equação C.3, na qual o termo $M_{i j}$ é dado pela equação C.4. 


$$
\begin{aligned}
& C=\frac{1}{2}\left(\frac{\widehat{L_{i j}} \overline{S_{i j}}}{M_{i j} \overline{S_{i j}}}\right) \\
& M_{i j}=\hat{\Delta}^{2}|\widehat{\bar{S}}| \widehat{\overline{S_{i j}}}-\Delta^{2}|\bar{S}| \overline{S_{i j}}
\end{aligned}
$$

Para se evitar que, localmente, a constante $C$ apresente problemas com os valores no denominador, outra forma de cálculo foi proposta por Lilly (1991), em que ao invés de se fazer a contração da equação C.3 pela variável $\overline{S_{i j}}$, optou-se pela minimização da somatória dos quadrados dos resíduos, obtendo-se a equação C.5.

$$
C=\frac{1}{2}\left(\frac{\widehat{L_{i j}} M_{i j}}{M_{i j}^{2}}\right)
$$




\section{Apêndice D}

\section{Solução de sistemas algébricos}

\section{D.1 Solução por Jacobi}

O método de Jacobi é baseado na solução explicita e iterativa das variáveis em cada célula do domínio, isto é, este método resolve a equação D.1 para cada volume de controle e assume que os valores das variáveis nas posições vizinhas são constantes durante cada passo de solução.

$$
\phi_{P}^{n+1}=\frac{1}{A_{p}}\left(S_{\phi}-\sum_{i} A_{i} \phi_{i}^{n}\right)
$$

Este é um dos métodos mais simples e estáveis de solução iterativa de sistemas lineares, porém a taxa de convergência da solução dos sisteas lineares é extremamente lenta.

\section{D.2 Solução por Gauss-Siedel}

O método de Gauss-Siedel é baseado no método de Jacobi, porém utiliza um avanço semi-implicito na solução das equações, isto é, para cada volume do domínio computacional, a equação D.2 é resolvida, utilizando valores parcialmente atualizados 
das variáveis durante o processo iterativo. É usual que os volumes adjacentes as faces "bottom", "west" e "south" da figura A.3 possuam valores atualizado para as variáveis e os volumes adjacentes as faces "top", "east" e "north", valores do passo iterativo anterior. Logo, é costume resolver este método com pelo menos duas iterações por toda a malha computacional.

$$
\phi_{P}^{n+1}=\frac{1}{A_{p}}\left(S_{\phi}-\sum_{i}^{t, e, n} A_{i} \phi_{i}^{n}-\sum_{i}^{b, w, s} A_{i} \phi_{i}^{n+1}\right)
$$

Apesar de ser um método iterativo, esta forma de solução de sistemas lineares apresenta boa taxa de convergência e é de fácil implementação.

No presente trabalho, para melhorar a taxa de convergência da solução numérica, este método foi implementado de forma a realizar dois passos pela equação D.1, uma para frente e outro para trás, por passo de iteração. Com isso, foi alcançada uma taxa $70 \%$ maior que a do método convencional. 


\section{Apêndice E}

\section{Formato do arquivo de entrada}

O arquivo de entrada possui todos os parâmetros necessários para que a análise seja realizada. Seu formato é em texto plano com as seguintes linhas de comando:

- *BC: identifica as faces do domínio que possuem condições de contorno.

- *Combustion: identifica o modelo de combustão a ser empregado na solução dos escoamentos.

- *Coord: especifica o sistema de coordenadas a ser utilizado.

- *Filemesh: especifica qual malha será utilizada na solução do escoamento.

- *Init: especifica as condições de inicialização do campo estudado.

- *Jet: define os parâmetros para análise de jatos.

- *ReadBackupFile: identifica se a análise parte de um campo já resolvido ou se ela inicia pelo comando Init.

- *Simulation: define os parâmetros globais da análise 


\section{Apêndice F}

\section{Formato do arquivo de malha}

O formato do arquivo da malha utilizado no LECS é baseado no formato Abaqus ${ }^{\circledR}$, em que se definem a posição dos nós da malha, bem como a tabela de conectividade desses nós para a formação das células do domínio computacional. Por ser definido segundo o formato Abaqus ${ }^{\circledR}$, as malhas podem ser feitas em geradores comerciais ou acadêmicos.

A figura F.1 apresenta a estrutura do arquivo da malha computacional e alguns comandos utilizados para descrever a posição dos nós, a formação das células volumétricas e as faces das condições de contorno.

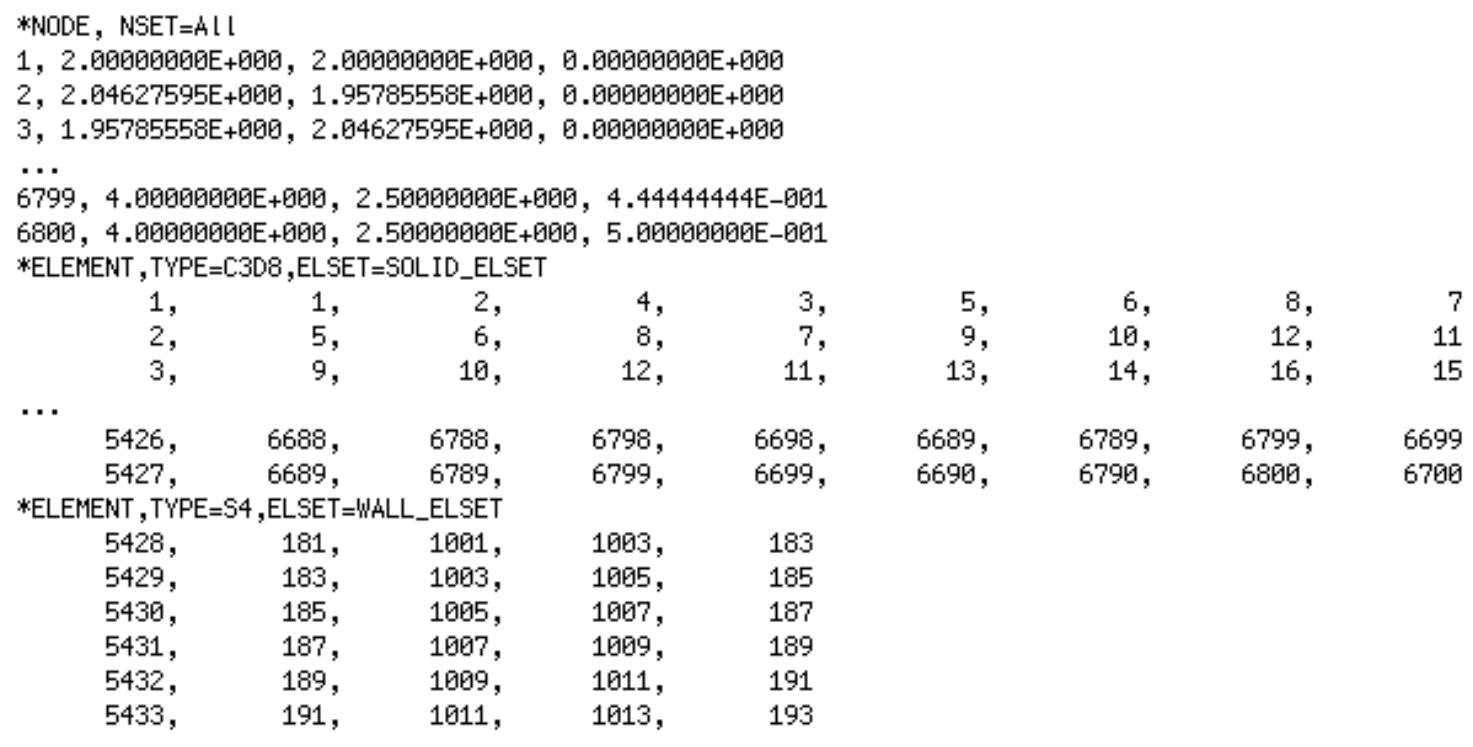

Figura F.1: Exemplo do arquivo da malha com os comandos *NODE e *ELEMENT. 
Neste arquivo são definidos dois comandos: *NODE e *ELEMENT. O comando *NODE define a posição dos nós segundo um sistema de coordenadas cartesiano adotado. Sua sintaxe é:

*NODE, NSET=texto de identificação

número do nó, coordenada X, coordenada $\mathrm{Y}$, coordenada Z

Já o comando *ELEMENT é utilizado para a formação das células volumétricas e das faces do contorno. Essa distinção é feita pelo parâmetro TYPE, em que TYPE=C3D8 indica uma célula interna, tri-dimensional (3D) com 8 nós. Já o TYPE=S4 indica uma face (S) com 4 nós.

A sintaxe do comando *ELEMENT é a seguinte:

*ELEMENT,TYPE=tipo de célula,ELSET=texto identificador número da célula, n1, n2, .., nn

Para este comando, o tipo de célula define o número de nós a serem utilizados, isto é, se o tipo é C3D8, nn será n8. Caso o tipo seja S4, nn será n4. 